\title{
AMBIENT NOISE MEASUREMENTS IN THE 200-300 Hz BAND DURING THE GREENLAND SEA TOMOGRAPHY EXPERIMENT
}

by

\author{
Hui-Xia Wu
}

B.S. Physics, XuZhou Normal College (1982)

M.S. Acoustics, Graduate School Academia Sinica (1985)

Submitted in Partial Fulfillment of the

Requirements for the Degree of

Master of Science

at the

Massachusetts Institute of Technology and the

Woods Hole Oceanographic Institution June 1992

(c) Massachusetts Institute of Technology and Woods Hole Oceanographic Institution

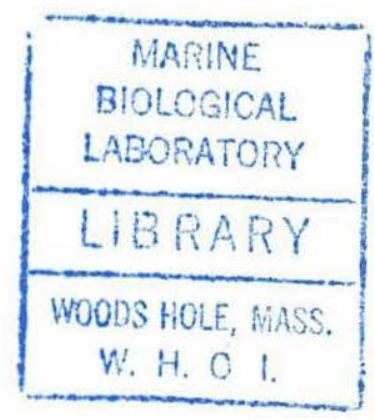

Signature of Author

Joint Program in Ocean Engineering Massachusetts Institute of Technology

Woods Elole Oceanographic Institution

Certified by

James F.Lynch

Associate Scientist, Thesis Supervisor

Certified by .

Henrik Schmidt

Associate Professor, Academic Advisor

Accepted by

Arthur B.Baggeroer

Chairman, Joineregrittee for Applied Ocean Physics and Engineering

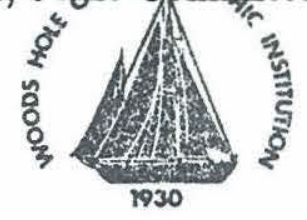

Massachusetts Institute of Technology

Woods Hole Oceanographic Institution 


\title{
AMBIENT NOISE MEASUREMENTS IN THE 200-300 Hz BAND DURING THE GREENLAND SEA TOMOGRAPHY EXPERIMENT \\ by \\ Huixia Wu
}

\author{
Submitted in partial fulfillment of the requirements for the degree of \\ Master of Science at the Massachusetts Institute of Technology \\ and the Woods Hole Oceanographic Institution \\ May 6, 1992
}

\begin{abstract}
A six mooring acoustic tomography array was jointly deployed by Scripps Institution of Oceanography and Woods Hole Oceanographic Institution in 1988, and a year long time series of ambient noise in the $200-300 \mathrm{~Hz}$ was collected by those moorings. Large scale meteorological environmental information, particularly wind, was provided during that same year by the British Meteorological Office. Time series of ice type and ice concentration were provided by Special Sensor Microwave Imager and Advanced Very High Resolution Radiometer satellite. Using those data sets, we were able to look at the characteristics of the ambient noise and to correlate the noise against significant environmental variables such as wind, ice concentration, ice edge position, etc.
\end{abstract}

The largest noise levels are generally seen during the winter months and are associated with periods of moderate to strong wind speed. The lowest noise levels are confined to summer; however, there is also an extremely quiet period in mid-winter, coincident with heavy ice cover.

During the ice-free periods, the ambient noise is higher than the Wenz ambient noise for open water. The regressions between the noise and wind speed show that the noise is wind dependent, with slightly lower slopes than the Wenz curve. Under the heavy pack ice cover conditions, noise levels are much lower than during the ice-free periods, even lower in fact than Wenz noise for open water when the wind speeds pass $11 \mathrm{~m} / \mathrm{s}$. The ambient noise is almost wind independent during this period. The overall noise levels are highest during the ice edge advance/retreat period; the noise is also wind dependent, with the regression slopes higher than that for ice-free period, but still lower than that of the Wenz curves.

Noise and wind fields correlate well in fall and during the ice edge advance/retreat periods, but are less correlated under the heavy ice cover and during low wind speed periods. The spatial cross correlations of the noise fields show quite 
high levels, up to 0.9 in fall and during the ice edge advance/retreat period, but there is less correlation during other periods.

The MIZ noise levels are dependent on the distance between the receiver and the ice edge and also the ice concentration. The noise peaks at the ice edge and diminishes faster going under the ice than into the open water. The measured noise levels near the ice edges are about 4 to $7 \mathrm{~dB}$ higher than open water, and about 7 to $10 \mathrm{~dB}$ higher than levels far into the ice field. In the MIZ, on-ice-wind results in higher noise than off-ice-wind. Ambient noise increases as on-ice-wind increases, but increases much slower or even decreases as off-ice-wind increases.

Thesis Supervisor:

Dr. James F. Lynch, Associate Scientist

Woods Hole Oceanographic Institution 


\section{Table of Contents}

$\begin{array}{ll}\text { Abstract } & 2\end{array}$

Table of Contents $\quad 4$

$\begin{array}{ll}\text { List of Tables } & 7\end{array}$

$\begin{array}{lr}\text { List of Figures } & 8\end{array}$

$\begin{array}{ll}\text { Acknowledgments } & 11\end{array}$

$\begin{array}{lr}\text { 1. Introduction } & 13\end{array}$

2. Arctic and MIZ Ambient Noise - Some Background 15

3. Environmental Variables and Their Measurements 20

3.1 Introduction $\ldots \ldots \ldots \ldots$

3.2 Ambient Noise Measurements . . . . . . . . . . . . 23

3.3 Wind Stress and Wind Velocity ............. 25

3.4 Ice Cover Observations .................. 27

4. Time Series of Ice Concentration, Noise and Wind Velocity 29

4.1 Ice Concentration Time Series . . . . . . . . . . . . . . 29

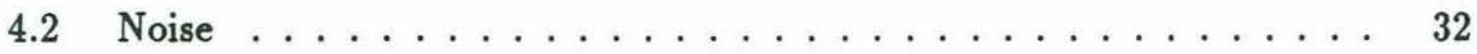

4.2.1 Ambient Noise Percentile . . . . . . . . . . . . . . 32

4.2.2 Ambient Noise Time Series . . . . . . . . . . . 36

4.2.3 Histograms of Ambient Noise . . . . . . . . . . . . 40 


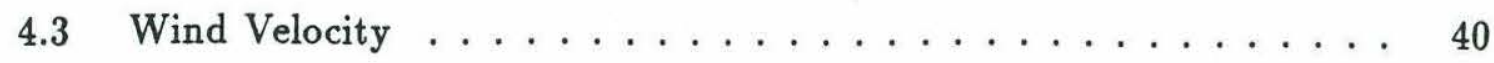

4.3.1 The Relationship between Wind Velocity and Wind Stress . . 40

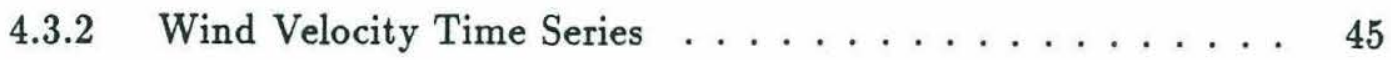

4.3.3 Histograms of Wind velocity . . . . . . . . . . . 49

4.4 Ambient Noise and Environmental Variables . . . . . . . . . . 49

4.4.1 Wind Speed and Ambient Noise . . . . . . . . . . 49

4.4.2 Comparing Extreme Noise with Wind Velocity and Ice Concentration .................... 54

5. Regression Analyses $\quad 59$

5.1 Seasonal Effects . . . . . . . . . . . . . . . 59

$5.1 .1 \quad$ Ice-free Period $\ldots \ldots \ldots \ldots \ldots \ldots \ldots$

5.1 .2 Heavy Ice Cover Period . . . . . . . . . . . . . 60

5.1 .3 Ice Edge Advance/Retreat $\ldots \ldots \ldots \ldots 66$

$5.2 \quad$ MIZ Ice Edge Noise $\ldots \ldots \ldots \ldots \ldots$

5.2 .1 The Spatial Variability of the Ice Edge . . . . . . . . . 69

5.2.2 Comparisons with Diackok and Winokur's Results . . . . . 71

5.2 .3 On/off-ice-wind versus Noise $\ldots \ldots \ldots \ldots \ldots \ldots$

6. Correlation Analysis $\quad 79$

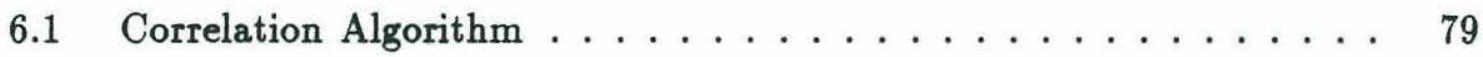

6.2 Noise/Wind Time Series Autocorrelations . . . . . . . . . . . . 82

6.3 Noise/Wind Cross Correlations . . . . . . . . . . . . . . . . 84

6.4 Cross Correlation of the Noise Levels between Moorings . . . . . . 87

6.5 Cross Correlation of the Noise with Ice Concentration and On/off-ice Wind . . . . . . . . . . . . . . . . 90 
7. Discussion and Conclusions

References

94 


\section{List of Tables}

2.1 Arctic ambient noise vs. wind

3.1 Environmental/experimental parameters for the GSP88 tomography 20

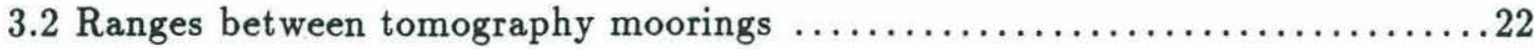

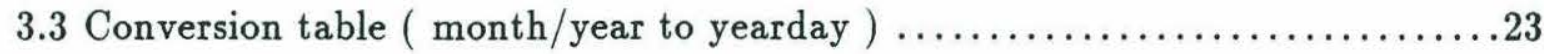

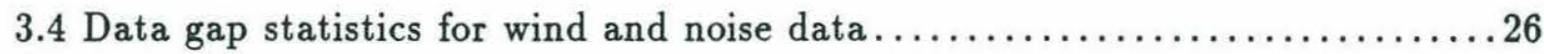

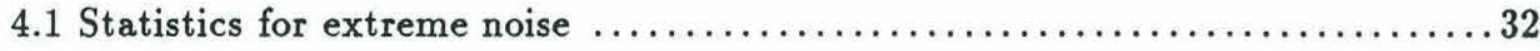

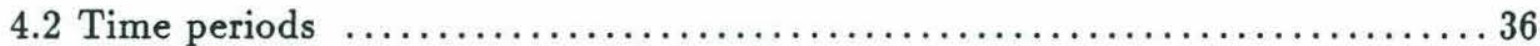

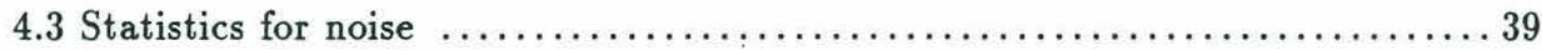

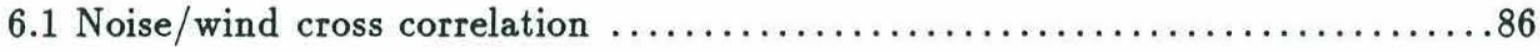

6.2 Cross correlation of noise levels between moorings $\ldots \ldots \ldots \ldots \ldots \ldots \ldots \ldots \ldots 9$ 


\section{List of Figures}

3.1 Tomography array region

4.1 Ice concentration time series

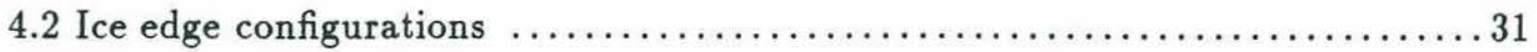

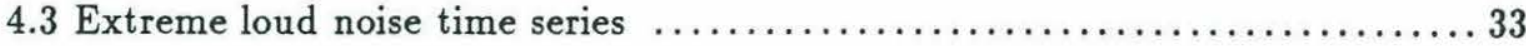

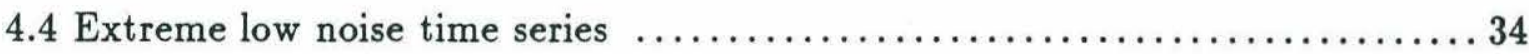

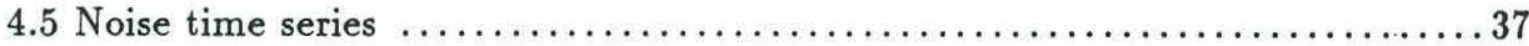

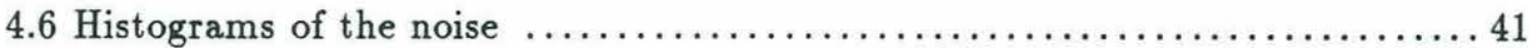

4.7 Comparison of the $10 \mathrm{~m}$ wind velocity with that derived form wind stress $\ldots 46$

4.8 The wind magnitude and the polar plot of the wind velocity $\ldots \ldots \ldots \ldots \ldots 48$

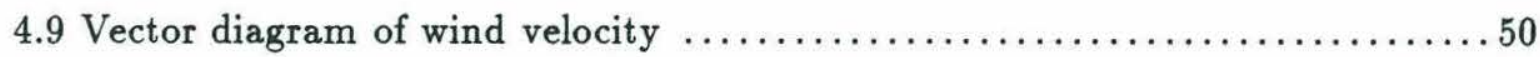

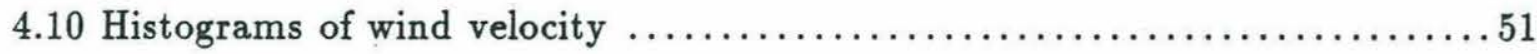

4.11 Wind speed and ambient noise time series $\ldots \ldots \ldots \ldots \ldots \ldots \ldots \ldots \ldots \ldots \ldots$

4.12 Comparison of winter extreme loud noise with environmental variables $\ldots \ldots 55$

4.13 Comparison of winter extreme low noise with environmental variables $\ldots \ldots 57$ 
5.1 Noise vs. wind speed during the ice free period $\ldots \ldots \ldots \ldots \ldots \ldots \ldots \ldots \ldots \ldots \ldots \ldots \ldots \ldots \ldots$

5.2 Noise vs. wind speed during the heavy ice cover period $\ldots \ldots \ldots \ldots \ldots \ldots 62$

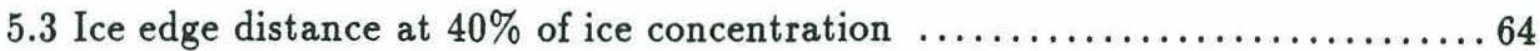

5.4 Noise excess time series during the heavy ice cover period $\ldots \ldots \ldots \ldots \ldots \ldots 6$

$5.5 \mathrm{Noise} /$ wind regression during the ice edge advance/retreat period $\ldots \ldots \ldots \ldots 67$

5.6 Noise excess time series during the ice edge advance/retreat period $\ldots \ldots \ldots \ldots 68$

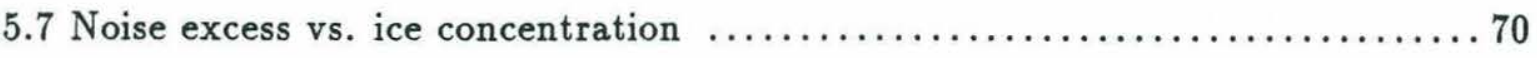

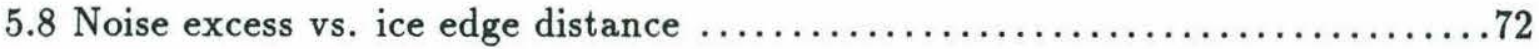

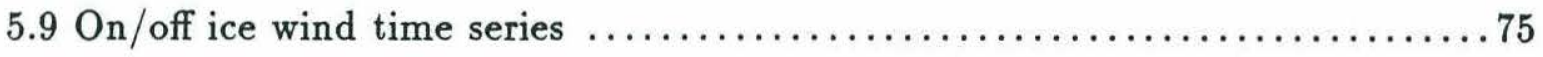

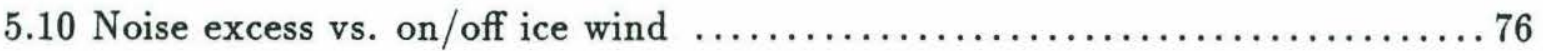

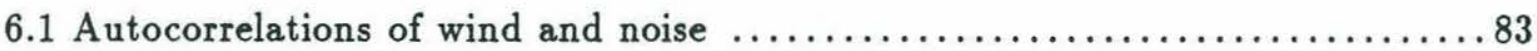

6.2 Cross-correlations between wind speed and ambient noise $\ldots \ldots \ldots \ldots \ldots \ldots 85$

6.3 Cross correlation of noise levels between moorings $\ldots \ldots \ldots \ldots \ldots \ldots \ldots \ldots, \ldots 8$

6.4 Cross-correlations of noise and on/off-ice winds $\ldots \ldots \ldots \ldots \ldots \ldots \ldots \ldots \ldots 1$ 


\title{
謹将此訅文献给我最亲爱的爸爸
}

$I$ hereby dedicate this thesis to my dearest father, Zhao-Zhang Wu.

\author{
I love you , $B a B a$
}




\section{Acknowledgments}

I would first of all like to thank my advisor James F. Lynch for his patient guidance and encouragement, for many valuable discussions and for his constructive criticisms of this work. Also, I would like to thank him for his efforts in editing my early, poorly written thesis drafts. His deep insight into a wide range of ocean sciences and his imagination have a great help to me.

I want to thank my academic advicer Henrik Schmidt, from whom I benefited tremendously in numerous consultations, who also was a reader of my thesis. I thank Professor Arthur B. Baggeroer for his helpful comments and suggestions.

I would also like to thank Dr. Er C. Shang, Ding H. Guan, and Tian F. Gao, who gave me great support when I studied and worked in the Institute of Acoustics, Academia Sinica.

I thank Arthur Newhall, who generously supplied me with a Fortran program which was used to calculate the ice edge distance from satellite data. I also received much help with using the computer from him.

The friendship and support of my fellow Joint Program students and friends has been invaluable. Rich Pawlowicz offered me useful programs and a lot of suggestions. Chang S. Chen taught me how to use thesis style files. Discussions with De Z. Chu and Kazuhiko Ohta made me more confident with my work.

My thanks also go to Ruth Keenan, who kindly provided many valuable references relating to ambient noise spectrum modeling.

I think all of the WHOI Education Office staff for their considerable help in my graduate study. 
My family has always provided a strong emotional foundation for me. I thank my parents Zhao Z. Wu and Xiu F. Zhang for their constantly encouragement and for taking care of my son while I studied here. I think my husband Zheng Y. Liu for his understanding and valuable suggestions. Thanks also to my son, Ning B. Liu, for being patient with his mom. 


\section{Chapter 1. Introduction}

As part of the Greenland Sea Project, a six mooring acoustic tomography array was deployed in the center of the Greenland Sea gyre from September 1988 to midSeptember 1989. The primary scientific purposes of the array were to : 1) monitor the formation of oxygen rich Greenland Sea deep water, 2) study the circulation dynamics of the Greenland Sea gyre, and 3) explore the details of the acoustic propagation and scattering in an Marginal Ice Zone (MIZ) region over a yearly cycle ${ }^{1}$. As a secondary objective, the ambient noise in the reception band of the tomography receivers, nominally $200-300 \mathrm{~Hz}$, was also measured.

During the course of the experiment, much large scale environmental information was also collected. The British Meteorological Office (BMO) provided a year long time series of wind stress data, primarily intended for circulation studies, but also of great importance to understanding the ambient noise field. Special Sensor Microwave Imager (SSM/I) and Advanced Very High Resolution Radiometer (AVHRR) satellite images of the region provided ice concentration and, to a limited extent, ice type. The tomographic array and frequent ship hydrographic surveys provided the

ocean sound speed profile throughout the year. By using the BMO wind field along with satellite ice information in a numerical model of the surface waves, the magnitude of the surface gravity wave field impinging on the ice can also be estimated.

The ambient noise measurements we will describe here were not among the primary scientific objectives of the experiment, and so were not designed to be optimal in any sense for answering questions about the noise field. For example, one would prefer to have many frequency bands, faster sampling, and high resolution beamforming capabilities ( both in the horizontal and vertical) to sort out the relative importance of the various noise generating processes. Instead, we can only report 
omnidirectional level measurements at one frequency every four hours. However, our data also has some unique assets which make its study worthwhile. First of all, it is a year long data set sampled at a rate which allows it to comment on temporal scales ranging from semidiurnal to seasonal. Second, it is set in a region in which variety of seasonally varying noise mechanisms come into play, particularly those associated with the MIZ. Third, it is in a region far from man made sources of sound, such as shipping. The fourth advantage is having four separated receivers, so that the spatial dependence and correlation of the noise field may be examined. The final advantage, and in some ways the most unique one about this data set, is the existence of the large scale environmental information previously mentioned. This information allows us to do many things. First, it allows us to correlate the noise against the most significant environmental variables : wind, waves, and ice concentration, in a manner analogous to the work performed by Makris and Dyer in their MIZ noise studies ${ }^{2}$. Second, it allows us to comment on just how useful large scale information, which is routinely available, is in describing and predicting the noise field. Can one use satellite maps to predict the MIZ noise, or does one need the detailed, finescale information which is closely related to the noise production processes to predict the observed field? Finally, this data set allows us to ask " can such large scale information tell us anything about the relative importance of the finescale noise generation processes, even if it cannot resolve them?"

This thesis is organized as follows. Following this Introduction, we discuss the background of previous research on ambient noise in the Arctic and its relation to our present experiment. In Chapter 3, we present details of our measurements of environmental variables, including noise. In Chapter 4, we discuss noise time series data collected, and their relation to ice and wind. Chapter 5 deals with regression analyses. Chapter 6 examines the correlation analysis of the data and the environmental variables. Final summary and conclusions are presented in Chapter 7. 


\section{Chapter 2. Arctic and MIZ Ambient Noise - Some Background}

The benchmark Wenz ${ }^{3}$ ambient noise curves are characterized by shipping and a broad, wind-dependent maximum in the $300-500 \mathrm{~Hz}$ region of interest. Carey and Monahan ${ }^{4}$ noted that it has been difficult to acquire ambient noise data in the absence of shipping noise, especially in the northern hemisphere. Ambient noise data that has been collected without shipping noise contamination ${ }^{5,6}$ show the noise to be wind speed dependent. This wind noise is characterized by two distinct regions, separated by the critical friction velocity associated with wave breaking. Kerman ${ }^{7}$ showed the noise intensity was proportional to the cube of the friction velocity prior to wave breaking and proportional to the critical friction velocity at about $6 \mathrm{~m} / \mathrm{s}$ (12 knots). A characteristic broad maximum between $300 \mathrm{~Hz}$ and $500 \mathrm{~Hz}$ has been observed in open ocean wind dependent ambient noise spectra, that shifts to lower frequencies as the wind speed increases. The decrease in spectral level with decrease in frequency below this broad maximum is less than $1 \cdot \mathrm{dB}$ /octave.

In the central Arctic pack ice, ambient noise has been associated with cracking due to ice stress. Ice stress is a nonlinear function of many variables: the speed and direction of the wind, current and ice, the temperature and the mechanical properties of the ice itself. Buck ${ }^{8}$ observed that the central Arctic noise levels follow the seasonal ice stress conditions : lowest in summer, increasing in the fall, remaining high in the winter, and dropping in the spring. As a result, ambient noise in the Arctic has not shown a consistent correlation with wind speed $^{9}$, as it does in the open ocean. Milne $e^{1} 0$ associated ambient noise in the $200-300 \mathrm{~Hz}$ band to thermal cracking. His measurement was in a sheltered, land-fast ice area of the Canadian Archipelago; central Arctic sites have not routinely exhibited this strong correlation 
with air temperature ${ }^{11}$. The impulsive, non-Gaussian ${ }^{12}$ character of Arctic ambient noise is different from open ocean noise. 'Noise episodes' associated with specific ice stress relief events are a common occurrence. Noise fluctuations between 10-20 dB on time scales of hours are quite common in the central Arctic ${ }^{9}$. The average spectral shape in the central Arctic shows a peak at about $20 \mathrm{~Hz}$, then a monotonic decay up to several kiloHertz ${ }^{13}$.

Ambient noise in the marginal ice zone ( MIZ) is quite different from the open ocean and pack ice covered oceans. The MIZ is a combination of individual ice floes and open water. The freedom of movement of an ice floe in the MIZ reduces the internal ice stress mechanism associated with the central Arctic noise. The presence of the ice floes also inhibits the breaking wave mechanism of the open ocean. In the marginal ice zone, one noise mechanism is due to the interaction of the wind and surface gravity waves with the ice floes, as the flexural failure of ice floes and floe-floe interaction generates the noise. As wind speed and ice concentration increase, the interaction of ice floes and noise will in general increase ${ }^{2}$. As our particular MIZ region saw a significant fraction of open water over the array at various times, it is likely that the noise observed was a combination of "open ocean" wave noise and the MIZ mechanisms discussed above. Inhibition of the wave field by the limitation of the wind fetch by heavy pack ice cover and ice edge advance/retreat events may also be important. Diachok and Winokur ${ }^{14}$ showed that the MIZ noise level was dependent on relative position to the ice edge and to ice concentration. They found that the noise level peaked at the ice edge and diminished faster under the ice covered waters than in open water. They attributed the noise peak at the ice edge to the wave/ice interaction and the higher attenuation of the noise in ice covered waters to the wave damping properties of the ice. Johannessen et al. ${ }^{15}$, have also observed this phenomenon, but not on all occasions ${ }^{16}$ Yang et al. ${ }^{17}$, found 'hot spots' of ambient noise in the MIZ and attributed them to ice eddies. Eddies, with their orbital motion, contribute to the increased probability of floe collisions. 
Seals and other marine life tend to concentrate in the MIZ and when present can dominate other noise sources. In the Barents Sea, Payne and Henderson ${ }^{16}$ found the spectral shape decreased from $20 \mathrm{~Hz}$ to $100-200 \mathrm{~Hz}$, then rose to achieve broad maximum between $500 \mathrm{~Hz}$ and $800 \mathrm{~Hz}$. Their measurement site was located in shallow water $(100 \mathrm{~m})$ and seals were commonly found along the ice edge. The seals were identified as the source of the dramatic increase in noise between $500 \mathrm{~Hz}$ and 800 $\mathrm{Hz}$. However, sensors distant from the high concentration of biologics also showed an increase in noise between $500 \mathrm{~Hz}$ and $800 \mathrm{~Hz}$. In these cases, the noise peak followed the more gentle Wenz curve. The biologic contribution was negligible at $1000 \mathrm{~Hz}$ and they found the ambient noise levels followed the same trend as wind speed, lagging 1.5 to 2 hours behind. However, the noise was 5-10 dB higher than the level expected from the Wenz curves for the same wind speed. They concluded that the ambient noise was not produced directly by local wind, but by ice movement that was forced, at least partially, by the wind. They observed in the Barents and Greenland Sea MIZ that there is sufficient energy stored in the ice field to sustain high noise levels even after the wind diminishes.

Buckingham and Chen ${ }^{18}$ examined MIZ data from deep water in the FRAM Strait and observed the spiky, impulsive noise associated with the central Arctic. The power spectra decayed monotonically above $50 \mathrm{~Hz}$ as $\mathrm{f}^{-n}$, where $\mathrm{n}$ was about 2 . The different spectral shape than that observed by Payne and Henderson ${ }^{16}$ suggests a different mix of generating mechanisms.

Table 2.1 lists approximate levels observed in $200-300 \mathrm{~Hz}$ band for open ocean, MIZ and central Arctic sites. Wind speed or ice speed is noted when available. The wind-dependent open ocean measurements are consistent with the Wenz 'predictions'. The central Arctic can be quieter than the open ocean sea state zero ( $\leq 3 \mathrm{kt}$ winds ) levels and commonly reaches sea state 7 ( $30-40 \mathrm{kt}$ winds ) noise conditions. On some occasions, such as a pressure ridging event, the ambient noise levels 
exceed the Wenz limits of prevailing noise. In the MIZ, the Payne measurements in the shallow water Barents Sea are higher than the Greenland Sea measurements. Keenan references unpublished measurements taken from a drifter buoy ${ }^{19}$ in the Greenland Sea between March and September 1988 in the vicinity of $80^{\circ} N-84^{\circ} N$. The Greenland Sea tomography measurements (WHOI) and drifter buoy measurements show similar levels. 
Table 2.1

Arctic ambient noise vs. wind

\begin{tabular}{|c|c|c|c|}
\hline & Reference & $\begin{array}{r}\text { Wind Speed } \\
(\mathrm{kts})\end{array}$ & $\begin{array}{r}\text { Noise Levels } \\
(\mathrm{dB})\end{array}$ \\
\hline \multirow{10}{*}{ Open Ocean } & Wenz $[3]$ & $\begin{array}{r}<3 \\
4-6 \\
7-10 \\
17-21 \\
34-40\end{array}$ & $\begin{array}{l}46 \\
55 \\
60 \\
67 \\
72\end{array}$ \\
\hline & Marrett/Chapman[20] & $5-8$ & 50 \\
\hline & Shooter [21] & 15 & $6 \overline{3}$ \\
\hline & Hollingberger [22] & $13-14$ & 60 \\
\hline & \multirow{3}{*}{ Wille[23] } & 56 & 80 \\
\hline & & 36 & 74 \\
\hline & & 14 & 67 \\
\hline & Perrone[24] & 13 & 63 \\
\hline & & 40 & 74 \\
\hline & Bannister[25] & 10 & $6 \overline{5}$ \\
\hline \multirow{3}{*}{ Central Zone } & Buck $[8]$ & seasonal & $50-62$ \\
\hline & Keenan $[19]$ & seasonal & $45-70$ \\
\hline & Alison ridging event[9] & & $75-90$ \\
\hline \multirow{12}{*}{ MIZ } & Payne[16] & 7 & $62-66$ \\
\hline & & 13 & $68-72$ \\
\hline & Buckingham/Chen [18] & $\overline{\mathrm{NA}}$ & $69-75$ \\
\hline & & 10 & $52-65$ \\
\hline & WHOI GSP(corrected/Hz) & 20 & $54-68$ \\
\hline & & 40 & $60-73$ \\
\hline & \multirow{6}{*}{ Keenan[26] } & ice speed(kts) & \multirow{6}{*}{$\begin{array}{l}55-70 \\
53-68 \\
55-73 \\
70-83 \\
75-85\end{array}$} \\
\hline & & 0.4 & \\
\hline & & 0.3 & \\
\hline & & 0.4 & \\
\hline & & 0.5 & \\
\hline & & 0.4 & \\
\hline
\end{tabular}




\section{Chapter 3. Environmental Variables and Their Measurements}

In this chapter, we describe the physical and acoustic environments of the Greenland Sea, and our measurements of them. The strengths and limitations of our data sets are given particular emphasis, as this comments on the usefulness of large scale environmental measurements for noise prediction and analysis.

\subsection{Introduction}

The Greenland Sea tomography experiment employed six acoustic transceiver moorings arranged in the center and on the vertices of a large pentagon of radius approximately $105 \mathrm{~km}$. The array was located over the abyssal plain of Greenland Sea basin from September 1988 to September 1989 in the region $74^{\circ} N-76^{\circ} N$ and $1^{0} \mathrm{E}-7^{0} \mathrm{~W}$. The location of the six-element array is shown in Fig.3.1. The environmental and experimental parameters as well as the ranges between moorings are listed in Tables 3.1 and 3.2.

Table 3.1

Environmental/experimental parameters for the GSP88 tomography

\begin{tabular}{|c|c|c|c|c|c|c|}
\hline Mooring & 1 & 2 & 3 & 4 & 5 & 6 \\
\hline $\begin{array}{l}\text { Source } \\
\text { depth(m) }\end{array}$ & 99.7 & 97.4 & 96.0 & 94.6 & 101.5 & 92.5 \\
\hline $\begin{array}{l}\text { Water } \\
\text { depth }(\mathrm{m})\end{array}$ & 3709 & 3717 & 3735 & 3466 & 3379 & 3629 \\
\hline $\begin{array}{l}\text { Position } \\
\text { (LoranC) }\end{array}$ & $\begin{array}{l}75^{\circ} 58.08^{\prime} \mathrm{N} \\
0011^{\circ} 50.00^{\prime} \mathrm{W}\end{array}$ & $\begin{array}{l}75^{\circ} 03.88^{\prime} \mathrm{N} \\
000^{\circ} 38.20^{\prime} \mathrm{E}\end{array}$ & $\begin{array}{r}74^{\circ} 00 . .38^{\prime} \mathrm{N} \\
0010.52 .90^{\prime} \mathrm{W}\end{array}$ & $\begin{array}{r}74^{\circ} 28.90^{\prime} \mathrm{N} \\
005^{\circ} 47.30^{\prime} \mathrm{W} \\
\end{array}$ & $\begin{array}{r}75^{\circ} 834.27^{\prime} \mathrm{N} \\
006^{\circ} 007.70^{\prime} \mathrm{W}\end{array}$ & $\begin{array}{r}75^{\circ} 03.60^{\prime} \mathrm{N} \\
0002^{\circ} 88.00^{\prime} \mathrm{W}\end{array}$ \\
\hline
\end{tabular}




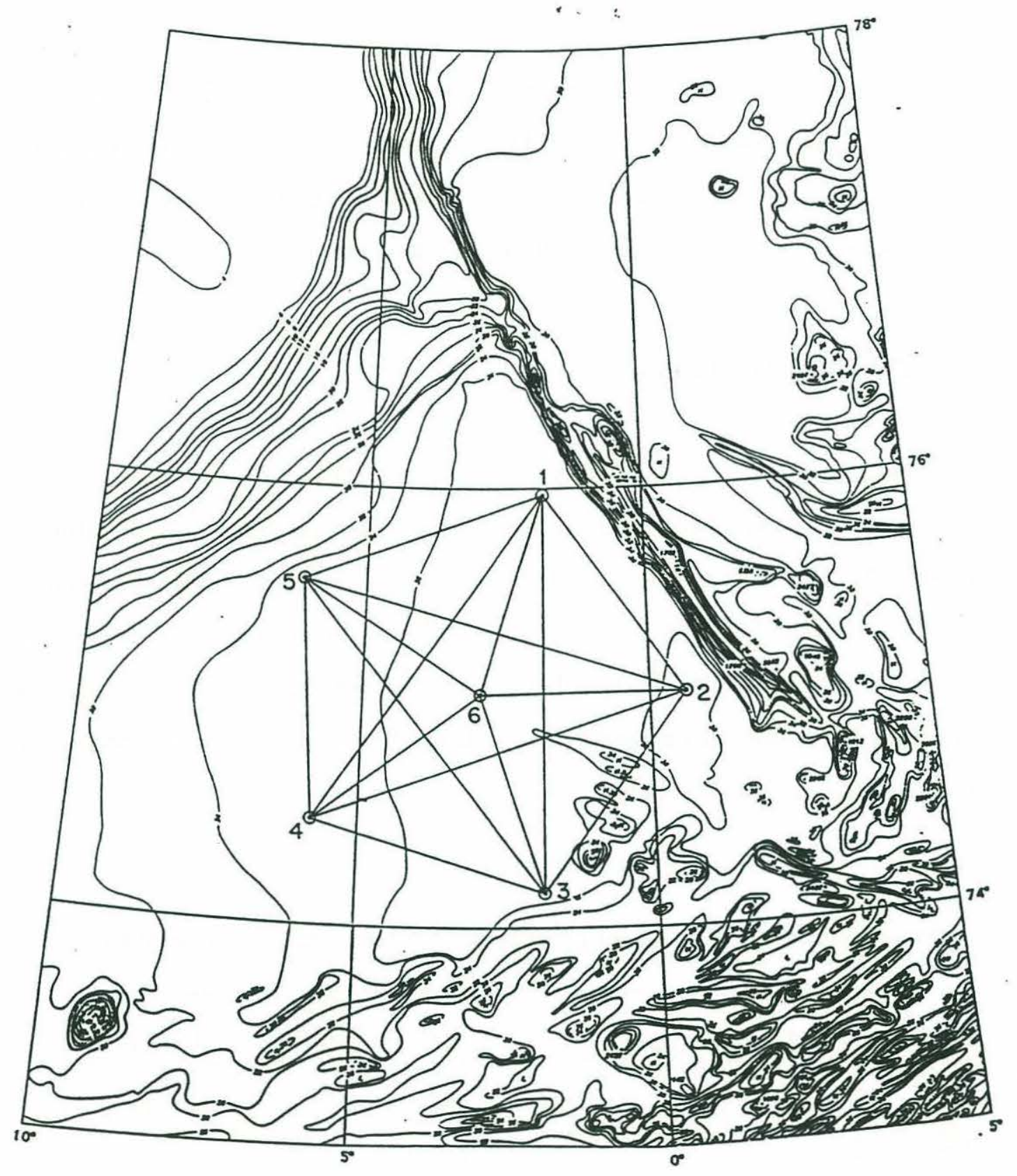

Figure 3.1: Tomography array region. $1,2, \ldots, 6$ are the mooring locations respectively. 
Table 3.2

Ranges between tomography moorings computed for the WGS 84 spheroid (km)

\begin{tabular}{|c|c|c|c|c|c|c|}
\hline Mooring & $\mathrm{m} 1$ & $\mathrm{~m} 2$ & $\mathrm{~m} 3$ & $\mathrm{~m} 4$ & $\mathrm{~m} 5$ & $\mathrm{~m} 6$ \\
\hline $\mathrm{m} 1$ & 0 & 122.120 & 202.258 & 200.405 & 125.922 & 106.179 \\
\hline $\mathrm{m} 2$ & & 0 & 125.927 & 199.232 & 199.500 & 103.706 \\
\hline $\mathrm{m} 3$ & & & 0 & 123.367 & 200.594 & 105.896 \\
\hline $\mathrm{m} 4$ & & & & 0 & 121.947 & 104.921 \\
\hline $\mathrm{m} 5$ & & & & & 0 & 106.109 \\
\hline $\mathrm{m} 6$ & & & & & & 0 \\
\hline
\end{tabular}

Mooring 2 failed completely soon after deployment, and the receiver on mooring 3 failed, leaving a 4 element array for noise measurement. Also, there was a significant number of bad data points in mooring 1 , particularly after yearday 500 . We will take those bad points as gaps in the data set.

For convenience, we give the conversion between yearday and month/year in Table 3.3. In our plots, it should be noted that we have extended 1988 yeardays into 1989 , i.e. past 366 ( since 1988 was a leap year). 
Table 3.3

Conversion table ( month/year to yearday )

\begin{tabular}{|c|c|c|c|c|c|c|c|c|c|c|}
\hline 1988 & Mar. & Apr. & May & June & Jaly & Aug. & Sept. & Oet. & Nor. & Dec. \\
\hline yoorday & 61 & 92 & 122 & 153 & 183 & 214 & 245 & 275 & 306 & 336 \\
\hline 1989 & Jan. & Pob. & Mar. & Apr. & Mey & Jane & Jaly & Ang. & Sept. & oct. \\
\hline A & 367 & 398 & 426 & 457 & 487 & 518 & 548 & 579 & 610 & 640 \\
\hline
\end{tabular}

\subsection{Ambient Noise Measurements}

Using the tomography array, we acoustically measured the sound speed, current, and the ambient noise fields. The current field is considered an unimportant factor in our discussion, as instrumental flow noise is not likely to be significant and our measurements are too coarse to resolve the fine scale, surface current shears responsible for floe bumping. The sound speed field is relevant to noise prediction since it determines the propagation paths that the noise takes. This determines the amount of surface and bottom interaction, as well as the geometrical spreading of the noise energy. Here, we will concentrate solely on the measurement of ambient noise.

As mentioned above, four transceivers measured ambient noise during the Greenland Sea tomography experiment, viz numbers 1, 4, 5, and 6 from Fig.3.1. Of these, two were Scripps (SIO) Avatar systems $(1,6)$ and two were WHOI Webb transceivers $(4,5)$. Due to differences in instrument design and internal storage capabilities, these instruments had different bandwidths, sampling schedules, and numbers of hydrophones. We next describe each of those instruments and the characteristics of the noise measurements made by each. 
The SIO Avatar systems measured the noise level in a band extending 135$375 \mathrm{~Hz}$ and then reduced it, using the assumption of a white noise spectrum over the bandwidth, to the noise in a $1 \mathrm{~Hz}$ band at the center frequency, $250 \mathrm{~Hz}$. The ambient noise was measured every four hours, at the time $0355,0755,1155,1555$, 1955 , and 2355. The actual time series of ambient noise measured at each time was 24.528 seconds long, the same length of time as used in the tomography transmissions. The SIO Avatars accommodated six independent hydrophones, located at depths of $4.5,13.5,22.5,31.5,58.5$, and $94.5 \mathrm{~m}$ below the tomography sources, which were nominally at $95 \mathrm{~m}$ depth (see Table 3.1 for exact values). The hydrophones were calibrated to have sensitivities of $-197 \mathrm{~dB}$ re $1 \mu \mathrm{Pa} / \sqrt{\mathrm{Hz}}$, plus or minus $1 \mathrm{~dB}$.

The WHOI Webb transceivers at moorings 4 and 5 measured noise in a $62.5 \mathrm{~Hz}$ band centered at $250 \mathrm{~Hz}$. This measurement was also processed, using the white noise assumption, to the noise in a $1 \mathrm{~Hz}$ band. Due to having a smaller mass storage capability, the Webb units stored the noise measurements only every third day, taking six measurements on those days at the times of $0355,0755,1155,1555$, 1955, and 2355. Each measurement made was based on five seconds of data. Only four hydrophone channels were available, at depths of $4.5,13.5,22.5$, and $31.5 \mathrm{~m}$ below the sources at (nominally) $95 \mathrm{~m}$. The hydrophones were identical to the SIO units.

In terms of whether our tomographic array will allow process studies of the noise, we note that our best horizontal resolution is about $40 \mathrm{~km}$, almost ten times the mesoscale dimension. Eddies of up to this size are seen in the MIZ, but we would not, for instance, be able to pick out the small regions of convergence in an ice edge eddy which have identified as noise "hot spots".

The ambient noise time series we use in this thesis were received by the shallowest hydrophones at moorings 1 and 6 , and the second shallowest hydrophones at moorings 4 and 5 , due to the misfunction of the shallowest hydrophones at mooring 
4. The difference in ambient noise level, which results from this slight depth difference, is experimentally less than $0.2 \mathrm{~dB}$ and can be ignored.

\subsection{Wind Stress and Wind Velocity}

The near surface wind correlates strongly to the ambient noise field, so that its measurement is a critical one. The measurements of wind used for this study were supplied by the British Meteorological Office (BMO), and are the outputs of its fine mesh data assimilating in a numerical weather forecast model. This model provides the wind stress, air and sea temperature, heat fluxes, etc. every three hours from yearday 241 to 640 of 1988 , starting midnight, on a grid which is $0.75^{\circ}$ in latitude by $0.938^{\circ}$ in longitude. The BMO also provided the $10 \mathrm{~m}$ wind velocity every 3 hours from yearday 251 to 570 of 1988 .

Climatologically, the Greenland Sea has very distinct wind patterns. Cyclonic circulation features travel northeastward on a track defined roughly by the line between Iceland and Bear Island (north of Norway). The size of these features is roughly the mesoscale length ( where the Coriolis force becomes important), given by

$$
L=\frac{|\vec{U}|}{f}
$$

where $\mathrm{L}$ is the mesoscale length, $\vec{U}$ is the ( characteristic upper level ) wind velocity, and

$$
f=2 \Omega \sin (\Phi)
$$

In $\mathrm{Eq}(3.2), \mathrm{f}$ is the Coriolis parameter, $\Omega$ is the earth's angular velocity and $\Phi$ is the latitude. At $74^{\circ} \mathrm{N}, f=1.4 \times 10^{-4}$. As typical wind velocities are on the order of $20 \mathrm{~m} / \mathrm{s}$, we see that $\mathrm{L}$ is on the order of $140 \mathrm{~km}$. This is of the same order of size as our tomography array. R. Pawlowicz $z^{27}$ has compared the mean wind stress and raw wind stress time series, and found that much of the variance of the computed 
means was associated with systems moving across the array. He noted that the raw stress magnitude time series was similar to that of the mean magnitude, the only noticeable difference being slightly larger peaks. He concluded that the spatial scales of variability were at least as large as the array size, so that time series at different moorings would probably differ at most by a lag factor. His conclusion is consistent with the result we present above. Thus, to a good first approximation, we can regard the winds as constant over our array at a given instant of time. This is in fact what we have done in our analysis, using the model grid point nearest to mooring 6 , the array center, for our wind field.

Since the number of the gaps during the measurement is an important factor in data processing, we give the number of data, number of gaps, gap percentage, and time series duration of the wind and noise in Table 3.4

Table 3.4

Data gap statistics for wind and noise

\begin{tabular}{|c|c|c|c|c|}
\hline & number of data & number of gaps & gap\% & $\begin{array}{c}\text { TS duration } \\
\text { (yearday) }\end{array}$ \\
\hline $\begin{array}{c}10 \mathrm{~m} \\
\text { wind speed }\end{array}$ & 2528 & 32 & 1 & $251-571$ \\
\hline wind stress & 3138 & 62 & 2 & $241-641$ \\
\hline $\mathrm{m} 1$ & 1592 & 388 & 20 & $267-597$ \\
\hline $\mathrm{m} 4$ & 630 & 0 & 0 & $264-577$ \\
\hline $\mathrm{m} 5$ & 630 & 0 & 0 & $261-574$ \\
\hline $\mathrm{m} 6$ & 1980 & 0 & 0 & $267-597$ \\
\hline
\end{tabular}




\subsection{Ice Cover Observations}

The experiment benefited from the incursion during the winter of two distinct ice regions. Each offered an opportunity to measure ambient noise as well as to examine the effects of the ice on propagation and travel time.

The first ice regime was the marginal ice zone (MIZ ) of the East Greenland current ice drift. After two short incursions into the northwest corner of the array on about yeardays 250 and 300 of 1988 , the MIZ spread over much of the northwest area of the array from yearday 320 onwards, lasting continuously until yearday 400 . Further sporadic incursions took place until yearday 470 . This ice regime is normally characterized by an ice area composed of a mixture of multi-year and first year ice from the Arctic Basin, broken up by wave action into distinct floes of typical diameter 40-80 m. The ice thickness distribution in such a region in this latitude range has been measured for the late winter of 1987 by upward sonar ${ }^{28}$, giving mean drafts of 0.9-1.9 $\mathrm{m}$ and pressure ridge distributions in which ridge keels were observed in small numbers up to a draft of about $10 \mathrm{~m}$. A study of passive microwave (SSM/I) data from this regime during the winter showed that the mean ice concentration was up to $98 \%$ at one point but was more usually $50-80 \%$ even during the main winter incursion.

The second ice regime was the extreme northern end of the Odden ice tongue, which intruded into the south and southeast parts of the array on a number of occasions throughout the winter, each time for only a few days. Odden is the name given to a tongue of ice protruding eastward from the main East Greenland current, and overlying the Jan Mayen Polar Current. It develops during most winters, and is often observed to make rapid fluctuations in size and shape, which indicate that it is composed largely of young ice which forms and melts locally. This repetitive ice formation and decay has been associated with a stepwise mechanism for driving deep 
convection in the Greenland Gyre (Rudels ${ }^{29}$ ). SSM/I data gave typical ice concentrations of $20-50 \%$ for Odden incursions, but a revealing Synthetic Aperture Radar (SAR ) image generated by an aircraft on March 26, 1989 showed that the Odden at this time was composed entirely of areas of either frazil ice, a milky suspension of ice crystals in water, covering up to $50 \%$ of the sea surface, or small floes only a few meters in diameter. The images were very similar to SIR-B images of the Atlantic MIZ given in Martin et al. ${ }^{30}$. This casts some doubt on multi-year fractions of up to $101 \%$ extracted from SSM/I data, but it is recognized that the SSM/I multi-year ice algorithm is erroneous at low concentrations.

In terms of the quantity and quality of ice cover data available for our analysis, there is a year of SSM/I imagery, augmented by AVHRR data when cloud cover openings permitted, as well as the SAR image taken during CEAREX (Coordinated Eastern Arctic Experiment ). The resolution of the SSM/I images is nominally 20 $\mathrm{km}$ and the AVHRR images $5 \mathrm{~km}$. 


\section{Chapter 4. Time Series of Ice Concen- tration, Noise and Wind Velocity}

In this chapter, we will examine details of the ice concentration, noise and wind time series. We will then compare the ambient noise with some of the environmental variables, such as ice concentration and wind velocity.

\subsection{Ice Concentration Time Series}

Ice-coverage time series at the mooring locations are derived from the SSMI and AVHRR data sets, which are available from yeardays 221 to 600 of 1988 . SSMI data were sporadically spaced, roughly weekly over most of the year and daily in the spring from yeardays 412 to 459 . We have 94 ice cover data sets in total. Linear interpolation between sets is used to get an ice cover time series to correlate against the ambient noise. The ice cover time series at the moorings and some representative ice edge configurations are plotted in Figs. 4.1 and 4.2. Three characteristics of those plots are worth mentioning. First, the main peak widths (ice concentration $>50 \%$ ) are narrower in moorings 1 (yeardays 351 to 365 ) and 6 (yeardays 346 to 373 ), and wider in moorings 4 (yeardays 331 to 388 ) and 5 (yeardays 323 to 396 ). Second, the maximum values of ice concentration are higher in moorings 4 ( $96 \%$ ) and $5(98 \%)$ than in moorings $1(69 \%)$ and $6(85 \%)$. Third, there is no extended ice-free period over mooring 5 . 

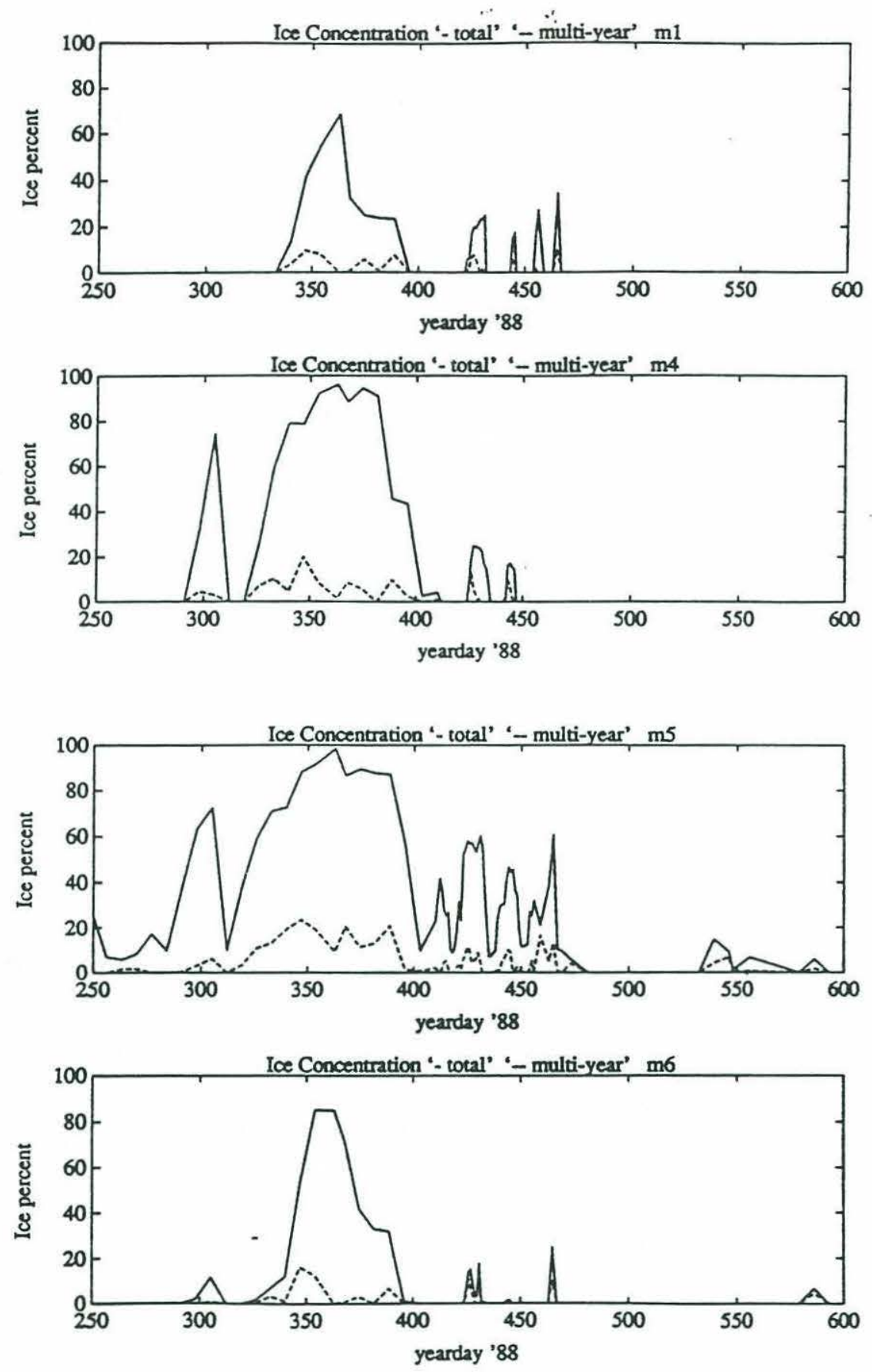

Figure 4.1: Ice concentration time series at moorings 1, 4, 5, and 6. 

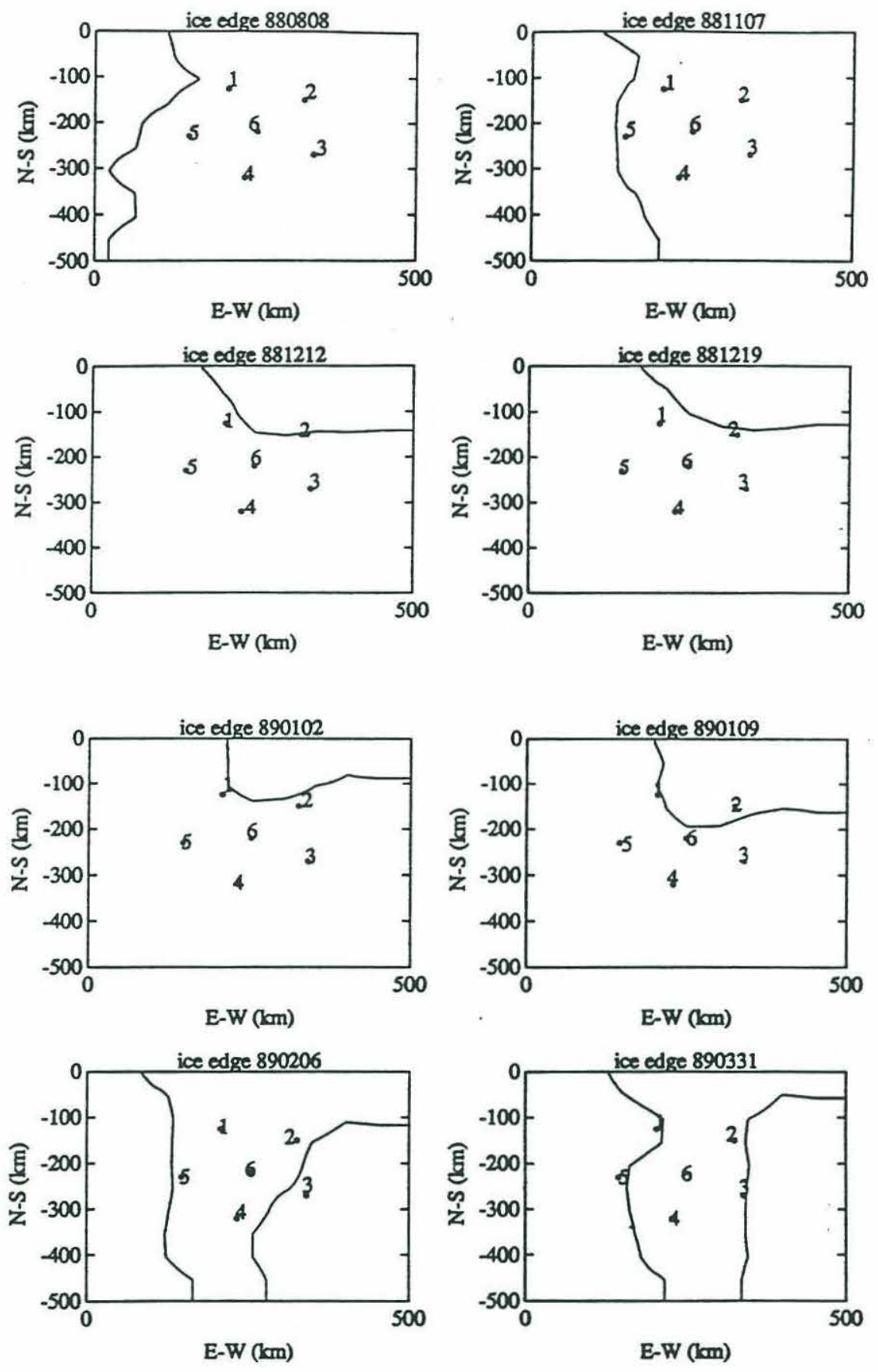

Figure 4.2: Ice edge configurations at $08 / 08 / 88,11 / 07 / 88,12 / 12 / 88,12 / 19 / 88,01 / 02 / 89$, $01 / 09 / 89,02 / 06 / 89$, and $03 / 31 / 89$. 


\subsection{Noise}

\subsubsection{Ambient Noise Percentile}

The extreme loud noises ( $>95 \%$ level), extreme low noises $(<5 \%$ level ), mean noise level, the number of extreme noise points, etc. are listed in Table 4.1.

Table 4.1

Statistics for extreme noise

\begin{tabular}{|l|c|c|c|c|}
\hline & $\mathrm{m} 1$ & $\mathrm{~m} 4$ & $\mathrm{~m} 5$ & $\mathrm{~m} 6$ \\
\hline $95 \%$ level(dB) & 85.7 & 77.6 & 81.2 & 83.1 \\
\hline $\begin{array}{l}\text { number of extreme } \\
\text { loud noise events }\end{array}$ & 80 & 31 & 31 & 90 \\
\hline $\begin{array}{l}\text { mean of } \\
\text { extreme loud noises (dB) }\end{array}$ & 88 & 80.6 & 84.5 & 85.4 \\
\hline $\begin{array}{l}5 \% \text { level (dB) } \\
\begin{array}{l}\text { number of extreme } \\
\text { low noise events }\end{array}\end{array}$ & 72.1 & 64.1 & 62.8 & 70.9 \\
\hline $\begin{array}{l}\text { mean of } \\
\text { extreme low noises (dB) }\end{array}$ & 71.3 & 63.2 & 61.6 & 70.5 \\
\hline $\begin{array}{l}\text { mean of } \\
\text { noise time series (dB) }\end{array}$ & 77.9 & 69.7 & 71.3 & 75.9 \\
\hline
\end{tabular}

The extreme noise time series are plotted in Figs.4.3 and 4.4. Ambient noise percentile levels vary seasonally at all moorings. Overall noise levels are considerably higher in winter. As a result, when percentile levels are based on a year of data, noise levels exceeding the $95 \%$ level are generally confined to the winter months for 

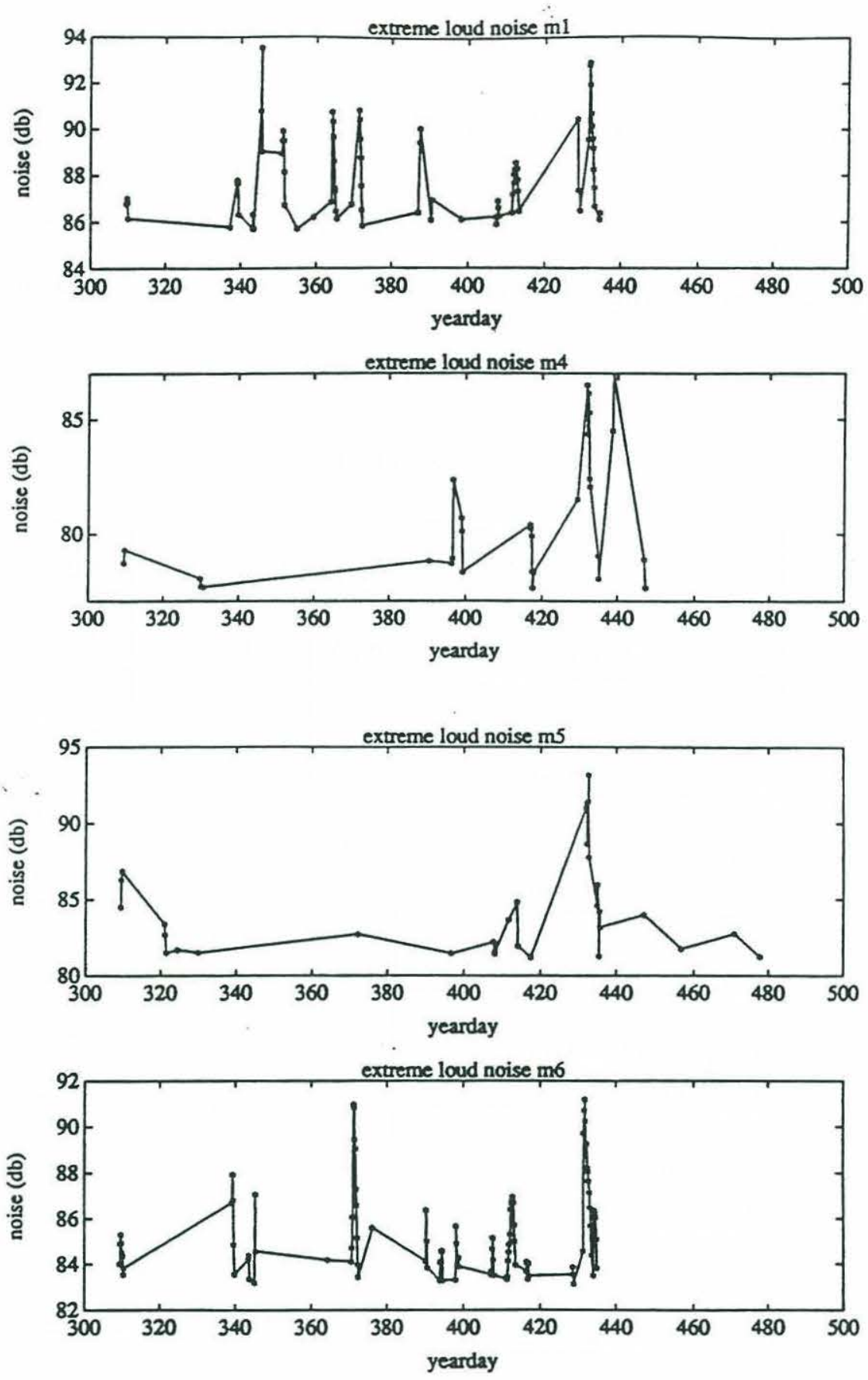

Figure 4.3: Extreme loud noise time series. Extreme loud noise levels are generally confined to the winter months. 

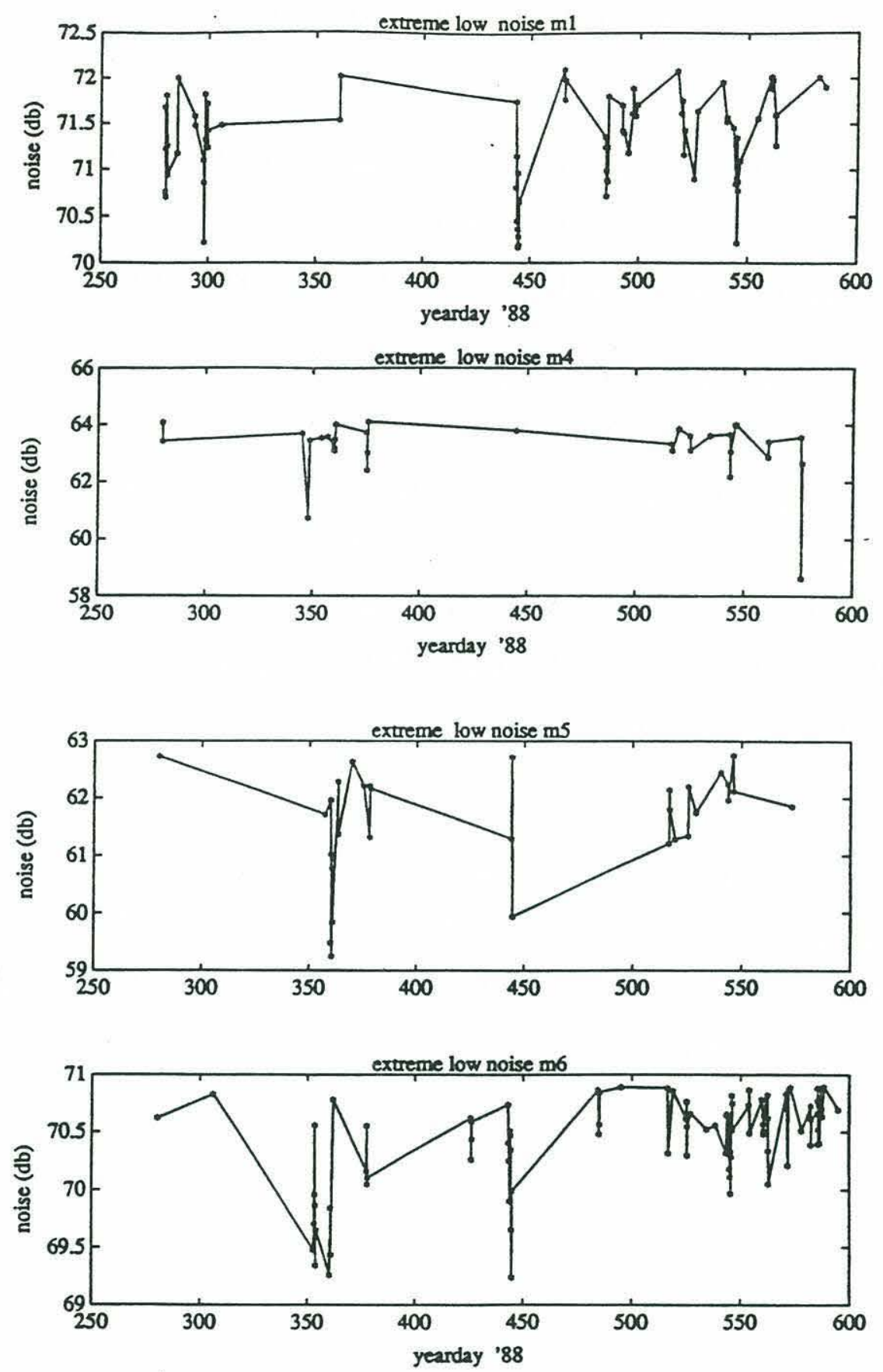

Figure 4.4: Extreme low noise time series. There is a quiet period during mid-winter at moorings 4 and 5 coincident with heavily ice covered conditions. 
moorings 1, 4 and 6 ( Nov. to Mar.), and slightly longer for mooring 5 ( Nov. to Apr.).

Long duration ( $>16$ hours ) extreme loud noise levels during winter months occur frequently. There are eleven time periods during the winter season when the noise level at mooring 6 exceeded the $95 \%$ level for longer than 16 hours.

Extreme low noise behaves quite differently at different moorings. At mooring 1 , extreme low noise events occur in fall, spring, and summer, leaving the winter months very noisy. At mooring 6, extreme low noise events occur through the whole year. At moorings 4 and 5 , extreme low noise events are generally confined to summer months; however, there is an additional quiet period during mid-winter coincident with heavily ice covered conditions. This mid-winter quiet period implies that heavy ice cover blocks ambient noise production.

In order to describe the noise field in terms of the dominant physical forcing functions, we divided each mooring time series into four segments : 1) fall, 2) heavy pack ice cover, 3) ice edge advance-retreat, and 4) spring-summer. The temporal extent of those regions is determined by the local ice cover as shown in Fig.4.1. The exact duration of each period is listed in Table 4.2. 
Table 4.2

Time periods

\begin{tabular}{|c|c|c|c|c|}
\hline \multirow{2}{*}{$\begin{array}{l}\text { ice state } \\
\text { yearday } \\
\text { mooring }\end{array}$} & \multicolumn{2}{|c|}{$\begin{array}{c}\text { ice free at } \mathrm{m} 1,4,6 \\
\text { some ice at } \mathrm{m} 5\end{array}$} & \multirow{2}{*}{$\begin{array}{c}\text { heavy ice } \\
\text { cover }\end{array}$} & \multirow{2}{*}{$\begin{array}{c}\text { ice edge } \\
\text { advance/retreat }\end{array}$} \\
\hline & fall & spr-sum & & \\
\hline $\mathrm{m} 1$ & $267-330$ & $480-596$ & $347-363$ & $420-475$ \\
\hline $\mathrm{m} 4$ & $267-288$ & $453-576$ & $332-391$ & $402-450$ \\
\hline $\mathrm{m} 5$ & $267-318$ & $483-576$ & $332-396$ & $402-480$ \\
\hline $\mathrm{m} 6$ & $267-290$ & $480-596$ & $347-370$ & $420-475$ \\
\hline
\end{tabular}

\subsubsection{Ambient Noise Time Series}

In Figs.4.5a-d, we show time series of the noise levels recorded at moorings 1 and 6 (Avatar systems) and moorings 4 and 5 (Webb systems). Many interesting features are evident in these figures. The most obvious feature is the difference in sampling frequency between the systems. The overall ambient noise level differences are also obvious between these figures. The levels in the Avatar systems are 6-10 $\mathrm{dB}$ higher than that of Webb systems, whose reading are in turn closer to the Wenz curves and other historical measurements.

We now look at the possible reasons for the seasonal noise level differences. First, we consider the ice edge's effect. The ice edge is a region of high noise production, i.e., ambient noise has a relative maximum at the ice edge. Thus, during the ice-free periods, noise levels in the Avatar systems should be lower than for the Webb systems since moorings 1 and 6 are far then from the ice edge than moorings 4 and 5 during this period. Second, we take ice concentration differences into consideration. During heavy ice cover periods, the ice shuts off the noise. Thus at those time, noise 

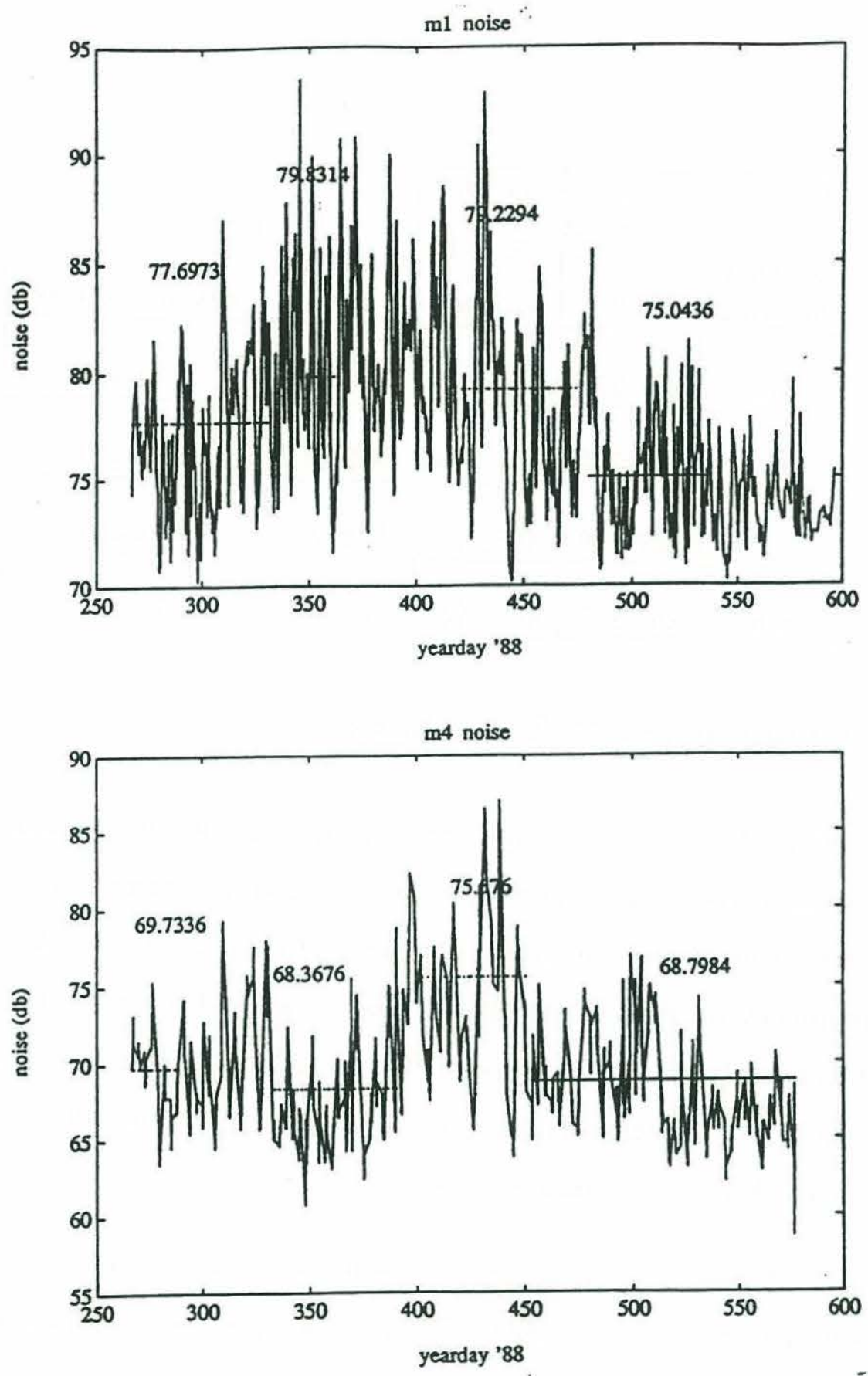

Fig. 4.5a-b Noise time series and the mean values of noise at four different periods moorings 1 and 4. 

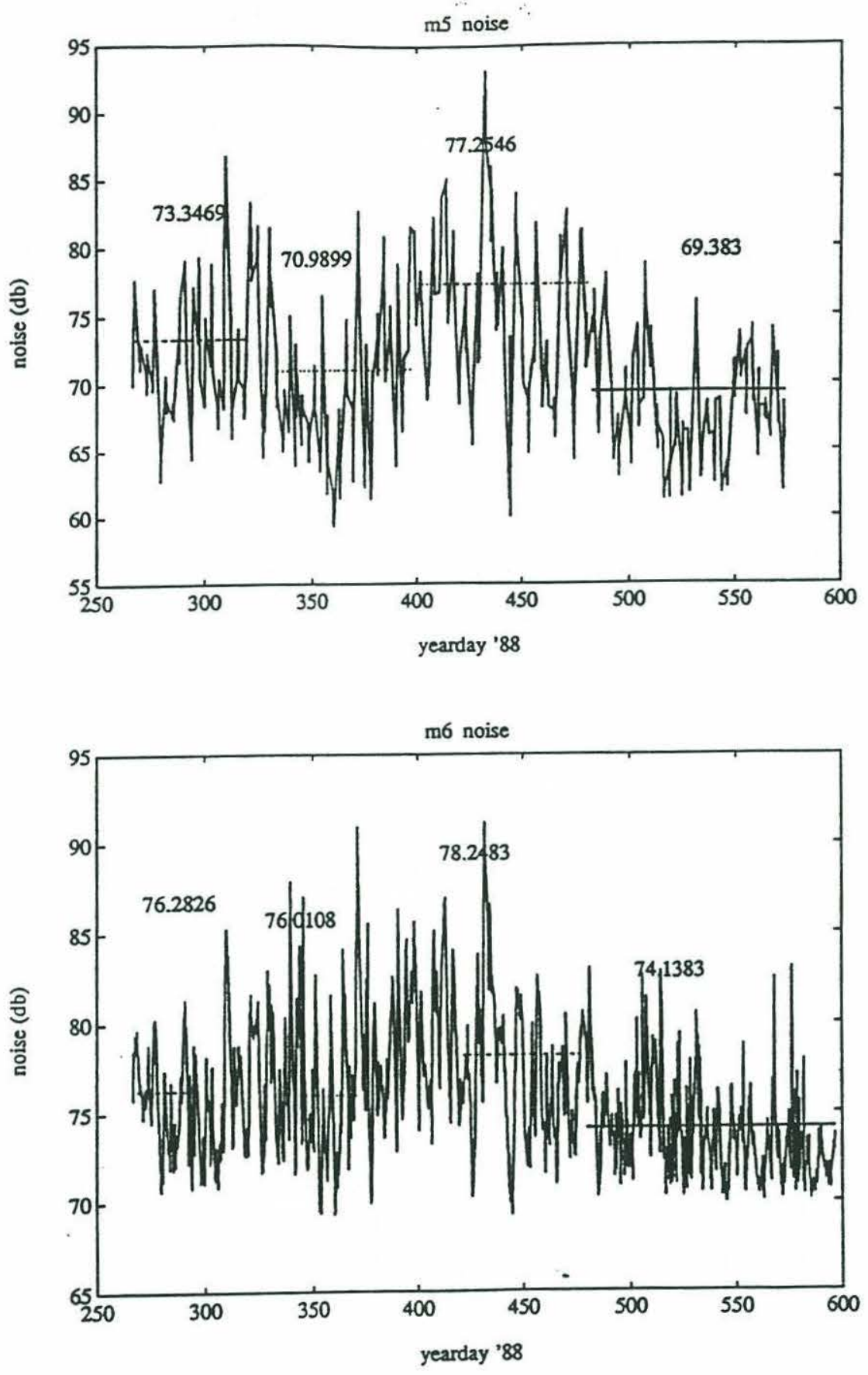

Fig. 4.5c-d See 4.5a for caption - moorings 5 and 6. 
at moorings 1 and 6 should be higher than at moorings 4 and 5, during to much heavier ice cover at moorings 4 and 5 . But it cannot explain the difference during the other periods. Third, we note that the Avatar systems measured the noise level in a band extending $135-375 \mathrm{~Hz}$ whereas the Webb systems measured the noise level in a $62.5 \mathrm{~Hz}$ band centered at $250 \mathrm{~Hz}$. The recent spectral analysis of Avatar data shows that the noise peaks at frequency of $250 \mathrm{~Hz}$. This implies that the overall levels at moorings 4 and 5 should be higher than that at moorings 1 and 6 . Thus the overall level difference of the ambient noise between the SIO and WHOI moorings remains unexplained.

The mean value, standard deviation, maximum noise, minimum noise, and maximum fluctuation are listed in Table 4.3.

Table 4.3

Statistics for noise

\begin{tabular}{|c|c|c|c|c|}
\hline & $\mathrm{m} 1$ & $\mathrm{~m} 4$ & $\mathrm{~m} 5$ & $\mathrm{~m} 6$ \\
\hline $\begin{array}{c}\text { mean value(dB) } \\
\text { standard }\end{array}$ & 77.86 & 69.66 & 71.32 & 75.94 \\
\hline $\begin{array}{c}\text { deviation (dB) } \\
\text { max noise (dB) }\end{array}$ & 4.29 & 4.47 & 5.84 & 3.87 \\
\hline min noise (dB) & 70.50 & 87.00 & 93.15 & 91.20 \\
\hline $\begin{array}{c}\text { max fluctuation(dB) } \\
\text { (at yearday) }\end{array}$ & $\begin{array}{c}9.27 \\
(526)\end{array}$ & - & - & $\begin{array}{c}7.72 \\
(345)\end{array}$ \\
\hline
\end{tabular}

The noise spreads up to $22-23 \mathrm{~dB}$ in moorings 1 , and 6 and 28-33 $\mathrm{dB}$ in moorings 4 , and 5. From the table, we also see that the noise evolves slowly, with the maximum fluctuation being less than $10 \mathrm{~dB}$ at moorings 1 and 6 . 


\subsubsection{Histograms of Ambient Noise}

As seen in Fig.4.6 a-d, histograms of the ambient noise levels for the different moorings during different periods show dynamic ranges spanning up to $33 \mathrm{~dB}$. Ice edge advance-retreat periods have broad distributions, which show the lowest and highest noise levels. Spring-summer periods show a predominance of lower level noise and narrower distributions. In all periods, the distributions show roughly Rayleigh looking trends from low to high noise levels.

\subsection{Wind Velocity}

\subsubsection{The Relationship between Wind Velocity and Wind Stress}

The BMO provided us with the wind stress for the Greenland Sea region covering the time period of the tomography experiment. 3-hourly analyses were available from yeardays 241 to 640 of 1988 (08/28/1988 to 10/01/1989). The BMO also provided the $10 \mathrm{~m}$ wind velocity data, consisting of data every 3 hours from yeardays 251 to 570 of 1988 . To get the summer wind speed, which we do not have, we look at the relation between the wind stress and wind velocity. Recalling the standard bulk formula for calculating wind stress from wind speed ${ }^{31}$

$$
\vec{\tau}=C \rho|\vec{U}| \vec{U}
$$

where $\vec{\tau}$ is the wind stress $\left(\mathrm{N} / \mathrm{m}^{2}\right), \vec{U}$ is the wind velocity, $\rho$ is the density of air $\left(1.225 \mathrm{~kg} / \mathrm{m}^{3}\right.$ US standard atmosphere at sea level), and $\mathrm{C}$ is the drag coefficient (of order 0.001 ). The major problem with this formula is the value used for drag coefficient. Guest and Davidson ${ }^{32}$ have pointed out that the surface drag coefficient is correlated with ice concentration, ice floe roughness and floe size. They estimated that $C=2.3 \pm 0.8 \times 10^{-3}$ for areas with less than $40 \%$ ice concentration, and $C=$ 

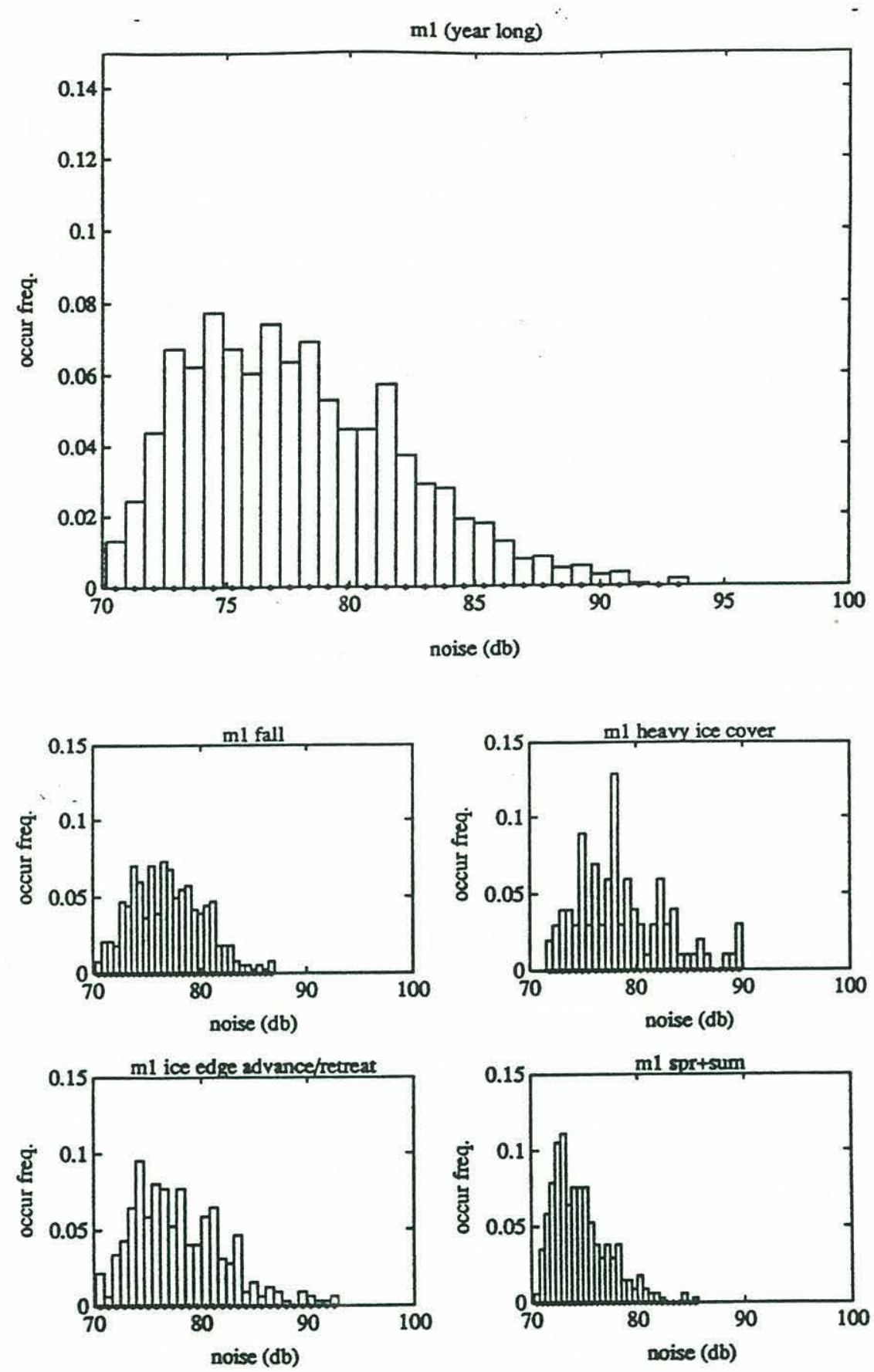

Fig. 4.6a Histograms of the noise. The distributions show roughly Rayleigh looking trends from low to high noise levels - mooring 1. 

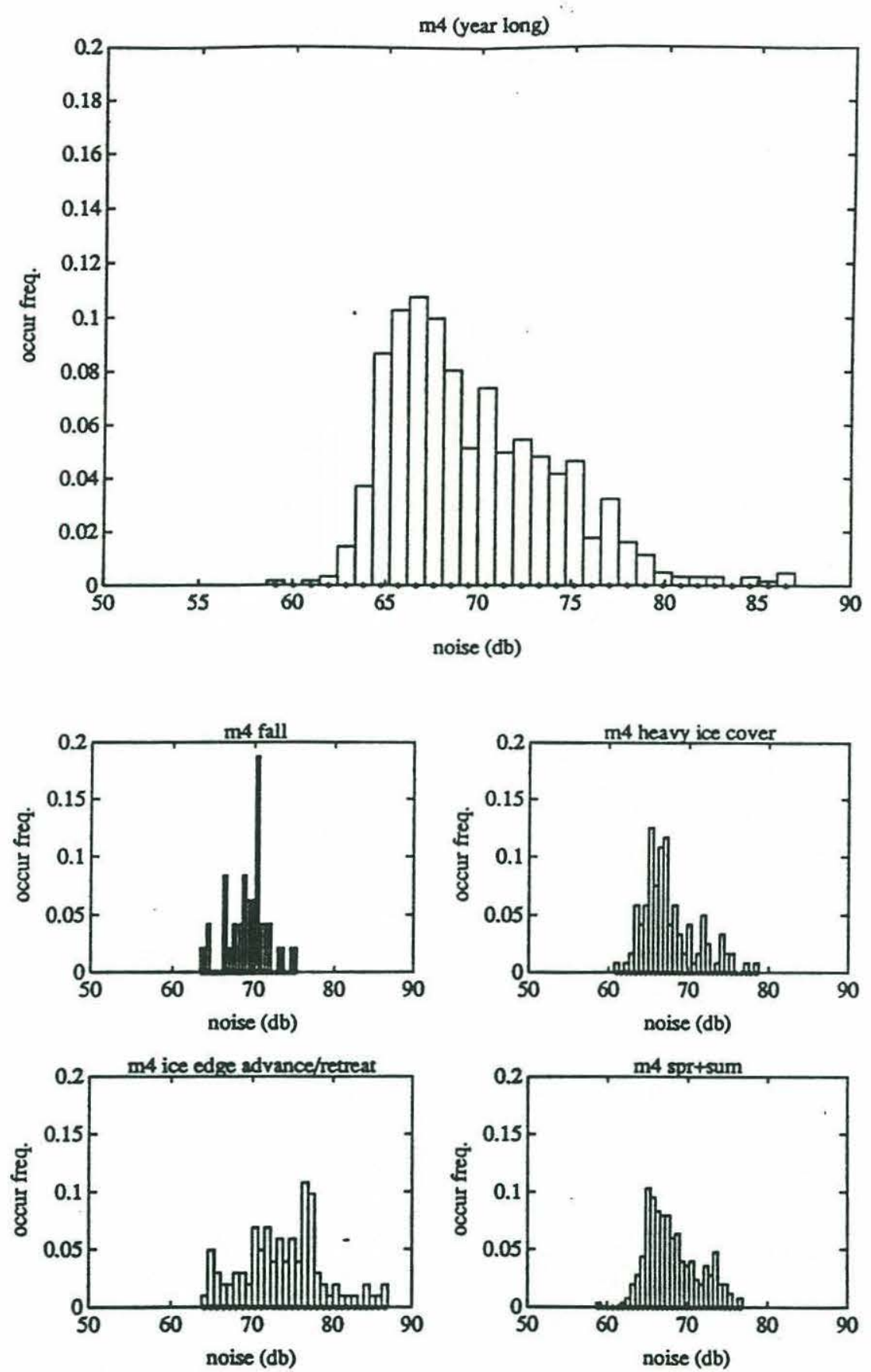

Fig. 4.6b See Fig. 4.6a for caption - mooring 4 

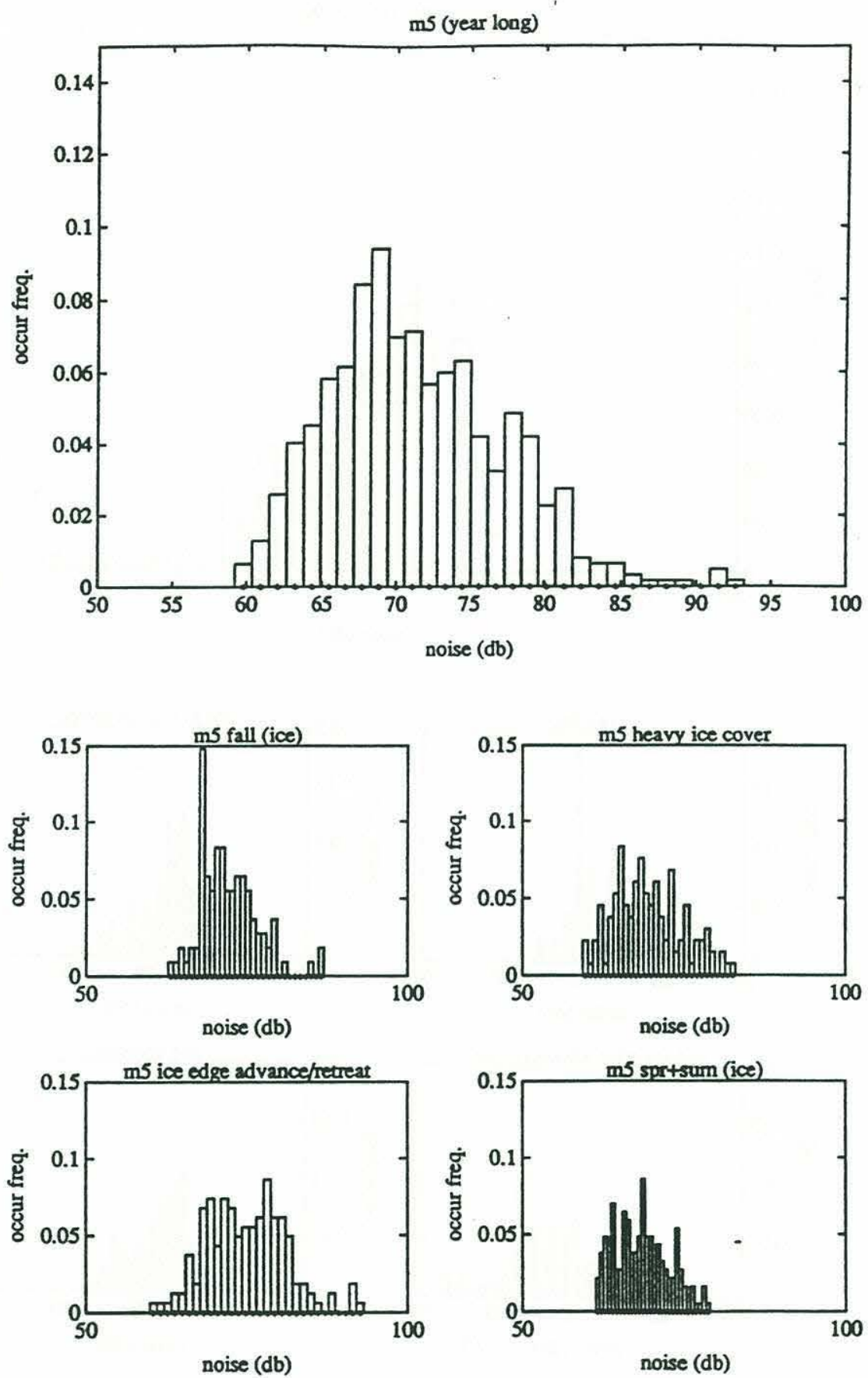

Fig. 4.6c See Fig. 4.6a for caption - mooring 5 

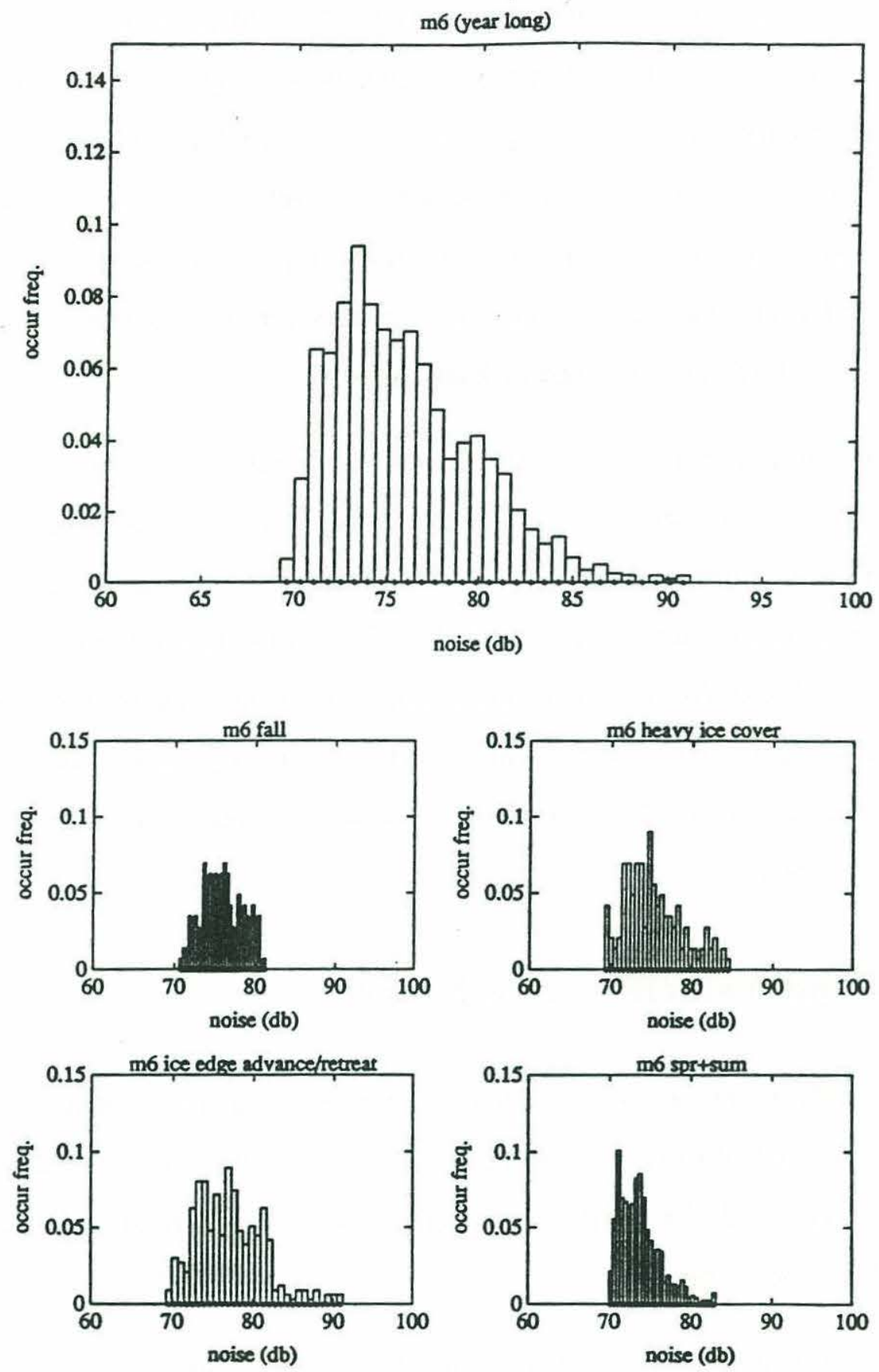

Fig. 4.6d See Fig. 4.6a for caption - mooring 6 
$4.0 \pm 1.1 \times 10^{-3}$ for ice concentrations greater than $70 \%$. The BMO stress values were calculated using a drag coefficient which is a function of a bulk Richardson number based on parameters in the planetary boundary layer which we do not have. To compare the wind stress vectors with the wind velocity, we can roughly estimate wind speed using the bulk formula with a constant drag coefficient $\mathrm{C}=0.0015$. The 3-hour-interval wind speed and direction converted from wind stress, together with the $10 \mathrm{~m}$ wind velocity, are plotted in Figs. 4.7a-b.

The similarity in the two amplitudes is extremely good except during the heavy ice cover period, where we need to modify the drag coefficient. The wind directions are also consistent during the whole year, even during the heavy ice cover period. The outcome of this comparison is that we can use the bulk formula to convert to $10 \mathrm{~m}$ wind velocity from wind stress using a constant drag coefficient ( 0.0015$)$ from yeardays 571 to 640 , during which period we do not have the wind velocity data. This is because in ice-free periods, we can use constant drag coefficient without causing large errors.

\subsubsection{Wind Velocity Time Series}

The BMO time series provided samples every 3 hours, while the ambient noise series consisted of data points every 4 hours. To allow direct comparisons, we interpolated/decimated the wind velocity time series to a 4 hour interval to match with the ambient noise series.

The wind magnitude and a polar plot of the wind velocity at mooring 6 are shown in Fig.4.8. It is seen that late winter and early spring (yeardays 400-470) have the strongest winds, along with the fall (yeardays 270-350). The late fall/early winter (yeardays 350-400) has the next to lowest winds; the winds during late spring and summer are by far the lowest, roughly half the average magnitude of the fall. 

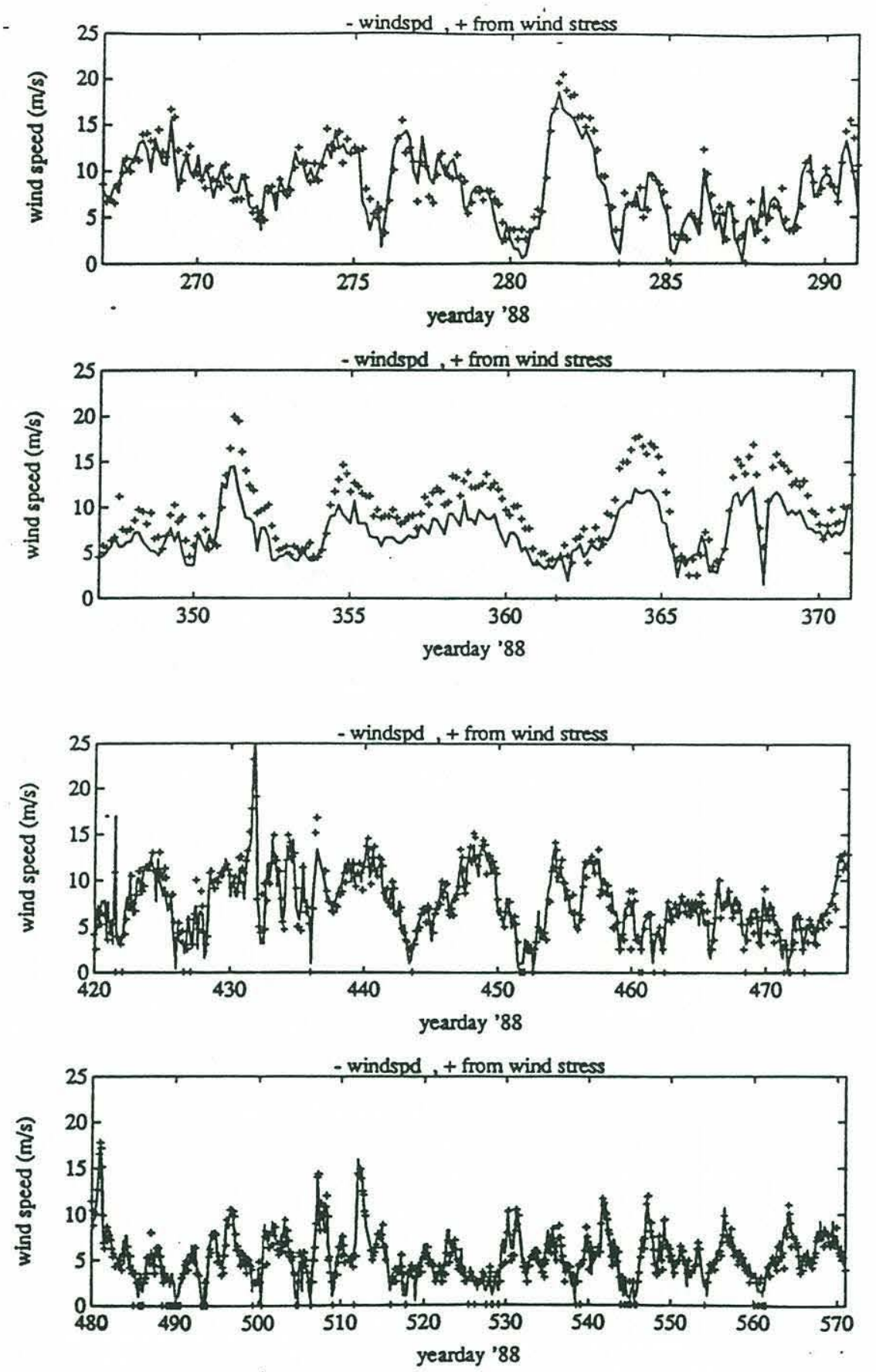

Fig. 4.7a Comparison of the $10 \mathrm{~m}$ wind speed ( - ) with that derived from wind stress using bulk formula (+). The similarity in the two amplitudes is extremely good except - during the heavy ice cover period. 

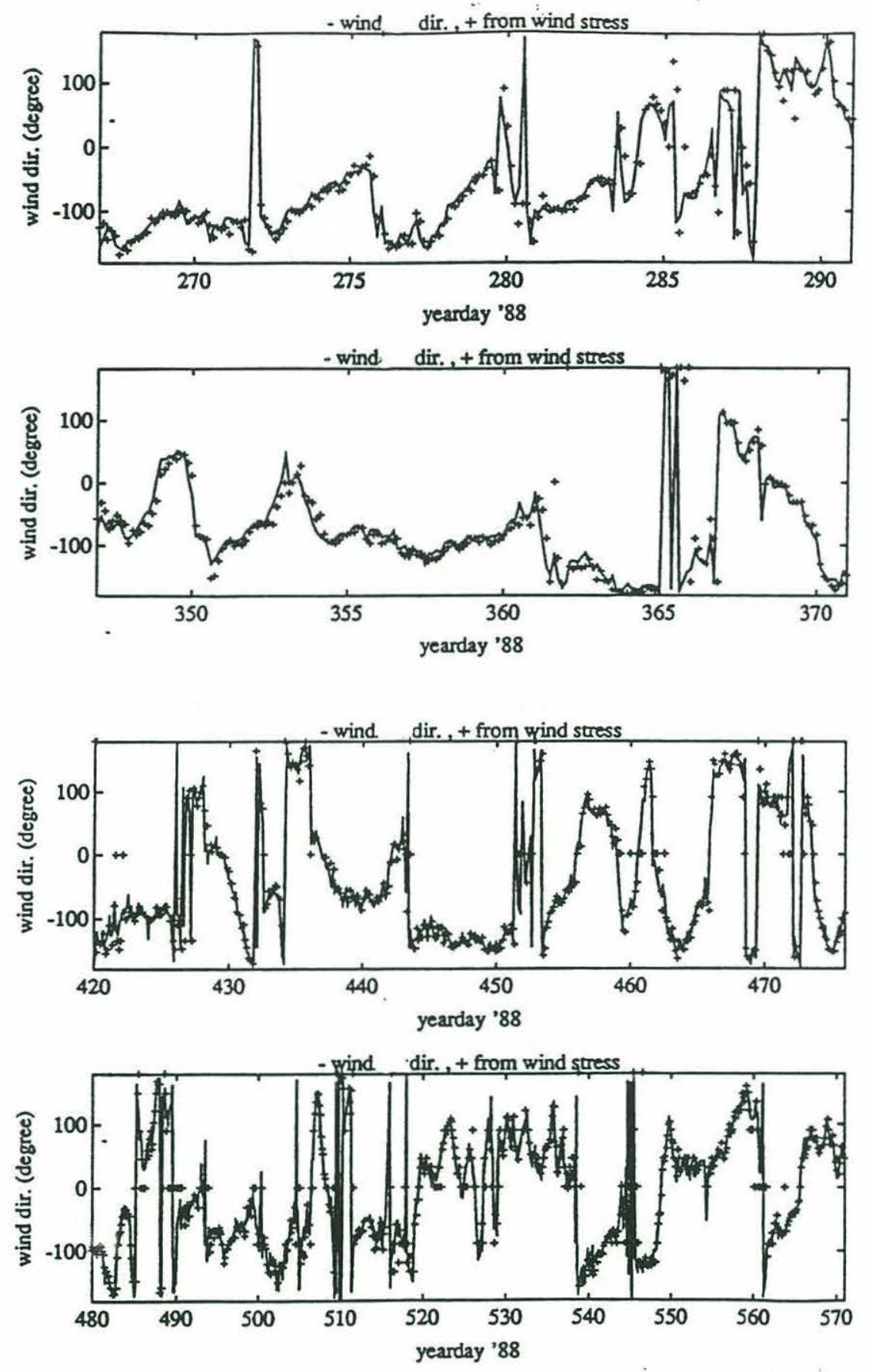

Fig. 4.7b Comparison of the $10 \mathrm{~m}$ wind direction ( -$)$ with the wind stress direction $(+)$. The two wind directions are consistent during the whole year. 

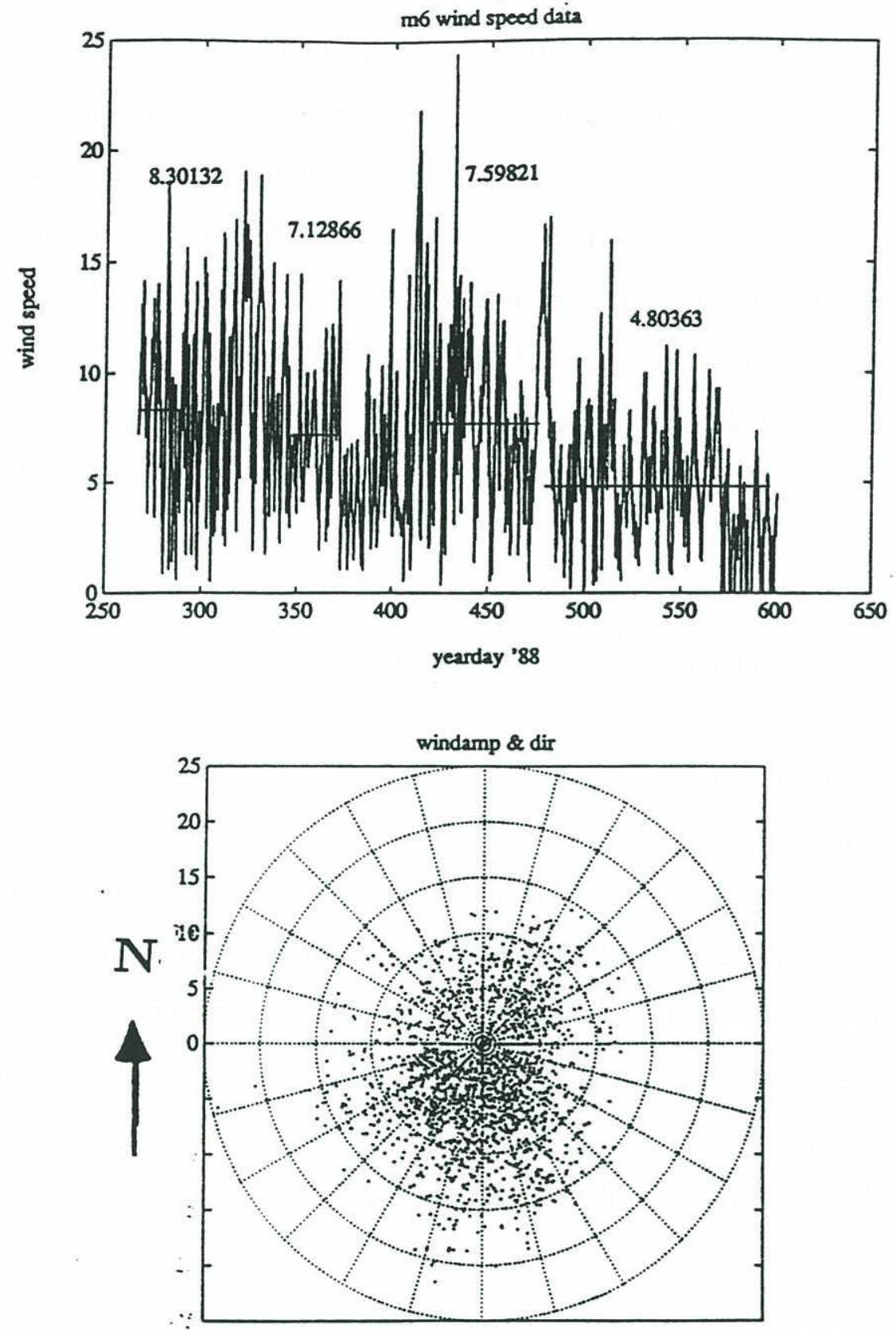

Fig. 4.8 The wind magnitude and a polar plot of the wind velocity at mooring 6 . The mean values of the wind amplitudes at four different periods are also shown in this figure. 
In Fig.4.9, we show the wind velocity in a vector diagram. It is seen that there is a strong tendency for the winds to be from north to south at our array. This is due to the winds being associated with predominately cyclonic circulation features moving on a track to the east of our array, as mentioned. The wind magnitude is the most important variable in noise studies, overall. However, the wind direction is also of importance, as it affects the fetch of the wind off the land and the ice, as well as the convergence and divergence of the ice edge. From a cursory intercomparison of Figs.4.5a-d, and Fig.4.8, one see that the noise and wind follow roughly the same trends.

\subsubsection{Histograms of Wind velocity}

The distributions of wind velocity show a predominance of low, north to south winds with a mean amplitude of $6.5 \mathrm{~m} / \mathrm{s}$, which is very close to the critical friction velocity for wave breaking. In the fall and during the heavy ice cover periods, wind speeds more or less tend to be uniform distributed, with wind from the northeast dominating. During the ice edge advance/retreat and spring-summer periods, the histograms show lower wind speeds dominanting and a uniform wind direction distribution. The highest wind speed occurs during the ice edge advance/retreat period. The histograms of wind velocity are shown in Figs.4.10a-b.

\subsection{Ambient Noise and Environmental Variables}

\subsubsection{Wind Speed and Ambient Noise}

To show how the wind and noise fields correspond in a time series sense, we show in Fig.4.11 the noise at mooring 6 (observed noise minus $2.1 \mathrm{~dB}$ and minus $68 \mathrm{~dB}$ ) vs. the wind speed. This crude regression allows one to clearly see some 


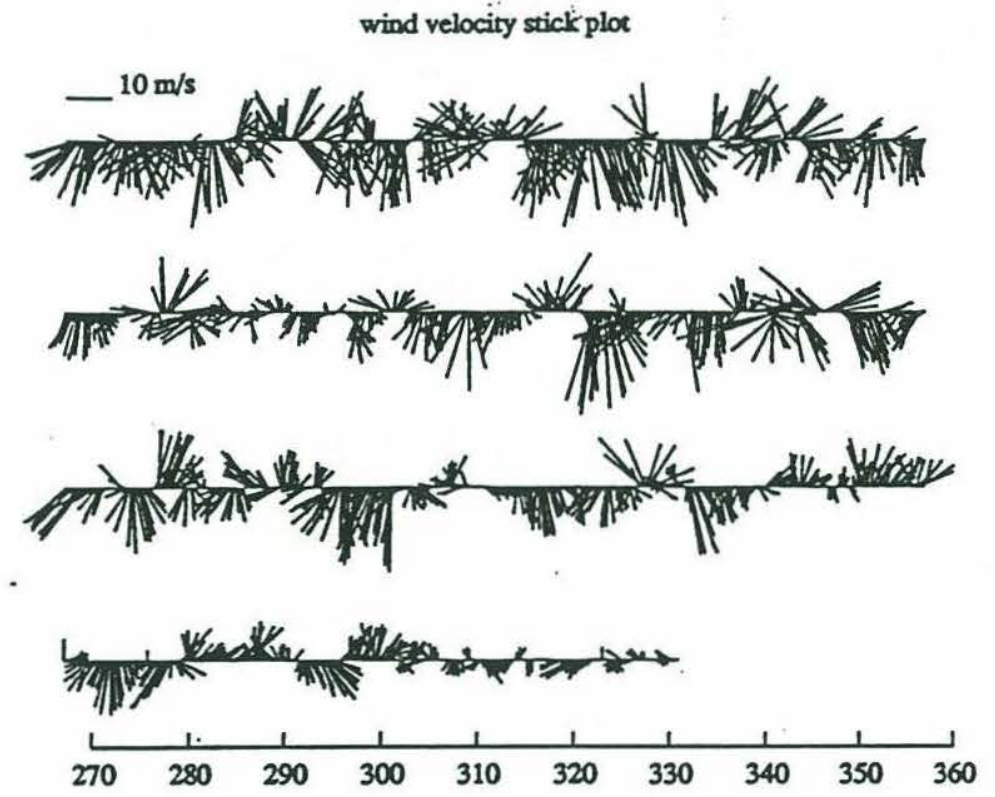

Fig. 4.9 Vector diagram of wind velocity at mooring 6 . There is a strong tendency for the winds to be from north to south at our array. 

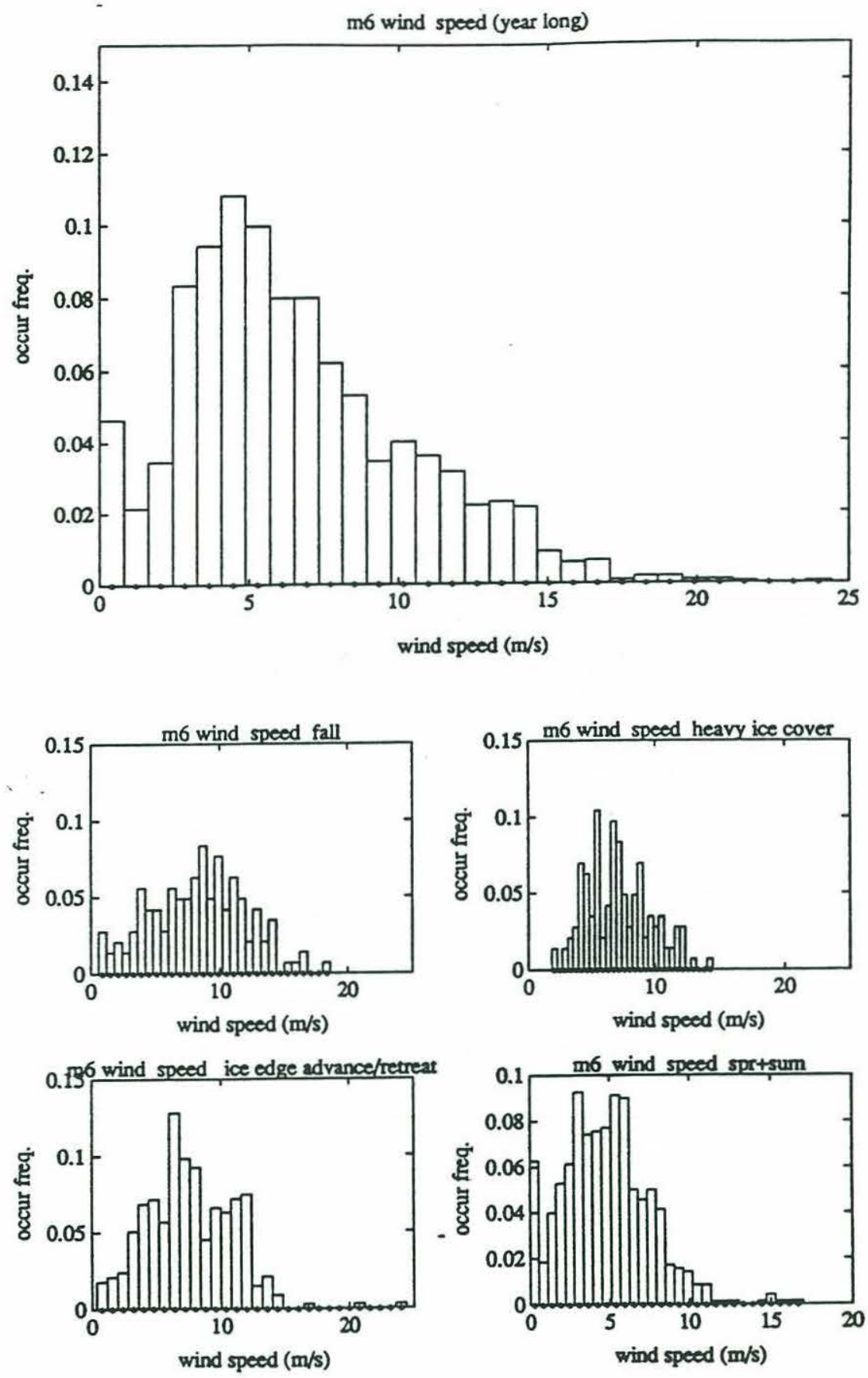

Fig. 4.10a Histograms of wind speed. The distributions of wind speeds show a predominance of low winds. 

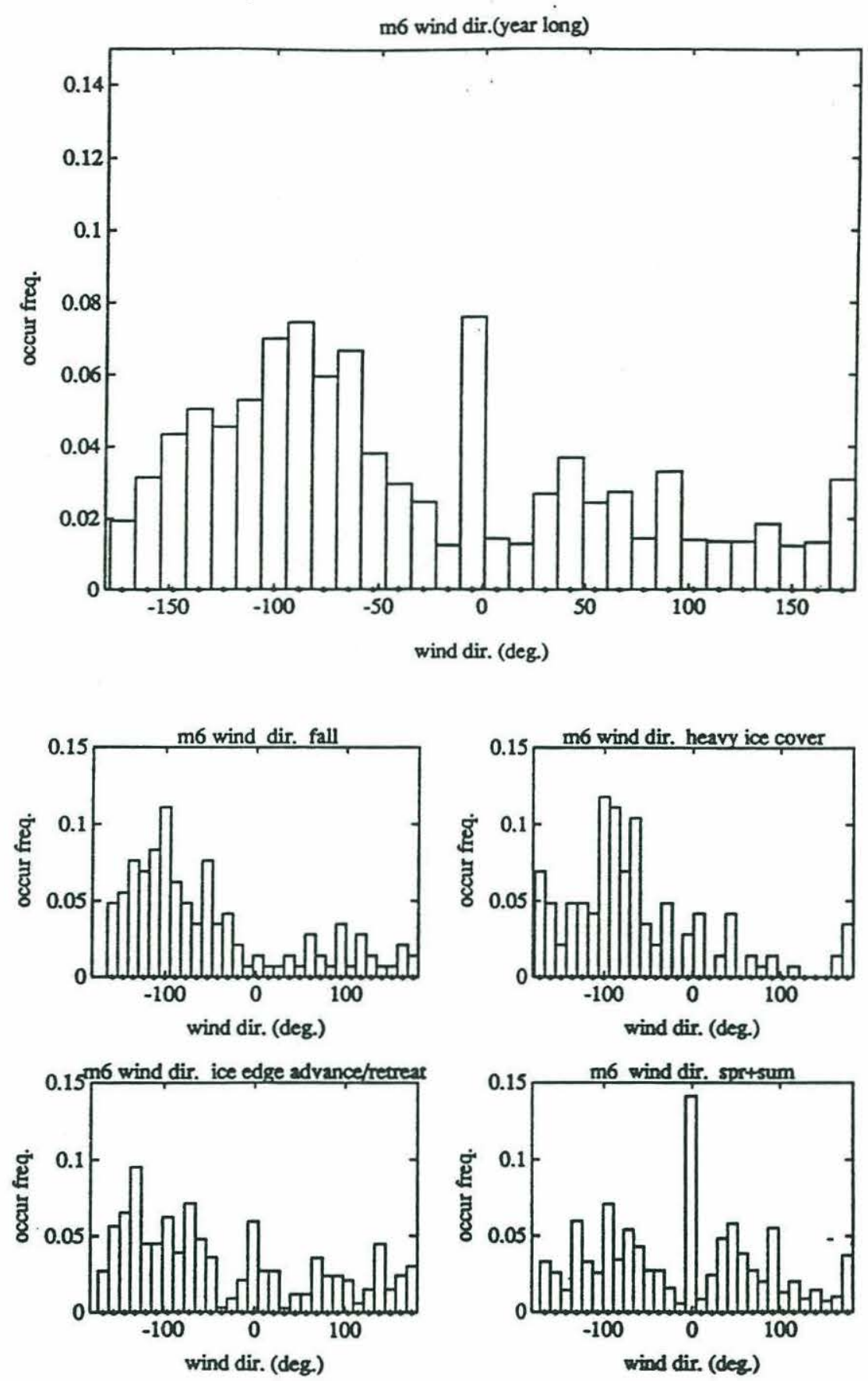

Fig. 4.10b Histograms of wind direction. The distributions of wind directions show a predominance of north to south winds. 

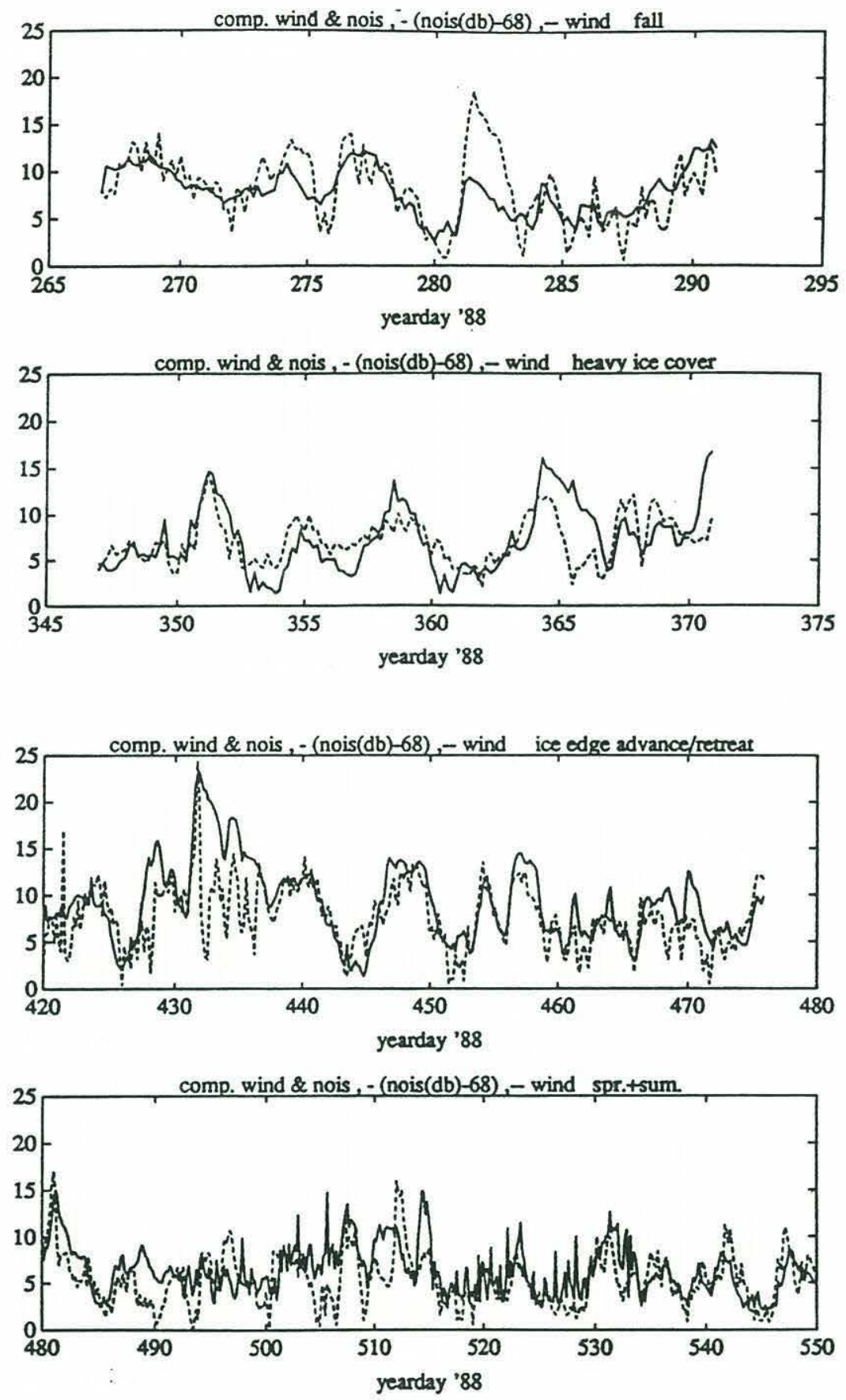

Fig. 4.11 Wind speed ( - ) and ambient noise minus $68 \mathrm{~dB}(-)$. The noise field varies a bit more smoothly than the wind field and the magnitude of the noise seems to scale with the wind reasonably well. 
relationships between the noise field and the wind. First, one can see that the noise field varies a bit more smoothly than the wind field. Therefore we expect that the temporal correlation length of the noise field should be longer than that of the wind. Second, the magnitude of the noise seems to scale with the wind reasonably well.

Wind speed is highest in the fall and during the ice edge advance/retreat period, and is lowest in spring-summer, while the noise field is highest during the ice edge advance/retreat period (expect mooring 1), the second highest in fall (except mooring 1), and the lowest in spring-summer (except mooring 4). Noise being highest during the ice edge advance/retreat period implies that ice edge related noise mechanisms, such as ice-floe collisions, cause the higher noise. The fact that the noise is not lower during the heavy ice cover period at mooring 1 as in other moorings could be explained by the narrower and lower peak value of ice concentration at mooring 1. We should perhaps say that the heavy ice cover period at mooring 1 should be considered an ice edge advance/retreat period instead.

Although the main peak ice concentration is higher and lasts longer at mooring 5 than at mooring 4 , only the ambient noise at mooring 4 reachs its relative lowest level during heavy ice cover period.

\subsubsection{Comparing Extreme Noise with Wind Velocity and Ice Concentration}

Extreme loud noise levels, wind speed, and ice concentration time series for winter months are plotted in Fig.4.12. The eleven samples of long duration (longer than 16 hours ) extreme loud noises (exceeding the $95 \%$ level ), referred to as events 1 through 11, are displayed in this figure. The longer duration extreme loud noises are almost always associated with moderate to strong wind flow. Extreme loud noise 

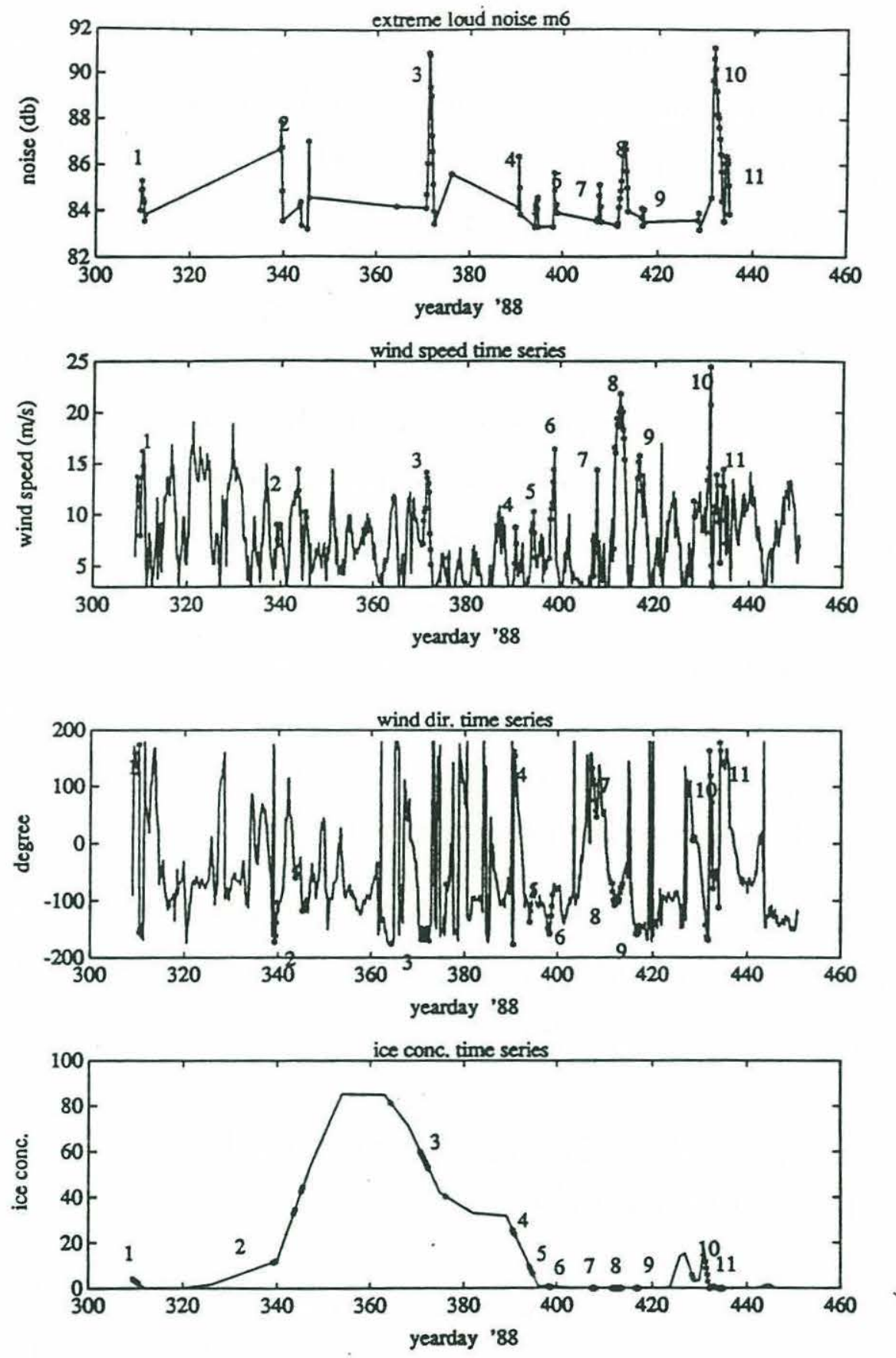

Fig. 4.12 Comparison of winter extreme loud noise with wind velocity and ice concentration. The eleven samples of long duration extreme loud noises, referred to as events 1 through 11, are displayed in those sub-figures. The longer duration extreme loud noises are almost always associated with moderate to strong wind flow. Extreme loud noise events generally occur at low to medium ice concentrations. 
events generally occur at low to medium ice concentrations; only one event is seen during heavily ice cover conditions (ice concentration $\geq 50 \%$ ).

For moorings 4 and 5,the extreme low noise events, as shown in Figs.4.13a-b, are associated with lower wind speeds, and occur primarily during period of northerly winds, and also occur during heavily ice cover conditions. Looking at the ice edge configuration samples plotted in Fig.4.2, we can say that the winter extreme low noise levels are associated with heavy ice cover ( $>75 \%$ ) and on-ice-winds. 

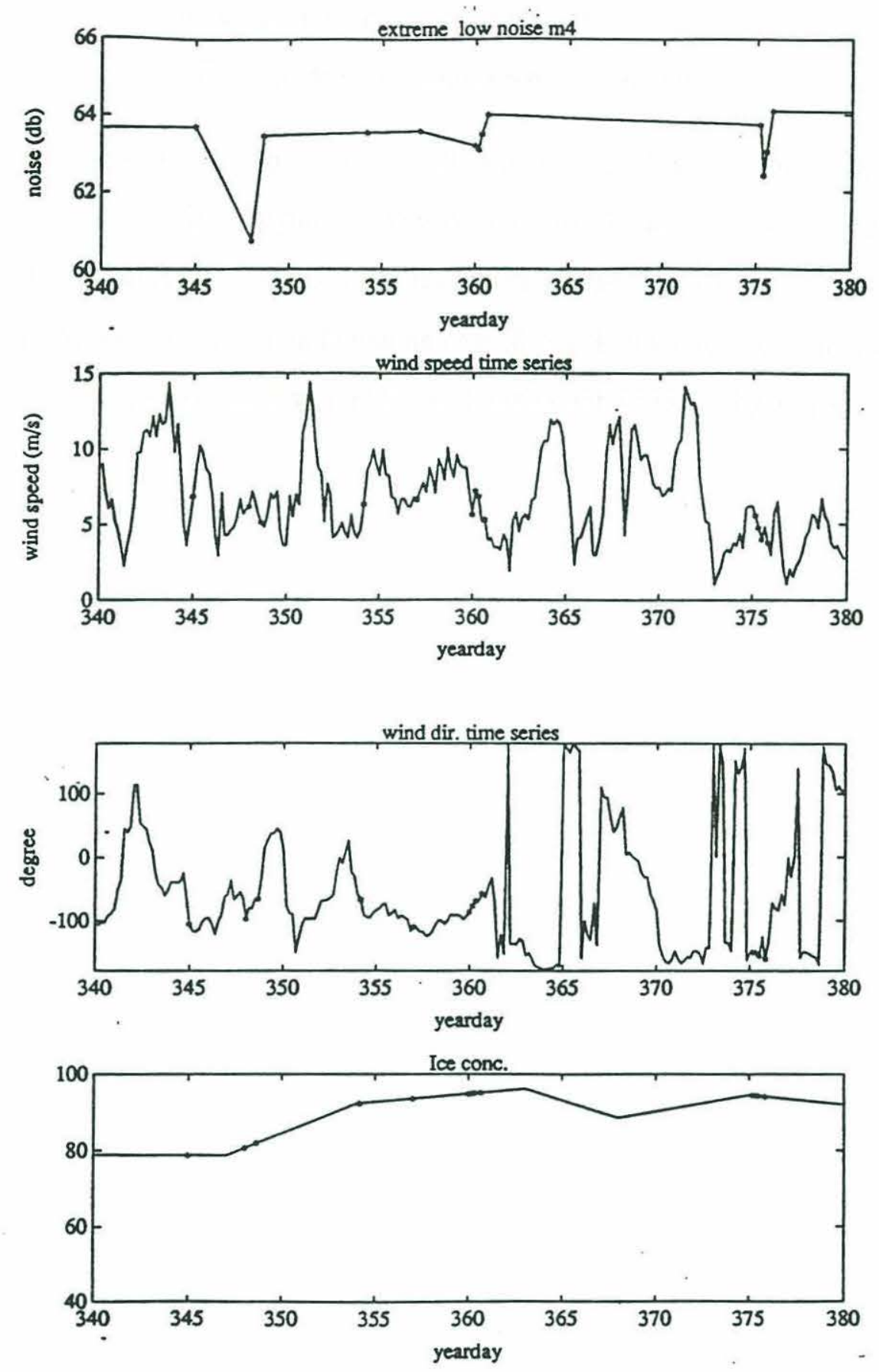

Fig. 4.13a Comparison of winter extreme low noise with wind velocity and ice concentration. The extreme low noise events are associated with lower wind speeds, and occur during heavily ice cover conditions - mooring 4 

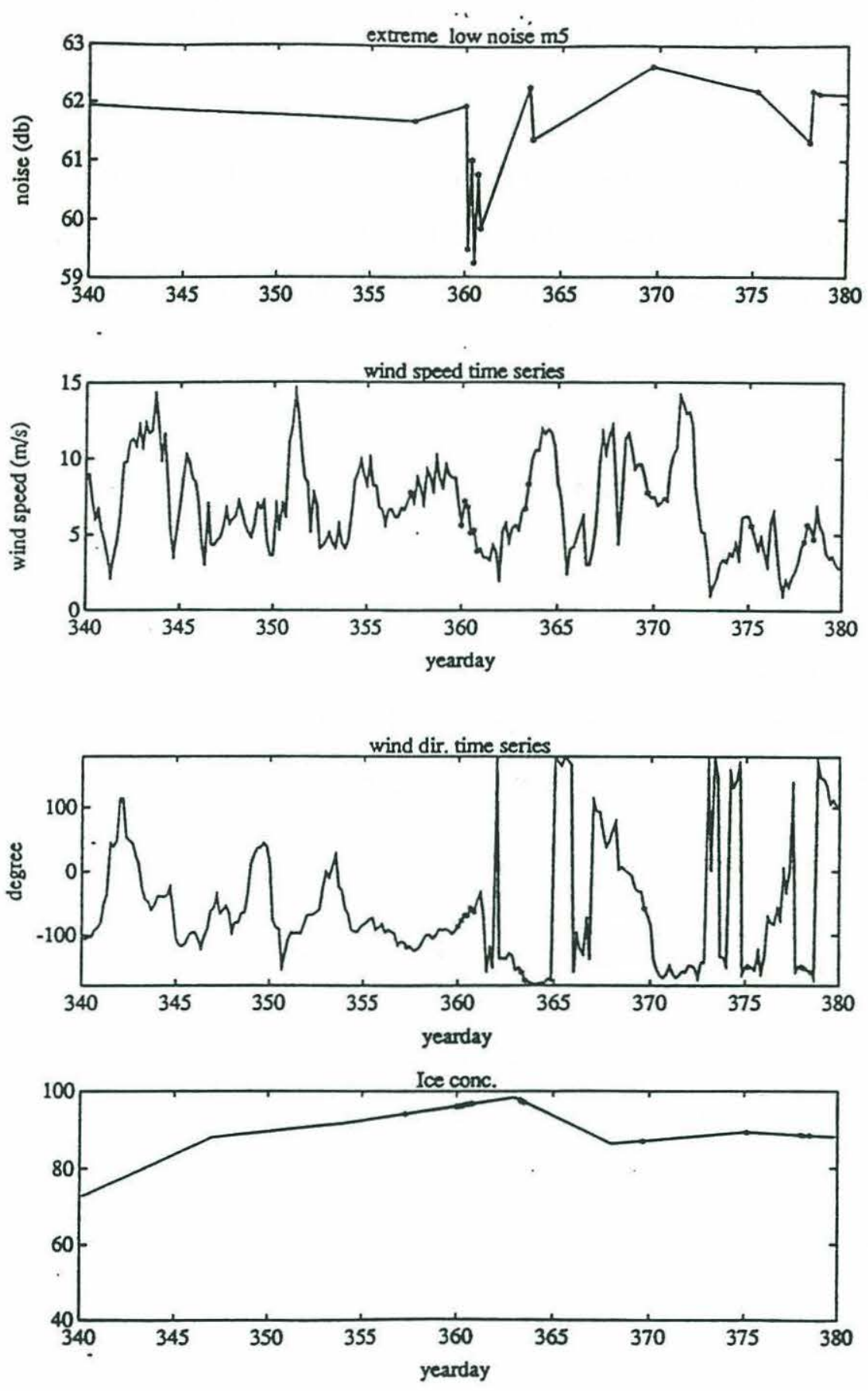

Fig. 4.13b See Fig. 4.13a for caption - mooring 5 


\section{Chapter 5. Regression Analyses}

In this chapter, we will look at using linear regression analyses between the wind and the noise to understand our data. We will also analyses the effect of the MIZ ice edge on ambient noise. Finally, we will examine the dependence of ambient noise on on/off-ice-wind.

\subsection{Seasonal Effects}

In this section, we compare our linear regression results during different time periods and at different moorings with the Wenz ambient noise spectrum. We also examine other possible ambient noise mechanisms during different periods by subtracting out, to a first approximation, the wind noise.

The Wenz ambient noise spectrum we use in this thesis is given by ${ }^{33}$

$$
\text { Wenz noise }=44+\sqrt{\frac{21 \times \text { windspd }}{0.51444}}+17 \times\left(3-\log _{10}(\text { freq })\right) \times\left(\log _{10}(\text { freq })-2\right)
$$

where Wenz noise is the noise due to surface agitation in $d B / / \mu p a / \sqrt{H z}$, windspd is the wind speed in $\mathrm{m} / \mathrm{s}$, and freq $(<1000 \mathrm{~Hz})$ is the frequency in $\mathrm{Hz}$.

\subsubsection{Ice-free Period}

The noise vs. wind speed dot plot ( not shown here) shows that there is a very strong ambient noise dependence on wind speed. The relationship between noise and wind is roughly linear, although a spatial averaging effect during to longdistance underwater noise propagation, which is roughly equivalent to a time average, smoothes the ambient noise somewhat in relation to the wind. Thus, we use a simple 
linear regression to describe the noise vs. the wind, as this is reasonably consistent with the Wenz ambient noise relation for open water.

Fig.5.1 shows the bin median noise, using sliding bins of width $2 \mathrm{~m} / \mathrm{s}$, versus the wind speed for our four moorings during the ice-free periods, with the Wenz curves immediately below. Comparing our results with Wenz noise, we first note that all the noise levels are above the Wenz levels, with moorings 1 and 6 being substantially above, as noted before, whereas moorings 4 and 5 are slightly above. One also sees that the data fit a linear regression well, with slopes slightly less than Wenz curve. The biggest discrepancy between the Wenz curve and our data occurs at low wind speeds, where the Wenz relation shows lower noise levels due to the change in the wave noise mechanism, as noted before. We speculate that the differences noted between our "ice-free" noise data and Wenz are due to ice noise, since we are never totally removed from the ice edge.

\subsubsection{Heavy Ice Cover Period}

In Fig.5.2, we show the regressions obtained during the heavy ice cover period. Quite different curves are obtained from the previous case. For moorings 4 and 5 , one sees : 1) much lower slopes than the ice-free period (in fact, nearly zero slopes, i.e. wind independent noise levels), and 2) much lower levels than the ice-free case, even lower than the Wenz curve past about $11 \mathrm{~m} / \mathrm{s}$ wind speed. The lower, wind independent noise levels seen at moorings 4 and 5 , which are deeply covered by ice during this period, are consistent with the explanation that the thick ice cover shuts off the local wind forced generation of the noise. For instance, this continuous cover of ice tends to insulate the under ice noise field from the ambient noise typically generated by wind and wave action in open water areas. Floes do not have enough room to build up speed and create bumping noise. Thus, the noise levels can be quite low. Also, during this period, the moorings 4 and 5 are far enough into the main 

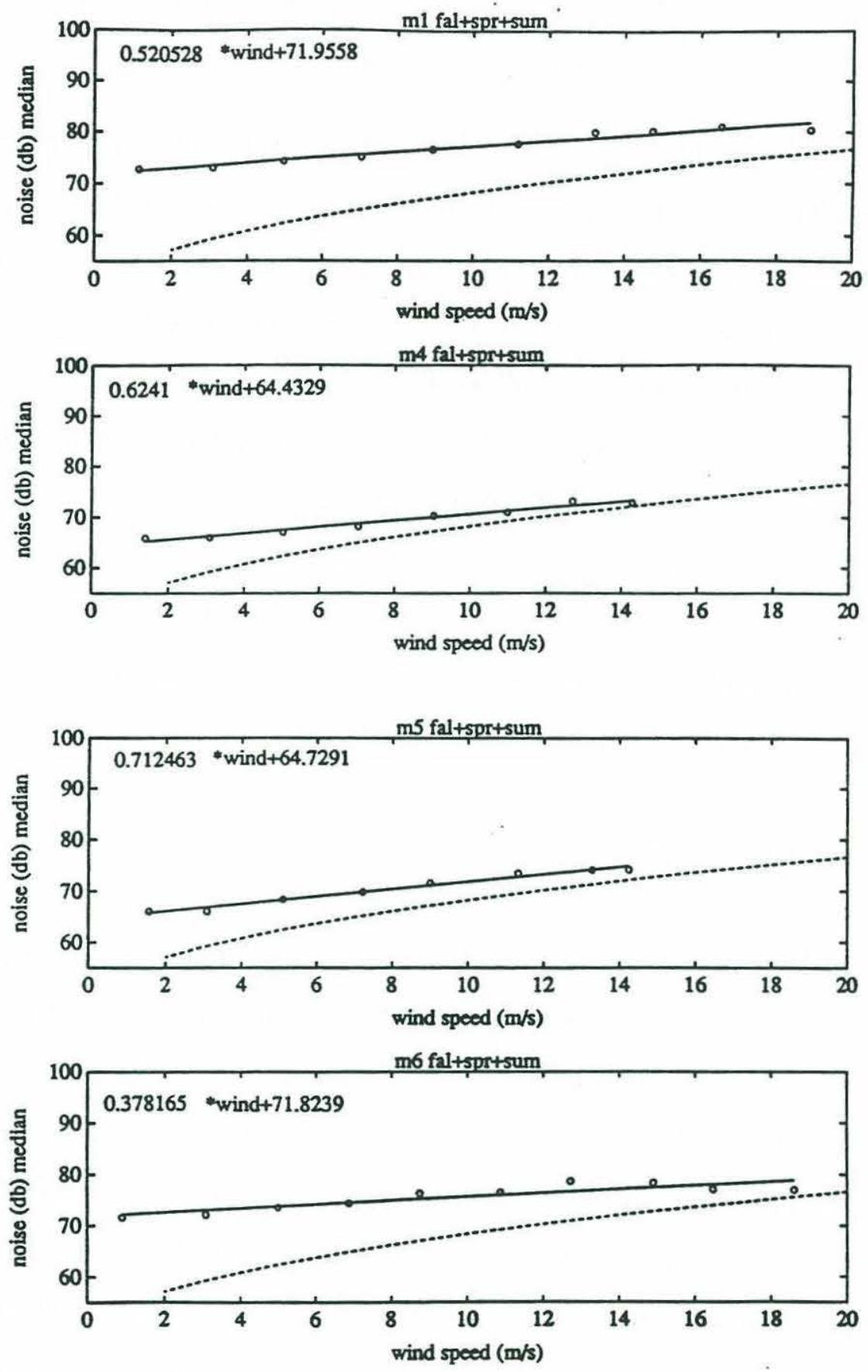

Figure 5.1: Noise versus wind speed during the ice free periods. All the noise levels are above the Wenz levels. The data fit a linear regression well. 

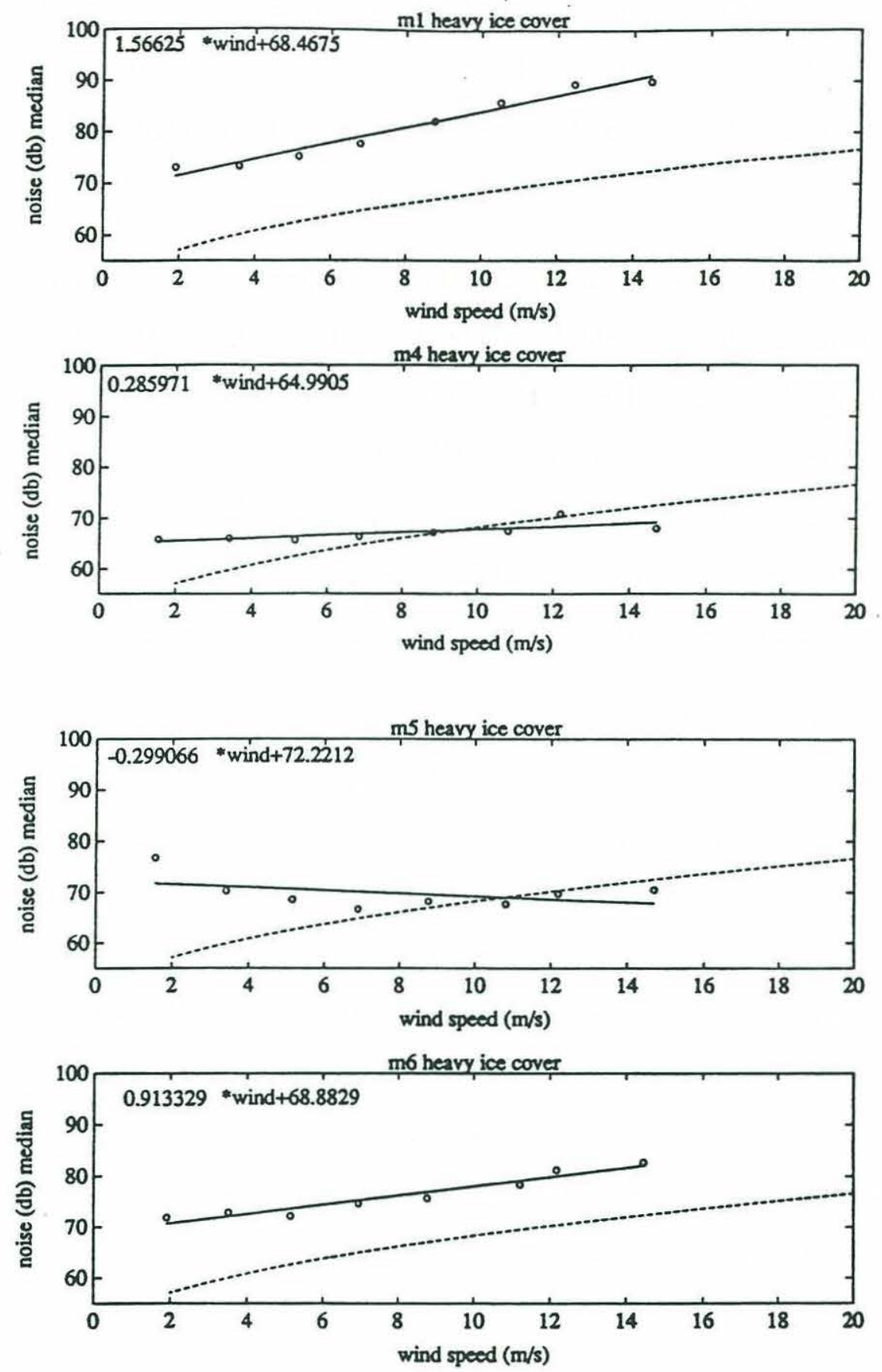

Figure 5.2: Noise versus wind speed during the heavy ice cover periods. Noise is wind independent and noise levels are lower than the Wenz curve past about $11 \mathrm{~m} / \mathrm{s}$ wind speed at moorings 4 and 5 . 
icepack that the ice edge noise is distant. To show this point, we display in Fig.5.3 the distance to the $40 \%$ ice edge for each mooring vs. time. It is seen that moorings 4 and 5 are quite far into the icepack during the period examined, away from any ice edge noise.

Moorings 1 and 6 in Fig.5.2 show much different behavior than moorings 4 and 5 during this period, which we attribute to : 1) incomplete shut off of the local wind forcing of the noise ( note the lower ice concentration in Fig.4.1), and 2) more ice edge noise ( note the much lower distance to the ice edge in Fig.5.3 for moorings 1 and 6 ). The mooring 1 especially comes quite close to the ice edge and shows the lowest ice concentration. The differentiation of purely local noise from nearby ice edge noise is an interesting problem, which we will treat in next section.

To further illustrate the change in levels from the ice-free periods to the ice covered periods, we have subtracted the regression for the ice-free periods at each mooring from the data for the ice covered periods, to give a "noise excess" time series. Physically, this is an attempt to subtract the wind generated noise from the total noise, so that one may examine mechanisms other than the (already well known ) wind. The way we have done this, however, makes the unwarranted assumption that the wind noise and other noise processes are independent and add linearly. Since we do not know all the other noise mechanisms precisely, and to make the regression analysis tractable, we have by necessity chosen this simple analysis. The result of this type of calculation for the heavy ice cover period is shown in Fig.5.4. For moorings 4 and 5 , one sees levels up to $10 \mathrm{~dB}$ less than the "wind noise" regression, and a general negative mean. This is consistent with our previous notion that deep into the highly concentration icepack, things are quieter. The mooring 6 data show a zero mean behavior, with marked oscillations corresponding to wind events ( not seen in the moorings 4 and 5 series ) being noted. The mooring 1 series shows a definite 


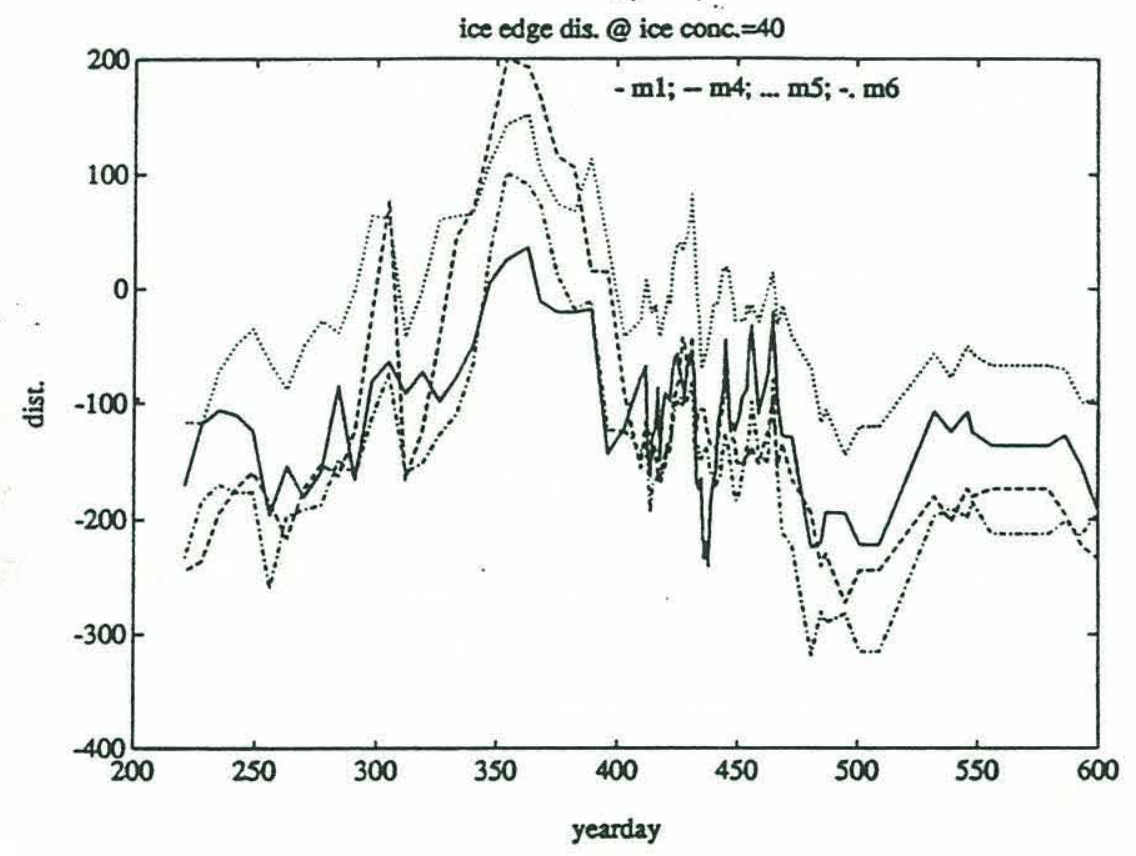

Figure 5.3: Ice edge distance at $40 \%$ of ice concentration. Positive distance implies ice covered conditions at the mooring. Moorings 4 and 5 are quite far into the icepack during the period examined, away from any ice edge noise 

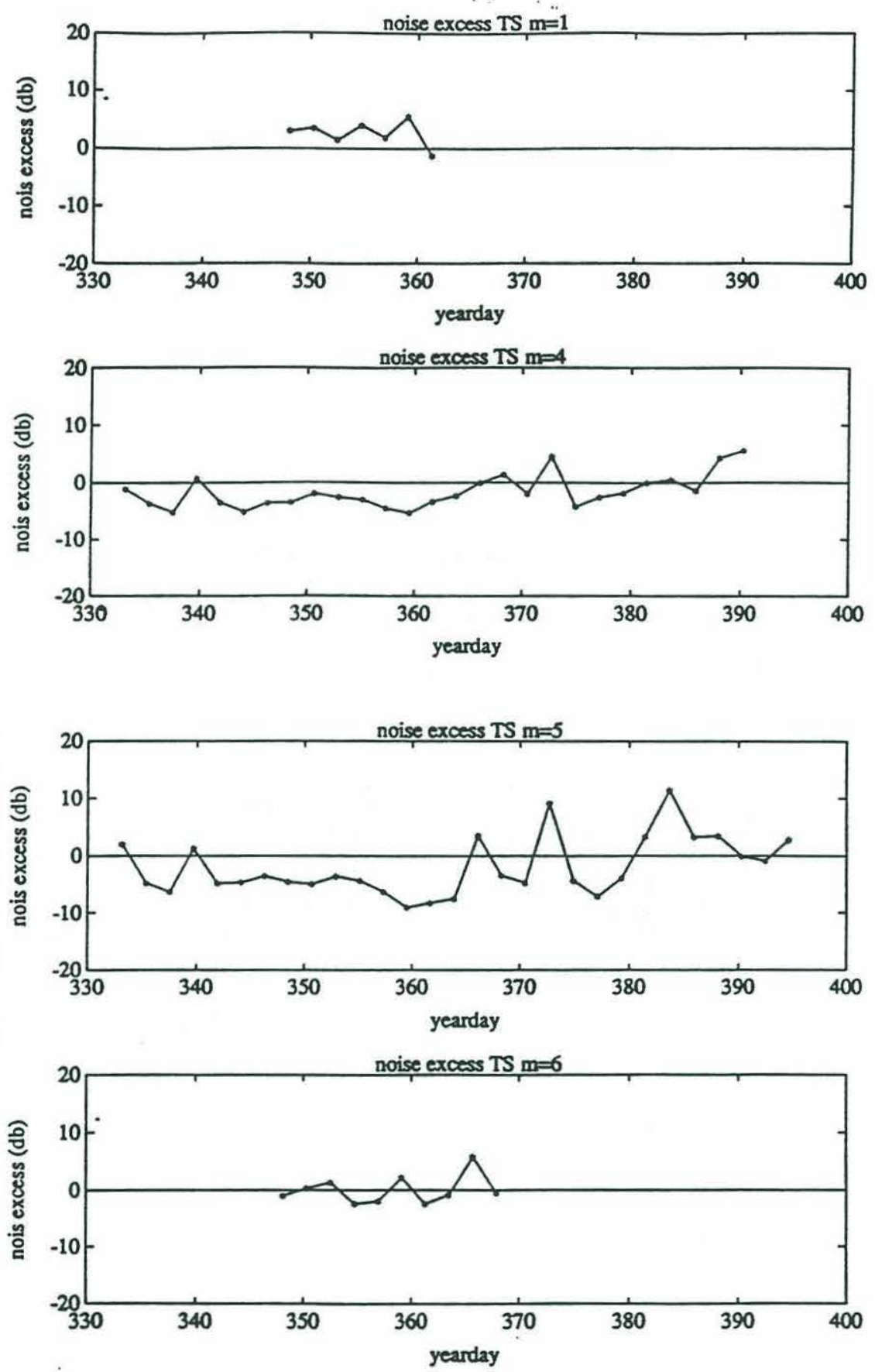

Figure 5.4: Noise excess time series during the heavy ice cover period. Moorings 4 and 5 show a general negative mean; mooring 6 data show a zero mean behavior; and mooring 1 series shows a definite positive mean. 
positive mean, with wind events clearly showing also, and is perhaps more in line with the "ice edge advance/retreat" regime we will discuss next.

\subsubsection{Ice Edge Advance/Retreat}

In Fig.5.5 we show the regressions of noise and wind speed for the ice edge advance/retreat period. The first thing note is the higher overall levels - in fact this period shows the highest levels at most of the moorings. The noise is also wind dependent, though with slightly lower slopes than the Wenz noise. In this period, both purely local and nearby ice edge mechanisms can be contributing to the noise levels seen, since the total ice concentrations is lower, and the ice edge generally is closer. The median value noise excess time series during this period are shown in Fig. 5.6. The noise levels are higher than the ice-free period noise levels at all moorings, as expected. The noise excess reachs the largest value at yearday 432 , which corresponds to a major wind storm. The noise excess at yearday 444 is less than the ice-free period noise level, even through the wind speeds are very high in that day. However, if we look carefully, we see that at yearday 443 , the wind speeds are very low. During ice covered periods, winds often lead the noise by about 1 day; thus this lower noise may be caused by lower wind speed one day before. We hypothesize that the lag between the wind and the noise is due to the wind taking some time to create waves, which then create noise at the ice edge.

Comparing the regressions for the ice edge advance/retreat period and for ice-free period, we note the slopes of the regression for ice edge advance/retreat period are larger than that for ice-free period in moorings 1,4 , and 6 , but lower in mooring 5. The lower slope for mooring 5 during this period is probably explained by the fact that there is no truly ice-free period for mooring 5. To explain the higher slopes in other moorings, we must understand the fine details of the various noise production processes very well. This is beyond the scope of this thesis. 

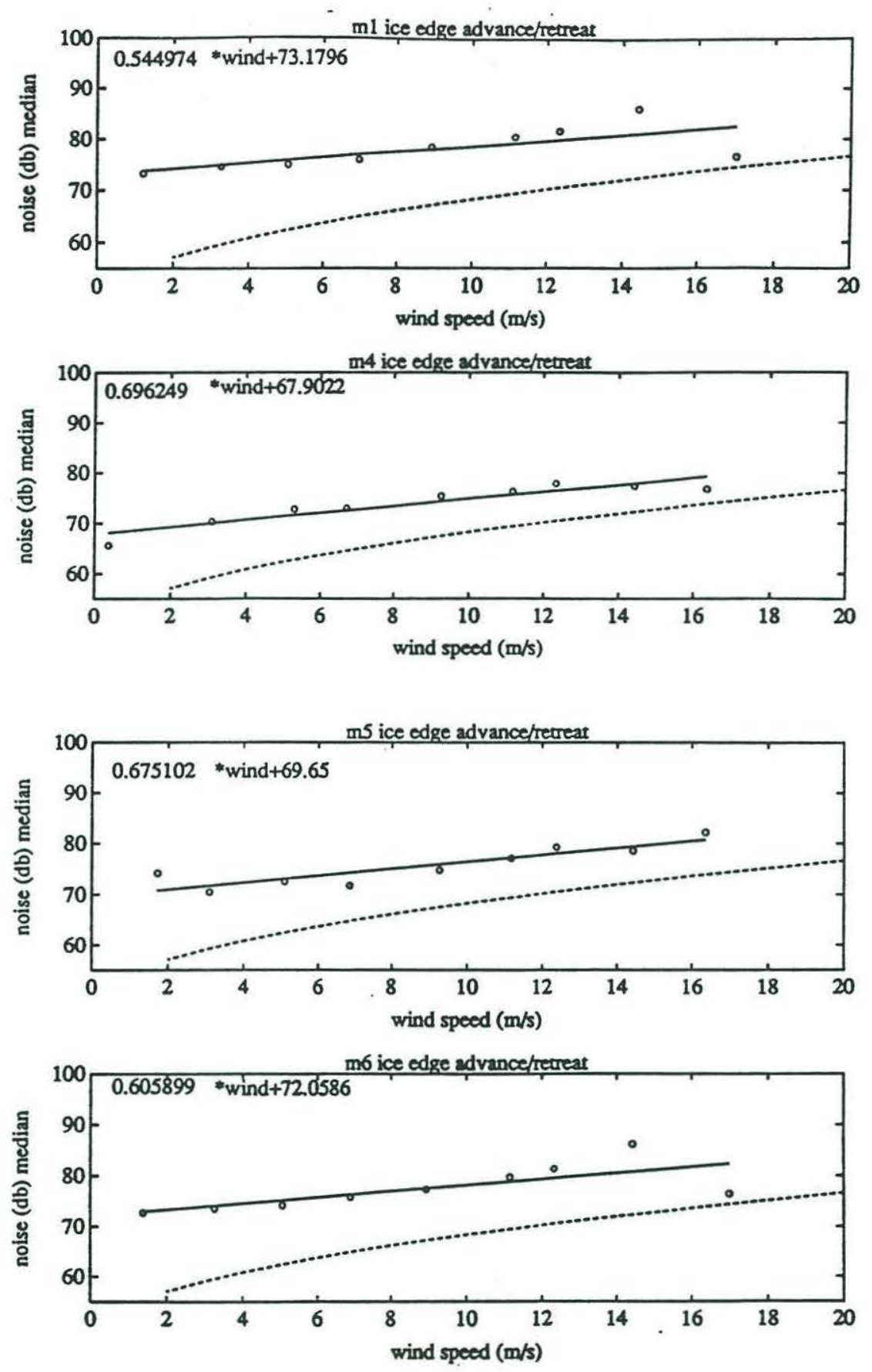

Figure 5.5: Noise/wind regression during the ice edge advance/retreat period for moorings $1,4,5$, and 6 . This period shows the highest levels at most of the moorings. The noise is also wind dependent. 

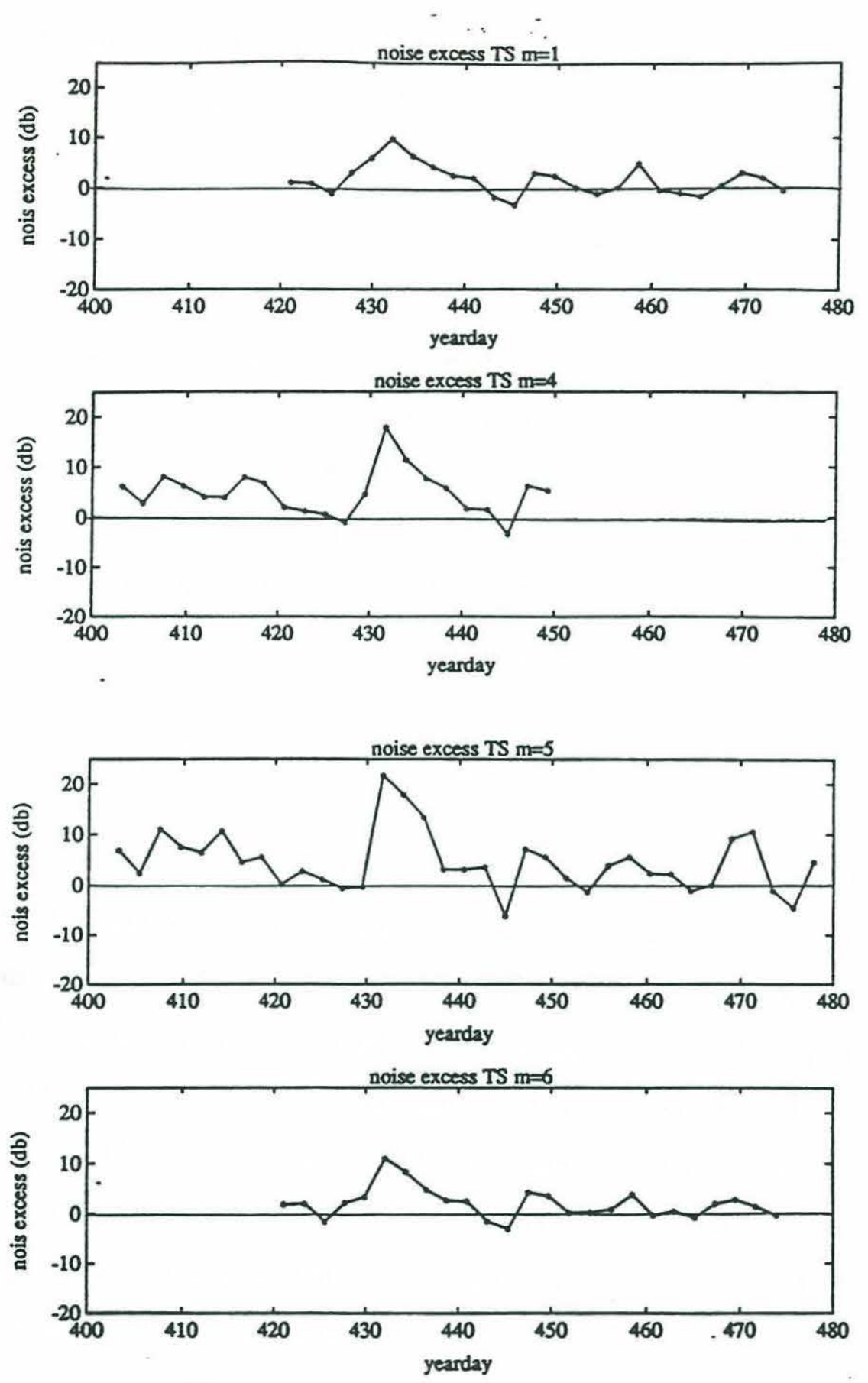

Figure 5.6: Noise excess time series during the ice edge advance/retreat period for morrings $1,4,5$, and 6 . Noise series shows a positive mean at all moorings. 
We will soon look further at the relation between wind and noise during the ice edge advance/retreat period by dividing the wind into on and off ice components.

\subsection{MIZ Ice Edge Noise}

Many researchers have investigated the ice edge as a region of high noise production. In this section, we too will look at ice edge noisiness. In particular, we will look at : 1) the noise excess (observed noise minus ice-free noise) vs. ice concentration at the ice edge, 2) the noise excess vs. distance to the ice edge, with the "best" ice edge concentration defined by the answer to question 1 above, and 3) the effect of on/off-ice-wind on ambient noise.

\subsubsection{The Spatial Variability of the Ice Edge}

The ice edge is actually a diffuse region over which the ice transitions from $0 \%$ to $100 \%$ concentration, as opposed to a sharp line. One can arbitrarily choose any concentration level as the ice edge for most purposes. However, for noise studies, we will try to find a "noise ice edge", i.e. an ice edge concentration which is noisiest overall. To do so, we first plot the median value of noise excess at the ice edge, for distances between the ice edge and mooring less than $35 \mathrm{~km}$ (The results are fairly insensitive to the window size. The $35 \mathrm{~km}$ is chosen by considering the resolution of the SSMI satellite, which is around 20-50 km), versus the ice concentration at each mooring as shown in Fig.5.7. It is clear that the ambient noise increases as ice concentration increases at lower concentration, and decreases as ice concentration increases at higher ice concentration in moorings 1,5 and 6 . At mooring 4, the ambient noise does not quite obey the same trend as at the other moorings. From the figures, one can see that the ambient noise has a relative maximum value at about $40 \%$ ice concentration at moorings 1,4 , and 5 , and $60 \%$ at mooring 6 . We 

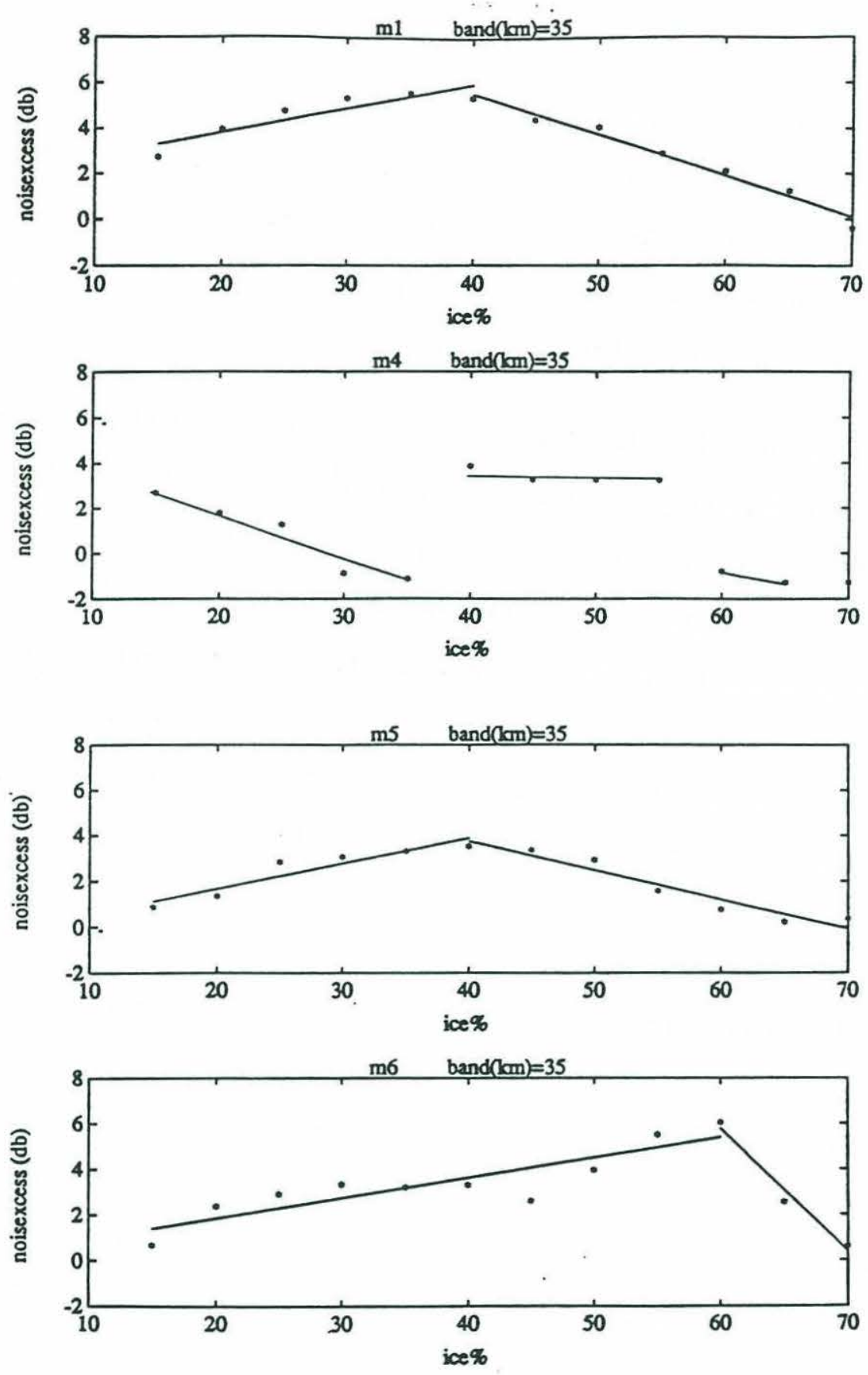

Figure 5.7: Noise excess versus ice concentration at the ice edge. Ambient noise has a relative maximum value at about $50 \%$ ice concentration 
conjecture that this is due to various tradeoffs in the noise production mechanisms. For instance, for floe-bumping one can envision a tradeoff between the floe speed of collision (enhanced by a bigger mean free path) and the number of collisions (which decreases with increasing mean free path ). For waves breaking up floes, perhaps the depth of wave penetration into the icepack vs. ice concentration is coming into play. We do not attempt to model these results here.

Having identified the "noise ice edge" at about $40-60 \%$, we next look at the median value noise excess vs. distance to the ice edge, with a window width of 35 $\mathrm{km}$. In Fig.5.8, one sees a distinct rise in noise near the ice edge, as well as sharp falloff as one goes deeper into the icepack. That is, the MIZ noise level depends on the relative position to the ice edge and to the ice concentration. The noise level peaks at the ice edge and diminishes faster under the ice covered water than in open water. The results show that the measured noise levels near the ice edge are about 3 to $7 \mathrm{~dB}$ higher than open water, and about 7 to $10 \mathrm{~dB}$ higher than levels far into the ice field.

\subsubsection{Comparisons with Diackok and Winokur's Results}

Diackok and Winokur ${ }^{14}$ have made measurements showing that noise levels near a compact ice edge are about $12 \mathrm{~dB}$ higher than open water levels, and about $20 \mathrm{~dB}$ higher than levels far into the ice field. Measured noise levels near a diffuse ice edge were about $4 \mathrm{~dB}$ higher than open water levels, and about $10 \mathrm{~dB}$ higher than levels far in the ice field. During their measurements near a relatively compact ice edge, it was noted that the ice concentration changed from $1 / 8$ to $7 / 8$ over a distance of $1-2 \mathrm{~km}$. The ice at the boundary was primarily composed of 1 - to $100-\mathrm{m}$ diameter, contiguous first-year ice floes. In the vicinity of a diffuse ice edge boundary, the ice concentration changed from $1 / 8$ to $7 / 8$ over a distance of about $100 \mathrm{~km}$. The ice at 

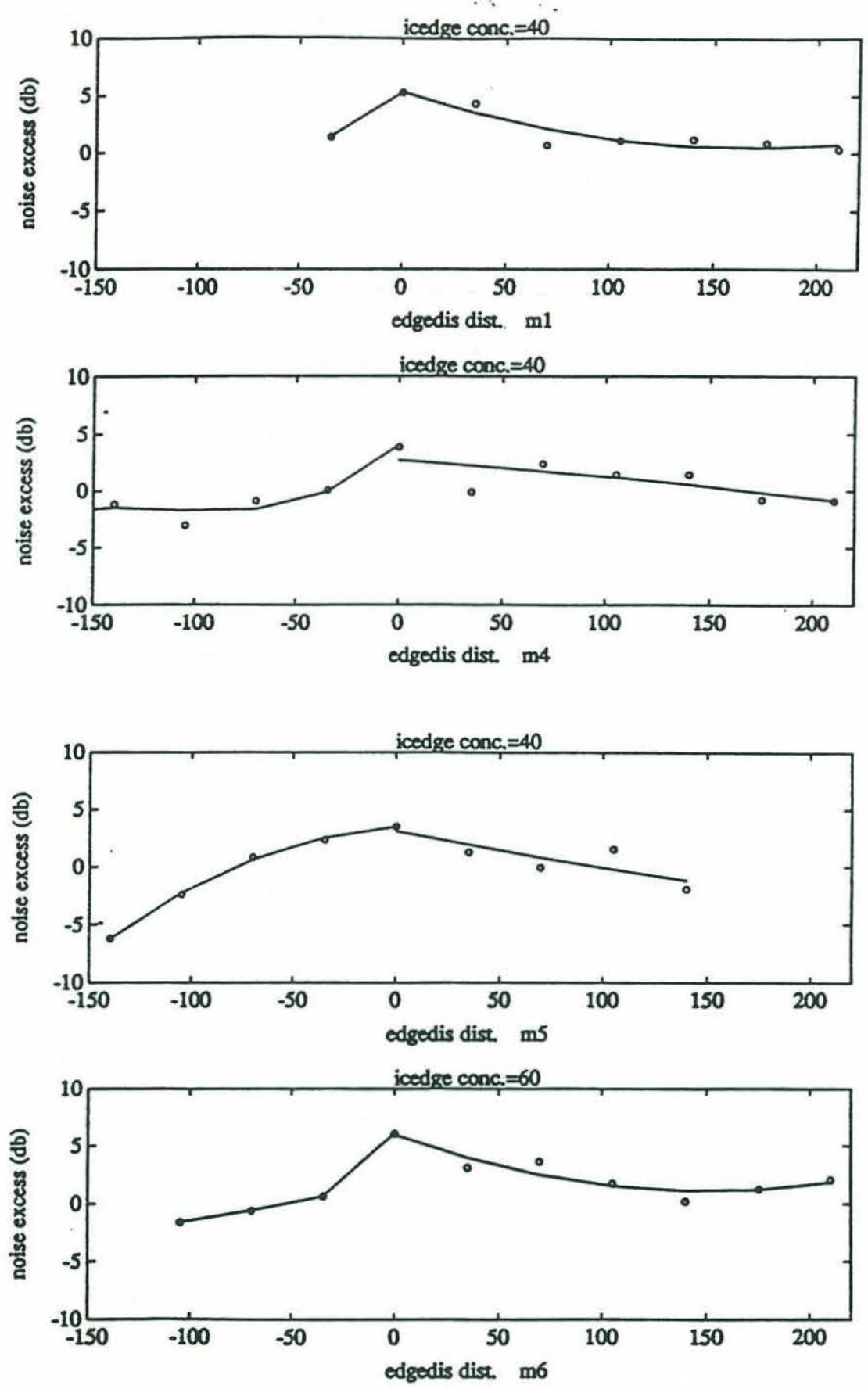

Figure 5.8: Noise excess versus ice edge distance. Noise peaks at the ice edge, and sharp falloff as one goes deeper into the icepack. 
the boundary was primarily composed of 1 - to 100 -m first-year ice floes, which were generally noncontiguous.

To compare our measurements of median ambient noise levels vs. distance to the ice-edge with those of Diackok and Winokur, we devise a composite of their results, which is good for both compact and diffuse ice edges. To do so, we first need to find out the amount of our noise data near both compact and diffuse ice edges. Using those numbers as a weighting factor, we combine Diackok and Winokur's two curves (for compact and diffuse ice edges) together and get a combined curve. The histograms of ice edge extent, which is defined as the distance between ice $25 \%$ and $75 \%$ of ice concentration, show that at all moorings, the percentage of ice edge extent less than $25 \mathrm{~km}$ is less than $10 \%$, whereas most of ice edge extents concentrate at around $100 \mathrm{~km}$. Furthermore, all of the extents less than $25 \mathrm{~km}$ occurred after yearday 467 . Looking at the ice concentration time series plotted in Fig.4.1, we see that after yearday 467 , the ice at the boundary is primarily composed of thin ice and/or noncontinuous ice floes, which is one of the characteristics of the diffuse ice edge. Thus, we can regard our measured ice edge as a diffuse ice edge rather than a combination of compact and diffuse ice edges. Having found out the type of our ice edge, we further use a moving window of width $35 \mathrm{~km}$ to smooth Diackok and Winokur's result for a diffused ice edge, thus simulating the finite resolution of a satellite SSM/I image. The smoothed Diackok and Winokur's result show the noise levels near a diffuse ice edge to be about $3 \mathrm{~dB}$ higher than the open water levels, and about $9 \mathrm{~dB}$ higher than levels far into the ice field. Our tomography noise results show that noise levels near ice edge are about 3 to $7 \mathrm{~dB}$ higher than open water, and about 7 to $10 \mathrm{~dB}$ higher than levels far into the ice field. Our results are thus seen to be quite consistent with Diackok and Winokur's. 


\subsubsection{On/off-ice-wind versus Noise}

Since the maximum noise occurs at the ice edge, the farther the moorings are away from the ice edge, the less the effect of the ice edge on ambient noise. To highlight the effects of the ice edge and on/off-ice-wind on the ambient noise, we examine only the wind and ambient noise data when the distances between the ice edge and moorings are less than $60 \mathrm{~km}$,i.e. roughly one convergence zone. We first plot all of the ice edge configurations ( some of them were shown in Fig.4.2), find the normal direction to the ice edge, and then linearly interpolate the normal direction to ice edge to 4 -hour intervals to match the ambient noise data. If the ice data are recorded once per week and the ice edge is close to a mooring $(<60 \mathrm{~km})$, we will regard the ice edges of 3 days before and 3 days after this record day as also being close to that mooring.

The on/off-ice-winds $U_{\text {on } / \text { off }}$ are calculated using

$$
U_{\text {on } / \text { off }}=|\vec{U}| \cos \left(\Theta_{\text {wind. dir. }}-\Theta_{\text {ice nor. dir. }}\right)
$$

where $\Theta_{\text {wind. dir. }}$ is the direction of wind velocity,$\Theta_{i c e}$ nor. dir. is the normal direction to the ice edge, and $U_{\text {on/off }}<0$ corresponds to on ice wind.

The on/off-ice-wind time series are shown in Fig.5.9. These plots show that on-ice-winds dominate, i.e. they occur more strongly and frequently than off-icewinds. During the winter heavy ice period of yeardays 345 to 390 , on-ice-winds are much stronger at moorings 1 and 6 , while the ice edges are far from moorings 4 and 5 ( $>60 \mathrm{~km}$ ). The median value ( using moving window of width $2 \mathrm{~m} / \mathrm{s}$ ) of noise excess vs. on/off-ice-wind speed together with linear regressions are shown in Figs.5.10a-b.

Clearly, for all moorings, noise increases as on-ice-wind increases. For moorings 1 and 6 , the noise is more or less independent of the off-ice-wind speed, whereas for moorings 4 and 5 , noise decreases as off-ice-wind increases. It is not presently 

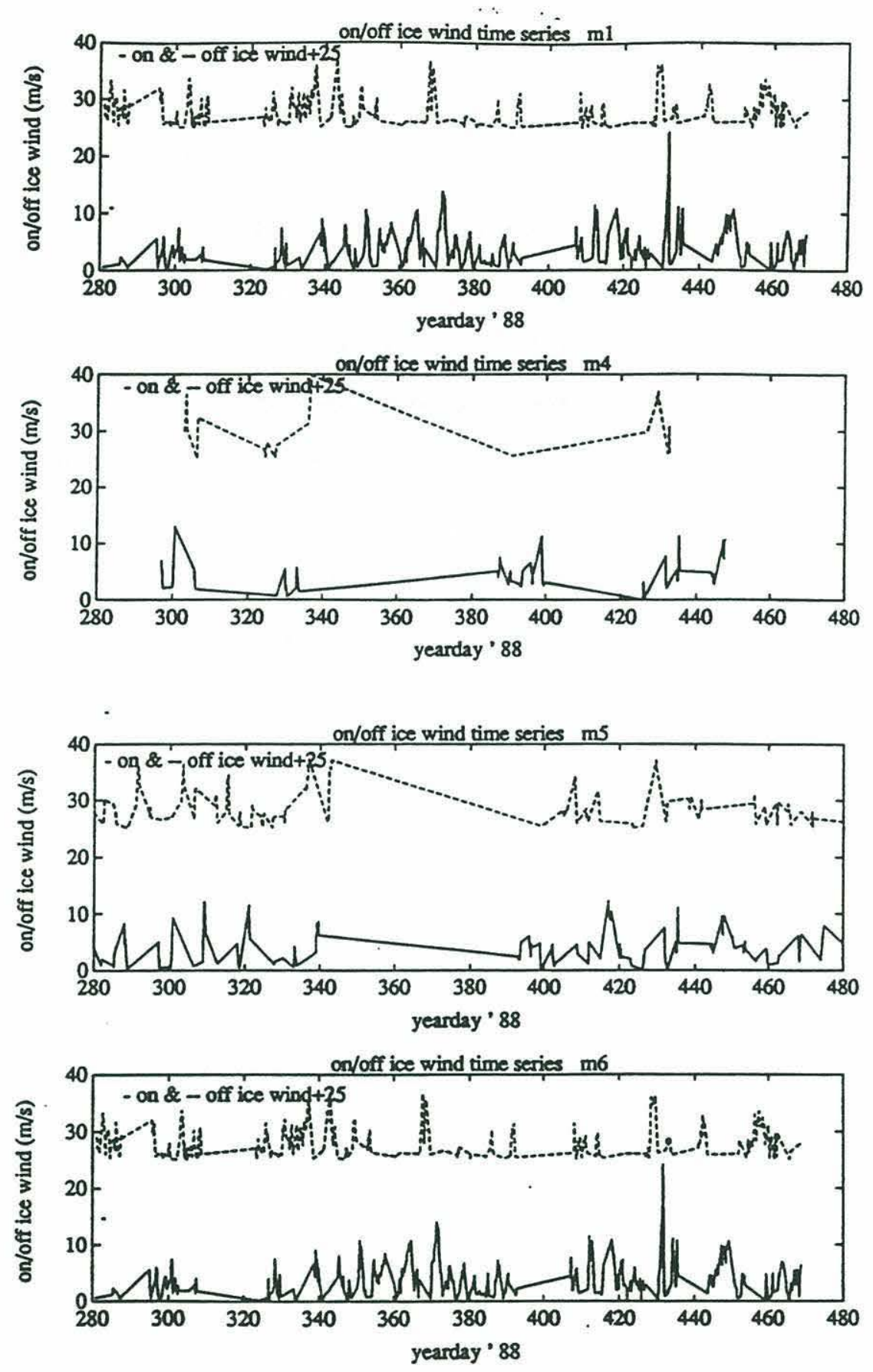

Figure 5.9: On/off-ice-wind time series at moorings 1, 4, 5, and 6. On-ice-winds occur more strongly and frequently than off-ice-winds 

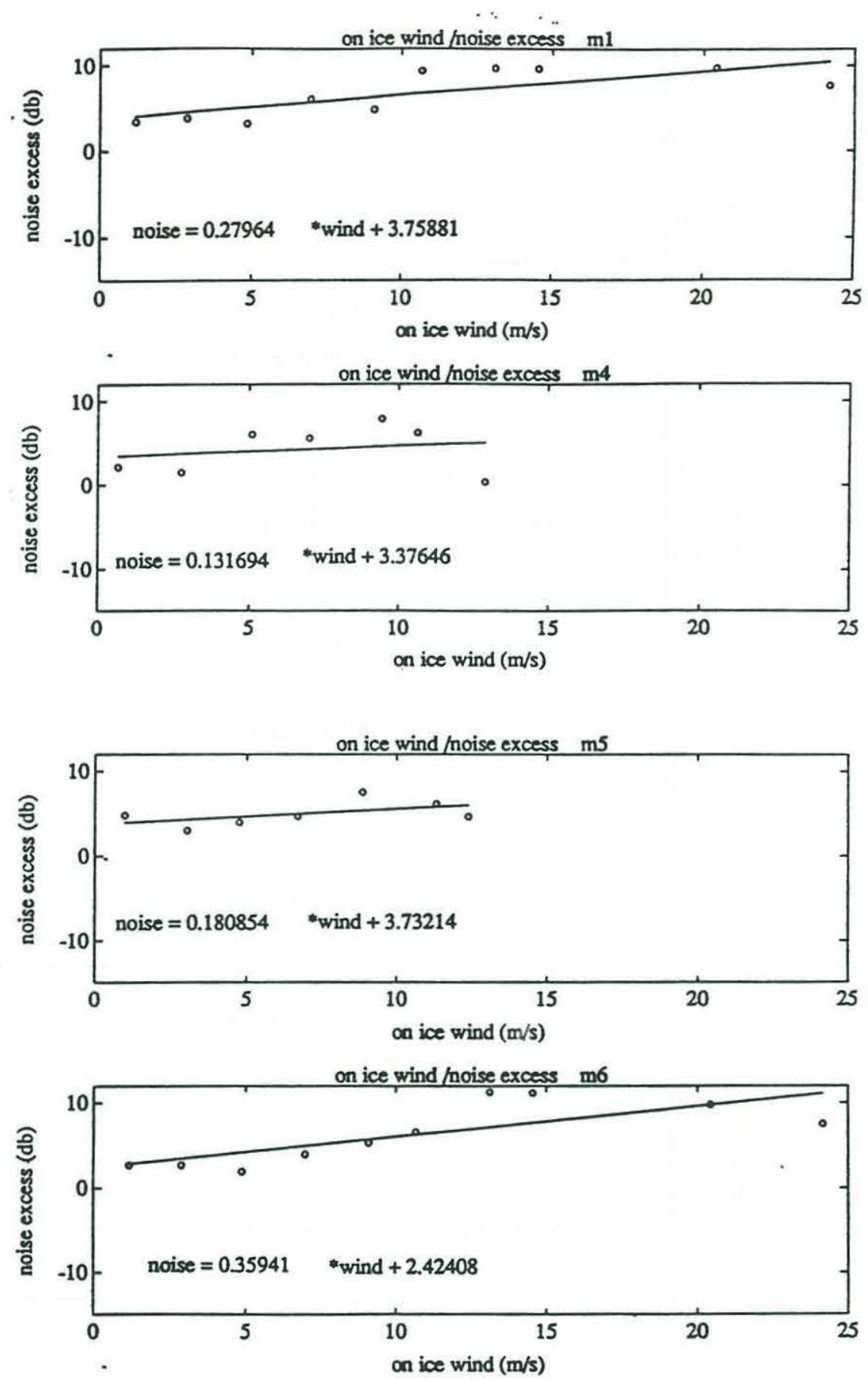

Fig.5.10a Noise excess versus on-ice-wind. Noise increases as on-ice-wind increases. 

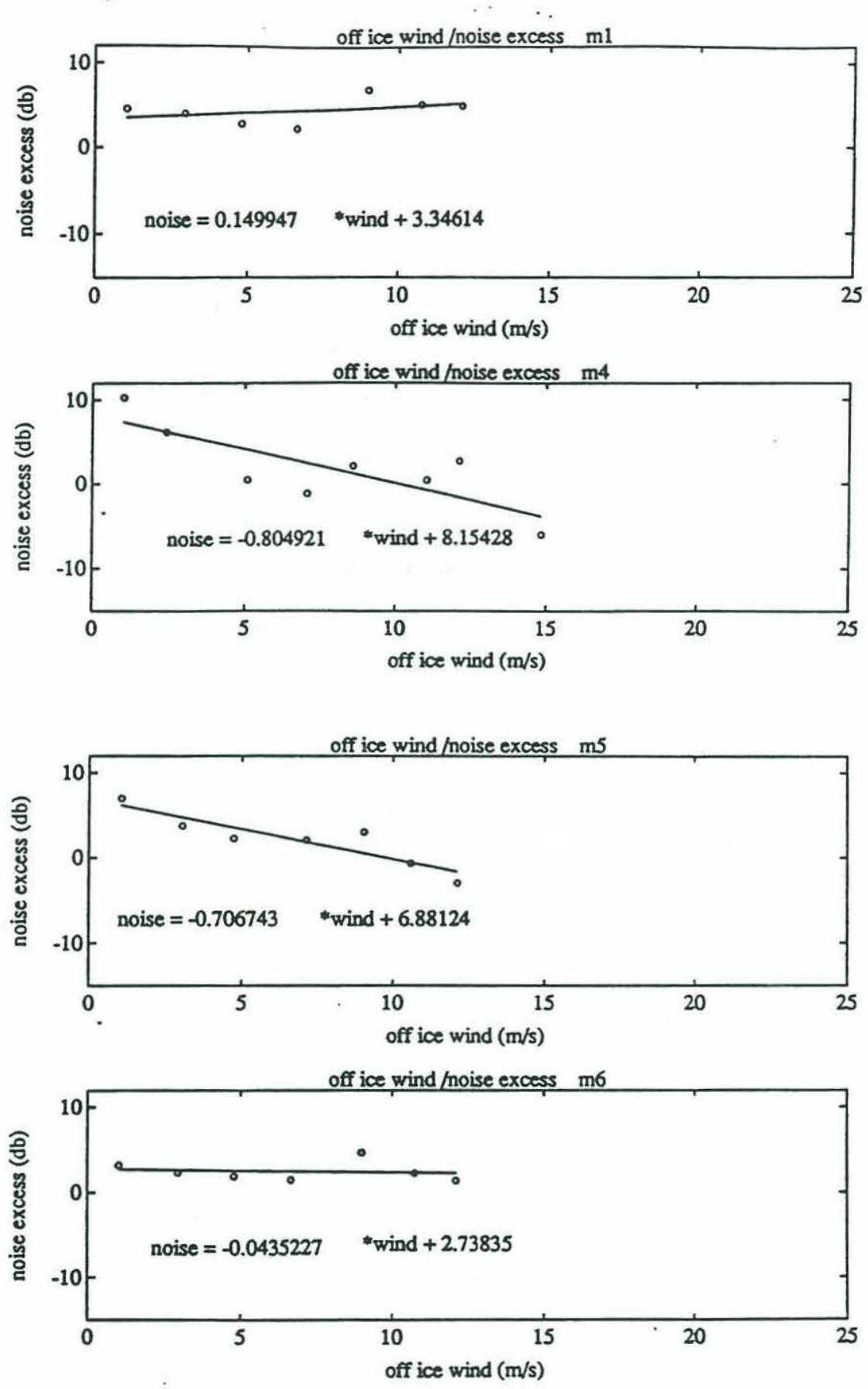

Fig.5.10b Noise excess versus off-ice-wind. Noise decreases as off-ice-wind increases at moorings 4 and 5. 
understand why increasing off-ice-wind decreases the noise levels for the thicker ice packs found at moorings 4 and 5 . 


\section{Chapter 6. Correlation Analysis}

We next examine correlation analyses of our data, which should be helpful in understanding the time scales of the noise and its forcing mechanisms. First we will derive a simple correlation algorithm for data with gaps. We next examine the autocorrelations of the wind and the noise time series, and then look at the cross correlations of the wind and the noise. Finally, we look at the noise-noise cross correlations between moorings.

\subsection{Correlation Algorithm}

From table 3.4, we note there are no gaps in the noise data at moorings 4, 5 , and 6. However, during to storage limitations, the WHOI transceivers on moorings 4 and 5 only recorded the ambient noise every third day. Thus, in fact, there are two-day gaps in each three days at moorings 4 and 5 . Noting there are no two-day gaps in the noise data at moorings 1 and 6 , to obtain a better correlation method for those data with gaps, we can first decimate the ambient noise data at moorings 1 and 6 to match the ambient noise data at moorings 4 and 5 . We then use several different data processing techniques to rebuild the data, and compare the different correlation results with the original correlation result between moorings 1 and 6 and find out which method is best to use. The different data processing methods we consider are: 1) bandlimited interpolation, 2) spline interpolation, 3) 3-day averaging, and 4) using the gappy data as they are. After comparing the correlation results using the different methods, we decided to use the original gappy data for correlation. This method requires no interpolation of data gaps and so introduces no hypothetical information. Time series has only to be resampled to a consistent sample period upon which gaps are reintroduced. For each lag, discrete correlation coefficients are computed by 
summing only overlapping samples and ignoring gap-gap and gap-sample overlaps in the convolution. The time series for each lag window are locally "zero-mean" and normalized by the root of the variance product of each time series using only non zero overlap samples in the local lag window. The scheme is symbolically described below.

The ideal time series with no data gaps are $x[n]$ and $y[n]$, of length $N$. Time series $\delta_{x}[n]$ and $\delta_{y}[n]$ are zero for data gaps and one otherwise at $\mathrm{n}$ such that $\delta_{x}[n] x[n]$ and $\delta_{y}[n] y[n]$ are the actual time series with data gaps.

The cross correlation function is then

$$
\begin{gathered}
R_{x y}(m)=\sum_{n=m+1}^{N} \frac{(x[n]-\bar{x}[m])(y[n-m]-\bar{y}[m]) \delta_{x}[n] \delta_{y}[n-m]}{\sigma_{x}[m] \sigma_{y}[m](N[m]-1)} \\
\text { for } 0 \leq m \leq N-1
\end{gathered}
$$

where

$$
\begin{gathered}
N[m]=\sum_{n=m+1}^{N} \delta_{x}[n] \delta_{y}[n-m] \\
\bar{x}[m]=N^{-1}[m] \sum_{n=m+1}^{N} x[n] \delta_{x}[n] \delta_{y}[n-m] \\
\bar{y}[m]=N^{-1}[m] \sum_{n=m+1}^{N} y[n-m] \delta_{x}[n] \delta_{y}[n-m] \\
\sigma_{x}^{2}[m]=N^{-1}[m] \sum_{n=m+1}^{N} x^{2}[n] \delta_{x}[n] \delta_{y}[n-m]-(\bar{x}[m])^{2} \\
\sigma_{y}^{2}[m]=N^{-1}[m] \sum_{n=m+1}^{N} y^{2}[n-m] \delta_{x}[n] \delta_{y}[n-m]-(\bar{y}[m])^{2}
\end{gathered}
$$

Having found the correlation coefficients as above, we further use a parabolic fit method to look for the peak value and lag. For convenience, we set the maximum 
correlation coefficient $y_{0}$ located at $\mathrm{x}=0$, and its two neighbors $y_{-1}, y_{1}$ at $\mathrm{x}=-1,1$. Using the parabolic equation

$$
y(x)=a x^{2}+b x+c
$$

and defining

$$
\begin{gathered}
y[-1]=y_{-1} \\
y[0]=y_{0} \\
y[1]=y_{1}
\end{gathered}
$$

we find that

$$
\begin{gathered}
a=\frac{y_{-1}+y_{1}}{2}-y_{0} \\
b=\frac{y_{1}-y_{-1}}{2} \\
c=y_{0}
\end{gathered}
$$

The peak location is given by

$$
y \prime\left(x_{p}\right)=0
$$

and thus we obtain

$$
x_{p}=-\frac{b}{2 a}=\frac{y_{-1}-y_{1}}{2\left(y_{-1}+y_{1}-2 y_{0}\right)}
$$

with the peak value

$$
y\left(x_{p}\right)=\left(\frac{y_{-1}+y_{1}}{2}-y_{0}\right) x_{p}^{2}+\frac{y_{1}-y_{-1}}{2} x_{p}+y_{0}
$$


After finding the peak location, we can easily get the lag. To get the fine scale correlation time, which is defined as the correlation width at the 0.5 peak level, we simply linearly interpolate the correlation coefficients to the interval of 0.25 hour. The same procedure is used for all correlations found in this thesis.

\subsection{Noise/Wind Time Series Autocorrelations}

In Fig.6.1, we show the autocorrelations of wind and noise at mooring 6, which is at the center of the array and about $105 \mathrm{~km}$ from all the other moorings. It is seen that the seasons except for late spring and summer show fairly uniform wind autocorrelations, with a time scale of 1 day. The noise autocorrelation functions show considerable variation among themselves, as well as in comparison with that of the winds. The overall autocorrelations of noise and wind show that noise is correlated over a time-scale about one day longer than wind speed. From Fig. 4.11, we also noted that the raw series for noise is smoother than that for the wind. This lead us to believe that locally generated noise propagates a significant distance and thus the ambient noise is in some sense a spatially-averaged function of the wind.

With the exception of spring-summer period, the noise field shows a longer correlation time than the wind. There are at least two good reasons why the noise should generally have a longer duration than the wind. First, the noise travels quickly and, at these comparatively low frequencies, over long distances, so that one can hear distant storms coming and going. Second, the waves and ice motions induced by the wind can produce noise long after the wind forcing is removed. For instance, the fall wind correlates for 25 hours, whereas the noise correlates for 47 hours. During the ice edge advance/retreat period, the wind correlates for 22.5 hours, the noise for 62 hours. The shortest noise correlation time being in the heavy pack ice cover period is consistent with the previous regression results that the thick pack ice noise is only 

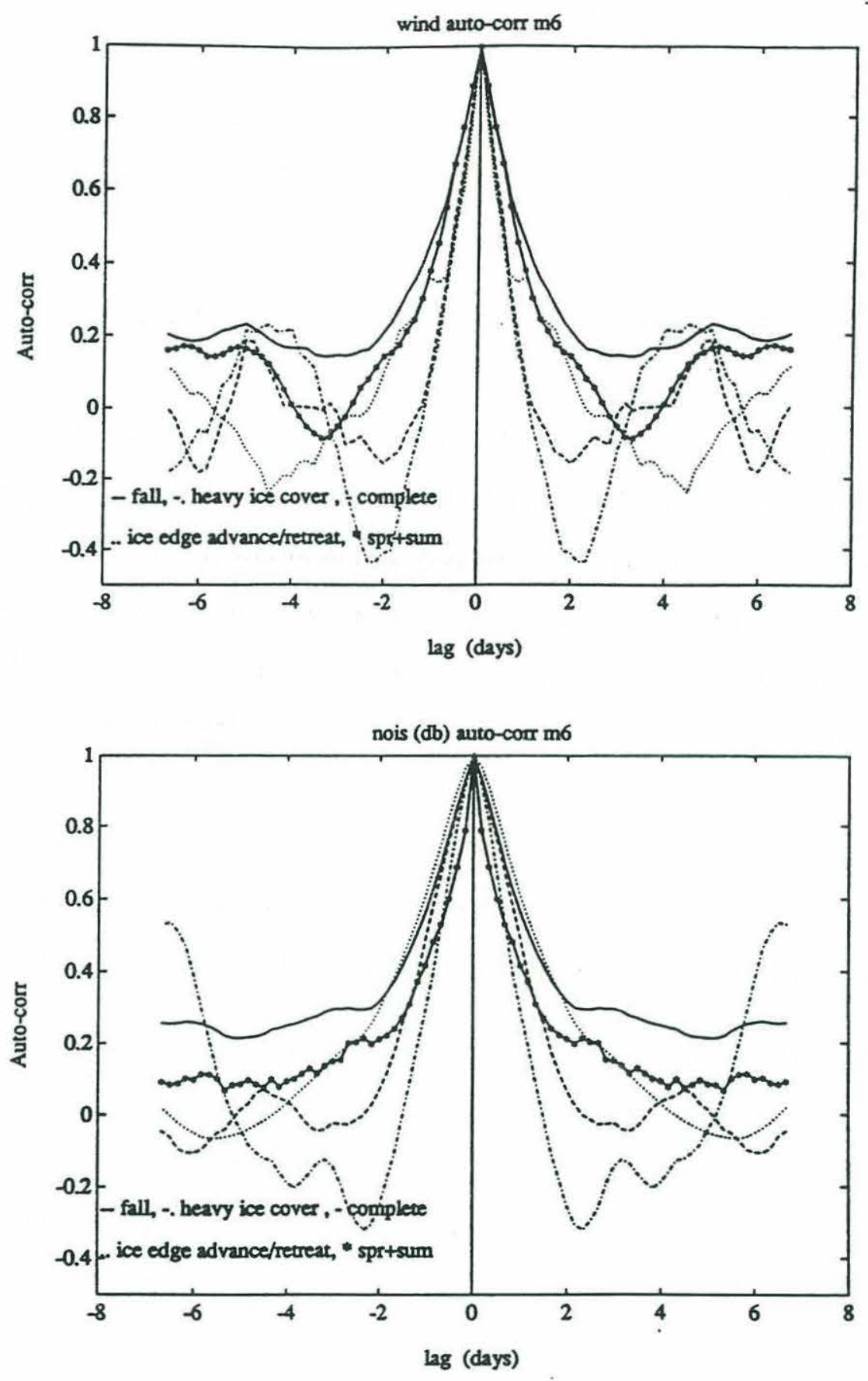

Figure 6.1: Autocorrelations of wind and noise at mooring 6. Noise is correlated over a time-scale about one day longer than wind speed 
marginally affected by the wind. The longest correlation time being during ice edge advance/retreat period reflects that the less dense ice cover is set into motion and continues in motion producing noise for a longer period. There is sufficient energy stored in the ice field motion to sustain high noise levels long after the wind diminishes. In the spring-summer period, the noise correlation time is shorter than in the fall and much closer to wind correlation time. This maybe explained by the lightness of the spring-summer winds and the open water conditions. As mentioned earlier, the wind/wave noise mechanism changes to wave breaking above $6 \mathrm{~m} / \mathrm{s}$; spring-summer is the only period where the average wind speed is below $6 \mathrm{~m} / \mathrm{s}$. Thus, only during the peak of a wind event does the wind go above $6 \mathrm{~m} / \mathrm{s}$ and create significant noise. The noise event thus does not evolve much faster than the wind event, as reflected by the autocorrelation function.

\subsection{Noise/Wind Cross Correlations}

Cross-correlations between wind speed and ambient noise were estimated for the different periods and are shown in Fig. 6.2. In Table 6.1, we show the peak values, correlation times and lags for all of the moorings. As mentioned, moorings 1 and 6 have uniformly sampled noise time series which produce smooth cross-correlation

functions. At moorings 4 and 5 , the noise time series have two-day gaps, thus the values in the table are only for reference. Also, using only the mooring 6 wind speed in our paper will cause a small error in lag value. 

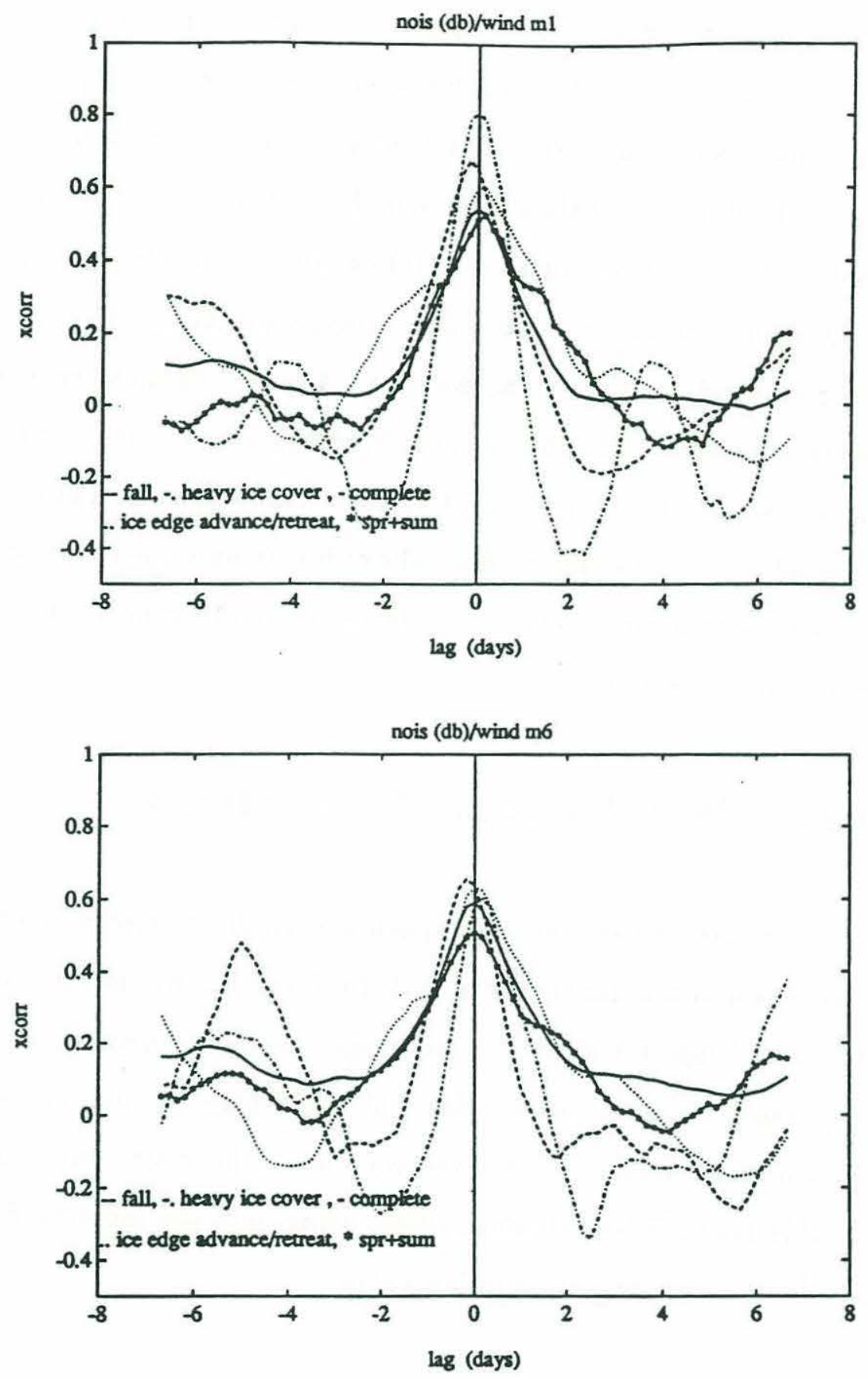

Figure 6.2: Cross-correlations between wind speed and ambient noise. Fall ice-free and ice edge advance/retreat periods show a high noise/wind cross-correlation. During the heary ice cover period, it appears that the degree of noise/wind cross-correlation is inversely proportional to the ice concentration found over the moorings. The spring-summer ice-free period shows a lower correlation level 
Table 6.1

Noise/wind cross correlation

\begin{tabular}{|c|c|c|c|c|c|}
\hline \multicolumn{2}{|c|}{$\begin{array}{l}\text { time period } \\
\mathrm{X} \text {-corr peak } \\
\text { mooring }\end{array}$} & fall & $\begin{array}{c}\text { heavy ice } \\
\text { cover }\end{array}$ & $\begin{array}{c}\text { ice edge } \\
\text { advance/retreat }\end{array}$ & $\begin{array}{l}\text { spring } \\
\text {-summer }\end{array}$ \\
\hline \multirow{4}{*}{$\begin{array}{l}\text { peak } \\
\text { value }\end{array}$} & $\mathrm{m} 1$ & 0.67 & 0.81 & 0.6 & 0.52 \\
\hline & $\mathrm{m} 4$ & 0.71 & 0.33 & 0.58 & 0.54 \\
\hline & $\mathrm{m} 5$ & 0.45 & 0.13 & 0.63 & $0 . \overline{35}$ \\
\hline & $\mathrm{m} 6$ & 0.66 & 0.60 & 0.63 & 0.51 \\
\hline \multirow{4}{*}{$\begin{array}{l}\text { lag(hrs) } \\
\text { (wind leads } \\
\text { is positive) }\end{array}$} & $\mathrm{m} 1$ & -3.73 & -0.08 & 1.87 & 2.86 \\
\hline & $\mathrm{m} 4$ & -11.80 & 4.95 & 11.70 & 1.48 \\
\hline & $\mathrm{m} 5$ & -2.40 & -- & 18.23 & 1.31 \\
\hline & $\mathrm{m} 6$ & -3.78 & 3.72 & 0.91 & 0.09 \\
\hline \multirow{4}{*}{$\begin{array}{c}15=l \|_{c=0.5 \text { peak }} \\
(\mathrm{hrs})\end{array}$} & $\mathrm{m} 1$ & 41.75 & 31.50 & 70.00 & 63.25 \\
\hline & $\mathrm{m} 4$ & 41.25 & 25.50 & 51.50 & 41.00 \\
\hline & $\mathrm{m} 5$ & 40.50 & -- & 38.75 & 24.25 \\
\hline & $\mathrm{m} 6$ & $36 . \overline{75}$ & 32.75 & 66.25 & 58.50 \\
\hline
\end{tabular}

The peak values of the noise/wind cross-correlation for the four moorings vs. the different periods are the first entries in the table. Looking at the fall ice-free period (moorings 1,4 and 6 ), we see a 0.66 -0.71 cross-correlation coefficient, the highest for the year overall. During the heavy ice cover period, it appears that the degree of noise/wind cross-correlation is inversely proportional to the ice concentration found over the moorings. The ice edge advance/retreat regime shows a fairly high noise/wind cross-correlation, but not quite as high as the fall ice-free case. This may due to the strongest weather systems and heaviest winds generally being in the autumn. The spring-summer ice-free period shows only about a 0.5 correlation level, probably due to the light summer winds. For mooring 5 , the cross-correlation coefficients are generally significant lower than that for the other moorings. This is likely due to it being more or less perennially under the influence of the thick ice peak.

The lags between noise and wind are the second entries in the table (where a positive lag means that the wind leads the noise). In the fall, we see that the noise 
leads the wind by a few hours, i.e. we hear the storm noise first. During heavy pack ice cover periods, the wind is often seen first ( see Fig.6.2 ), leading to positive lags. The noise mechanism believed to be responsible for this is the wind building up waves which then produce noise at the ice edge. The ice edge advance/retreat period shows small positive lags, possibly due to being a mixture of open water (negative lag) and ice covered ( positive lag ) conditions. The spring-summer period shows even smaller positive lags. This is perhaps due to the influence of the summer light winds, which only produce significant noise at the windstorm peaks. The BMO data is also less accurate at very low wind speeds, which could result in less accurate lags.

The last entries in the table are the cross correlation peak widths. During fall, we see $36-41$ hour correlation times at the 0.5 peak level. The pack ice period shows shortest cross correlation times, as expected due to the ice shielding the wind effects. The ice edge advance/retreat period shows a longest cross correlation times, probably due to the noise field persisting longer due to ice motion.

\subsection{Cross Correlation of the Noise Levels be- tween Moorings}

In Table 3.2, we showed the distance between moorings $1,4,5$, and 6 . Due to the array symmetry, these fall into three relative range categories, i.e. $105 \mathrm{~km}, 124$ $\mathrm{km}$, and $200 \mathrm{~km}$. The seasonal and regional dependencies of the noise greatly affect the cross correlation, however, so that one should probably not be tempted to think of the correlation function of the noise as $\mathrm{C}(\mathrm{r})$, but rather as $\mathrm{C}\left(\overrightarrow{r_{1}}, \overrightarrow{r_{2}}, t\right)$, i.e the most general case. We look at that case in Table 6.2. The cross correlations of the noise between moorings are shown in Fig.6.3. 


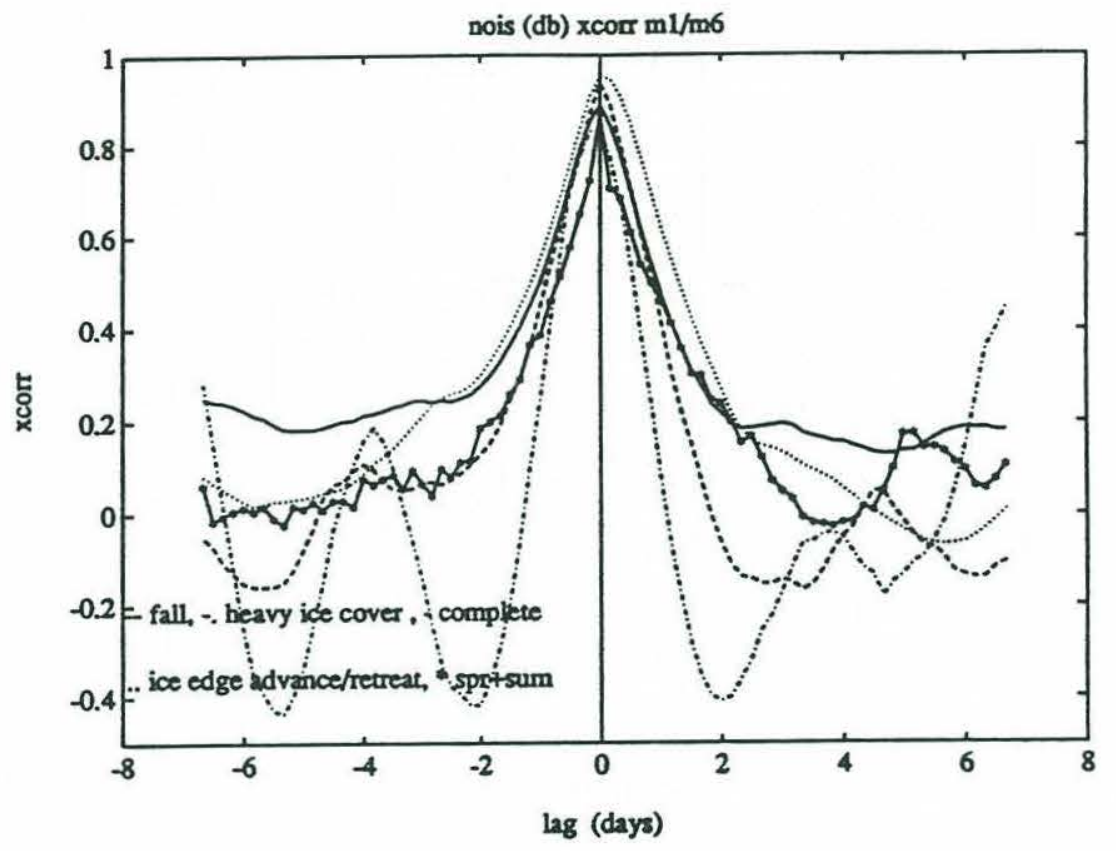

Figure 6.3: Cross correlation of noise levels between moorings. Fall ice-free period and ice edge advance/retreat period show a quite high cross correlations. During the pack ice cover period, the cross correlations drop considerably, particularly when moorings 4 and 5, which have heavy ice cover, are involved. The spring-summer period shows a general decrease in correlation overall. 
Table 6.2

Cross correlation of noise levels between moorings

\begin{tabular}{|c|c|c|c|c|c|}
\hline \multicolumn{2}{|c|}{$\begin{array}{c}\text { mooring } \\
\begin{array}{c}\text { X-corr peak } \\
\text { mooring } \\
\text { time period }\end{array}\end{array}$} & $\mathrm{m} 1$ & $\mathrm{~m} 4$ & $\mathrm{~m} 5$ & $\mathrm{~m} 6$ \\
\hline \multirow{2}{*}{ fall } & $\mathrm{m} 1$ & 1 & 0.83 & 0.78 & 0.94 \\
& $\mathrm{~m} 4$ & & 1 & 0.76 & 0.91 \\
& $\mathrm{~m} 5$ & & & 1 & 0.83 \\
& $\mathrm{~m} 6$ & & & & 1 \\
\hline heavy & $\mathrm{m} 1$ & 1 & 0.57 & 0.70 & 0.84 \\
pack-ice & $\mathrm{m} 4$ & & 1 & 0.62 & 0.60 \\
& $\mathrm{~m} 5$ & & & 1 & 0.60 \\
ice edge & $\mathrm{m} 6$ & & & & 1 \\
\hline advance/retreat & $\mathrm{m}$ 4 & 1 & 0.90 & 0.86 & 0.96 \\
& $\mathrm{~m} 6$ & & & 0.86 & 0.92 \\
& $\mathrm{~m} 1$ & 1 & 0.56 & 0.68 & 0.88 \\
& $\mathrm{~m} 4$ & & 1 & 0.65 & 0.61 \\
spring & $\mathrm{m} 5$ & & & 1 & 0.75 \\
-summer & $\mathrm{m} 6$ & & & & 1 \\
\hline
\end{tabular}

Starting with the fall, we see generally quite high cross correlations, up to the 0.9 level. During the pack ice cover period, the cross correlations drop considerably, particularly when moorings 4 and 5 , which have heavy ice cover, are involved. The ice edge advance/retreat period again shows a strong correlation between all the receivers, the highest level in all the periods. The spring-summer period shows a general decrease in correlation overall. 


\subsection{Cross Correlation of the Noise with Ice Con- centration and $\mathrm{On} /$ off-ice Wind}

To be complete, we also correlate the ambient noise at mooring 6 with some remaining environmental variables, such as ice concentration and on/off-ice-winds etc.

The cross correlation results show that there is a very poor correlation between ambient noise and ice concentration. with the maximum correlation coefficient of 0.31 at mooring 1 .

In chapter 5 , we also showed that ambient noise increased as on-ice-wind increased, and stayed constant or even decreased as off-ice-wind increased. We thus correlated the ambient noise with on-ice-winds and off-ice-winds. The results showed that the correlations between the noise and on-ice-wind are at the 0.5 level, and there is no correlation between the noise and off-ice-wind, as shown in Fig.6.4 

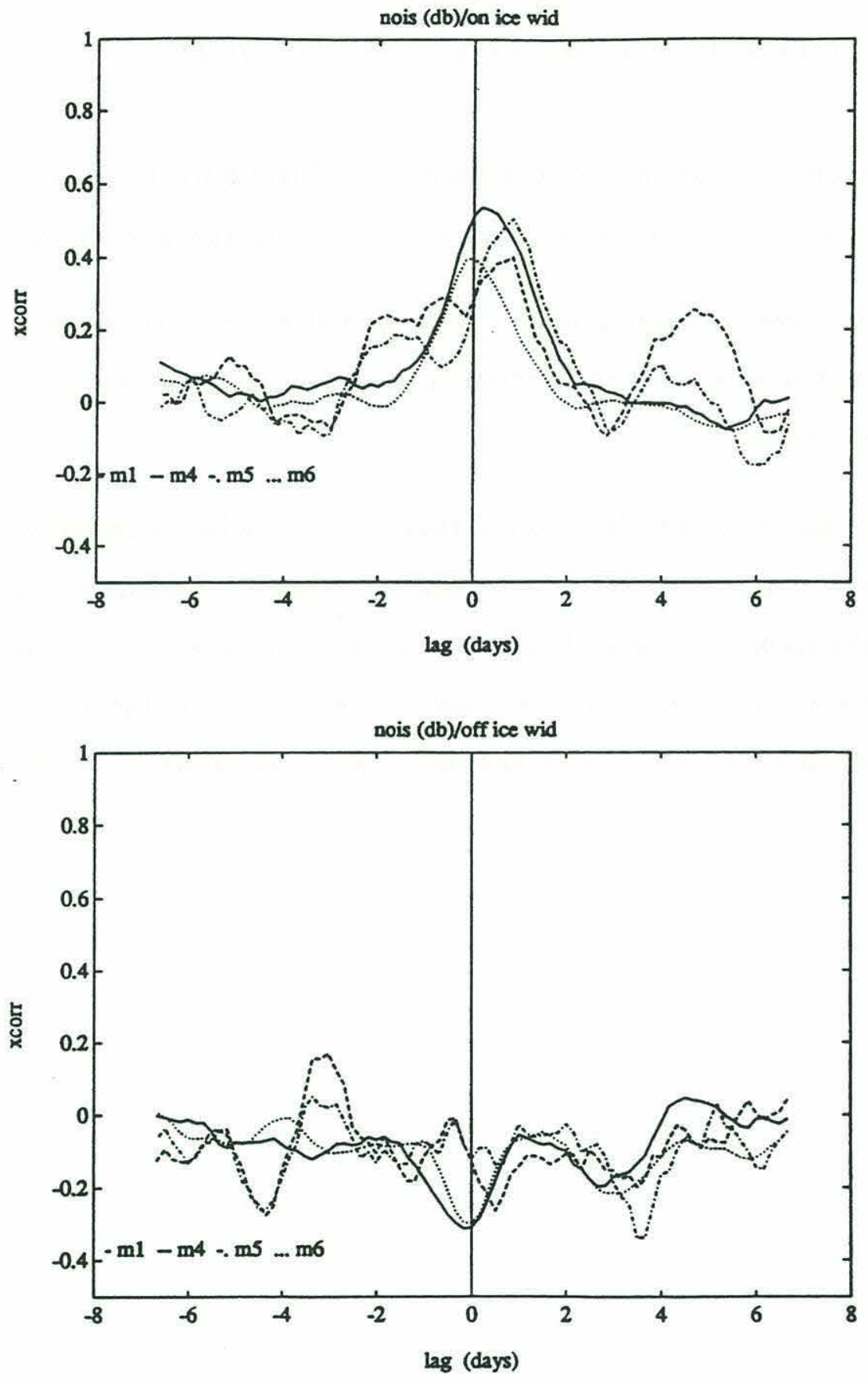

Figure 6.4: Cross correlations of noise and on/off-ice winds. The correlations between the noise and on-ice-wind are at the 0.5 level, and there is no correlation between the noise and off-ice-wind. 


\section{Chapter 7.Discussion and Conclusions}

The analyses of ambient noise above are based only on the ice concentration and wind speed. The results are generally consistent with the results of other noise researchers. Thus, we can say that large scale information such as wind and ice concentration, which is routinely available, is good in qualitatively or even in quantitatively describing and predicting the noise field. Based on the assumption that the wind noise and other noise processes are independent and add linearly, we could distinguish between the wind noise and the ice noise, though we could not further separate the different noise mechanisms due to lack of resolution. For instance, one cannot see eddies and their "hot spots" or very local small scale wind events; thus, we "averaged over" the fine scale noise production. Fine scale satellite information could help explain some of the fine structure in data like ours. The new satellite series ERS (Earth Resources Satellite) has, as its mission aims, the measurement of sea state, altitude, and windspeed over major ocean currents and the ice edge. Its wind scatterometer enables wind velocity to be determined over a swath $400 \mathrm{~km}$ wide. Its Synthetic Aperture Radar (SAR) can produce high resolution radar imagery of oceans and ice. The SAR can operate in Image mode or in Wave mode to generate image spectra of the ocean wave-field, and hence significant wave height ${ }^{34}$. Hopefully, the ERS can offer us fine scale as well as large area environmental information, which can help us to understand the details of noise production.

The ambient noise measurements we described here were over a limited band at a center frequency of $250 \mathrm{~Hz}$. Even so, we were still able to do some frequency analysis resently based on the Avatar noise data, which is in a band extending 135-375 $\mathrm{Hz}$. The preliminary spectral analyses seem to show that the noise peaks at frequency of $250 \mathrm{~Hz}$. While Wenz noise spectra shown that the maximum in the $300-500 \mathrm{~Hz}$ region. It is suspected that the low frequency higher noise levels are related to ice 
noise, which shifts the peak of the noise spectra to lower frequency. The eventual results will be included in reference [35].

The acoustic propagation conditions change throughout the year. During the late spring, summer, and early autumn, there is a warm surface layer which pushes the sound below it, whereas in the winter, a cold near surface duct forms, channeling any low angle noise energy closer to the surface. The relation of the depths and magnitudes of the mixed layer and surface duct to the receiver position determines how much these affect the surface noise coming to the receiver. The predominantly dipole nature of the noise tends to lessen the effect of the near surface propagation in favor of deeper paths. To model these propagation effects, the Navy standard parabolic equation model 3.1 is used to predict transmission loss. The results show that in the upper $500 \mathrm{~m}$ of the water column there is more energy propagating in the water column in the winter than in the summer for a dipole source at the surface. Several ambient noise features are noted: 1) the local noise sources make up nearly $90 \%$ of the total measured noise level, 2) the winter noise levels are higher by a $1 \mathrm{~dB}$ offset for a noise source area within a $25 \mathrm{~km}$ radius of the receiver, and 3) the noise level is depth independent among the mooring receiver depths, as seen experimentally. See reference [35] for details.

Wave noise is another important noise source. We are soon going to examine correlations and regressions between the ambient noise and the wave field. These further analyses results may improve our recent results. Again, the details will be shown in reference [35]. 


\section{REFERENCES}

1. Worcester, P., J. F. Lynch, et al., "Ocean acoustic tomography in the Greenland Sea"; to be published

2. Makris, N. C., "Environmental correlates of Arctic ice edge noise"; Ph.D Thesis, MIT, Sept. 1990

3. Wenz, G. M., "Acoustic ambient noise in the ocean : spectra and sources"; JASA, 34(12), pp1936-1956, Dec 1963

4. Carey, W. M., and E. C. Monahan, "Guest Editorial"; IEEE J. Ocean Eng., 15 (4), Oct. 1990.

5. Hollett, "Underwater sound from white caps at sea"; JASA,85(s1), p 145, 1989.

6. Farmer, D., and S. Vagle, "Waveguide propagation of ambient sound in the ocean surface bubble layer"; JASA , 86 (5) , pp1897-1908, 1989.

7. Kerman, B. R., "Underwater sound generation by breaking waves"; JASA, 75(1), pp149-165, 1984

8. Buck, B. M., "Acoustic noise measurement experiment using NIMBUS 6 data buoys (U)"; J. Underwater Acoust., 27 , pp827-838, 1977 (Confidential).

9. Keenan, R. E., and E. C. Gough, "Arctic ambient noise characteristics (U)"; J. Underwater Acoust., 39(4), 1989 (Confidential).

10. Milne, A. R., "Thermal tension cracking in sea ice : a source of underwater noise"; JGR, 77 , pp2177-2192, 1972

11. Keenan, R. E., "The correlation of mid-frequency pack ice noise with environmental parameters"; in Sea Surface Sound : Natural Mechanisms of Surface Greenland Noise in the Ocean, ed. B. R. Kerman, NATO ASI Series C, Vol.238, 1988. 
12. Dwyer, R. F., "A technique for improving detection and estimation of signals contaminated by under ice noise"; JASA, 74, pp124-130, July 1983.

13. Dyer, I., "The song of sea and other Arctic ocean melodies"; in Arctic Technology and Policy, ed. I. Dyer and C. Chryssostomidis, Hemisphere Publishing Corp., Washington, pp11-40, 1984

14. Diachok, O. I., and R. S. Winokur, "Spatial variability of underwater ambient noise at the Arctic ice-water boundary"; JASA, 55(4); pp750$753,1974$.

15. Johannessen, O. M., K. V. Starke, and S. G. Payne, "Ambient noise in the marginal ice zone"; Technical Report No.14, The Nansen Remote Sensing Center, Bergen, Norway, 1988.

16. Payne, S. G., and C. H. Henderson, "Ambient noise in the marginal ice zone of the Barents Sea during MIZEX87"; Applied Research Laboratories, University of Texas, ARL-TR-89-47,Oct.1989.

17. Yang, T. C., G. R. Giellis, C. W. Votaw, and O. I. Diachok, "Acoustic properties of ice edge noise in the Greenland Sea"; JASA, 82(3), pp10341038 , Sept. 1987.

18. Buckingham, M. J., "Ambient sound at the ice edge"; paper to be presented at Undersea Defence Technology conference, 7-9 Feb. 1990,London, England.

19. Keenan, R. E., unpublished data.

20. Marrett, R., and N. R. Chapman, "Low frequency ambient noise measurements in the south Fiji Basin"; IEEE JOE , 15(4), pp311-315, Oct. 1990.

21. Shooter, J. A., T. E. DeMary, and A. F. Wittenbourn, "Depth dependence of noise resulting from ship traffic and wind"; IEEE JOE, 15(4), pp292298, Oct. 1990. 
22. Hollingberger,D. E. and D. W. Bruder, "Ambient noise data logger buoy"; IEEE J. Oceanic Engineer., 15(4), pp286-291, Oct.1990.

23. Wille, P. C., and D. Geyer, "Simultaneous measurements of surface generated noise and attenuation at the fixed acoustic shallow water range 'NORDSEE"'; in Sea Surface Sound : Natural Mechanisms of Surface Generate noise in the Ocean, ed. B. R. Kerman, Kluwer Press, pp295-308.

24. Perrone, A. "The correlation of deep open ocean ambient noise spectra with wind speed and wave height for frequencies from 11 to 2816 Hertz"; USL Report No. 935, p12.

25. Bannister, R. W., A. S. Burgess, and D. J. Kewley, "Estimation of source characteristics from underwater noise field measurements"; in Sea Surface Sound : Natural Mechanisms of Surface Generate noise in the Ocean, ed. B. R. Kerman, Kluwer Press, pp377-390.

26. Keenan, R. E., L. R. Merriam, and E. C. Millier, "Lincoln Sea Noise : NAVOCEANO drifter buoy analysis (U)"; AEAS 90-C003, March 1990 (CONFIDENTIAL).

27. Pawlowicz R., "An exploratory investigation of the temporal variability of the wind stress in the Greenland Sea with some musings on the applicability of the results to the GS tomography project modeling effect "

28. Wadhams P., "See ice thickness distribution in the Greenland Sea and Eurasian Basin, May 1987"; to be published

29. Rudels, B., et al., "Greenland Sea convection in the winter of 1987-1988"; $J G R, 94(\mathrm{c} 3), \mathrm{pp} 3223-3227,1989$

30. Martin et al. "Shuttle imaging radar-B and scanning multichannel microwave radiometer ice concentrations" JGR, 92(c7), pp7173-7179, 1987 
31. Gill, A. E., "Atmosphere-Ocean Dynamics"; United Kingdom Edition published by ACADEMIC PRESS, INC. (LONDON) LTD., 1982

32. Guest P. S., and K. L. Davidson, "The effect of observed ice conditions on the drag coefficient in the summer east Greenland Sea marginal ice zone"; JGR, 92 (c7); pp6943-6954, 1987.

33. Weinberg H, "Generic Sonar Model" NUSC Technical Document 5971, 1 January 1979 pp6-42

34. "ERS-1 Mission and Scientific Objectives"; WOCE NOTES, Vol.2 No.5, August 1990

35. Lynch J. F., P. Worcester, and R. E. Keenan et al., "Acoustic noise measurement in the $200-300 \mathrm{~Hz}$ band during the Greenland Sea tomography experiment"; to be published 